\title{
THERMODYNAMIC BASED MODEL ELICITING ACTIVITIES FOR UNDERGRADUATE MECHANICAL ENGINEERING EDUCATION
}

\author{
A Thesis \\ presented to \\ the Faculty of California Polytechnic State University, \\ San Luis Obispo
}

\author{
In Partial Fulfillment \\ of the Requirements for the Degree \\ Master of Science in Mechanical Engineering \\ by \\ Paul van Bloemen Waanders \\ June 2011
}


(C) 2011 Paul van Bloemen Waanders ALL RIGHTS RESERVED 


\section{COMMITTEE MEMBERSHIP}

TITLE: Thermodynamic Based Model Eliciting Activities For Undergraduate Mechanical Engineering Education
AUTHOR:
Paul van Bloemen Waanders
DATE SUBMITTED:
June 2011

COMMITTEE CHAIR: Andrew Kean, Mechanical Engineering Professor

COMMITTEE MEMBER: Brian Self, Mechanical Engineering Professor

COMMITTEE MEMBER: Glen Thorncroft, Mechanical Engineering Professor 


\author{
ABSTRACT \\ Thermodynamic Based Model Eliciting Activities For Undergraduate \\ Mechanical Engineering Education \\ Paul van Bloemen Waanders
}

Undergraduate engineering education is designed to prepare students for their careers. The rise of technology in modern engineering allows for a shift in the way undergraduates are prepared for the modern workplace. Model Eliciting Activities (MEAs) allow students to think critically about their own work and allow instructors to analyze the students' problem solving methods. To ensure that new MEAs are as effective as possible they are subject to six basic principles: model construction, reality, generalizability, self-assessment, model documentation, and effective prototype.

This document focuses on evaluating new MEAs for their adherence to the six principles from an instructor's and student's perspective. Four new MEAs were created and implemented in the school year of 2009-2010. Two of the MEAs were designed to target a sophomore level thermal engineering class. The first was an introduction to data acquisition systems (DAQs) and the second was an introduction to strain gauges. These two MEAs were tested on two separate classes and were evaluated strictly from an instructor's perspective. The two MEAs met their objectives for introducing DAQs and strain gauges respectively and managed to reinforce existing ideas at the same time. However, the MEA about DAQs appeared to adhere to all of the six principles while the MEA about strain gauges did not.

The other two MEAs were designed for an introductory thermodynamics course. The students' solutions to the MEAs were analyzed to determine the MEAs' effectiveness as well as how well they follow the six principles of MEAs. The first MEA was centered around a supermileage vehicle and asks the students to model an engine cycle from a P-V diagram of a real engine cycle. Careful analysis of the solutions that the students turned in found that the MEA did not provide a way for the students to verify their models. It was also found that students were learning about isothermal and adiabatic curves on their own which satisfied the main goal of the MEA which was to familiarize the students with simple processes. The second activity was based upon an industrial process that delivered waste energy into a river and the students were asked to model a power plant that could use the energy and lower the amount of heat dumped into the river. The objective was to get the 
students to think about entropy and how much energy can be salvaged in the system. A vast majority of students enjoyed the activity saying it was well worth their time, while only half of the students identified that entropy had some part in the MEA. Whether or not the objective to get the students to associate usable energy with entropy production was accomplished is uncertain. What was determined was that some students were unable to check their answers and they developed models that were inaccurate. From this observation it was seen that the self assessment principle was not being properly addressed.

All of the developed MEAs satisfied their end goals of teaching the students the material that the MEA was developed around. The two most prominent issues were students misunderstanding the problem statement and students not being able to verify their models. These are important observations for these particular MEAs that were only possible through intensive analysis of the solutions from a student's perspective. The detailed analysis of the solutions using the six principles as a guideline provided insight to some of the problems students were having. For future work, these same MEAs could be improved upon and then analyzed again to see if the analysis is consistent and that the identified problems were corrected.

Keywords: Thermodynamics, Model Eliciting Activities, Engineering, 


\section{TABLE OF CONTENTS}

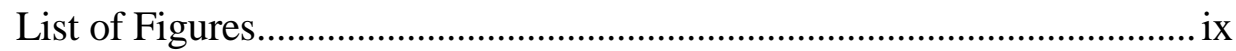

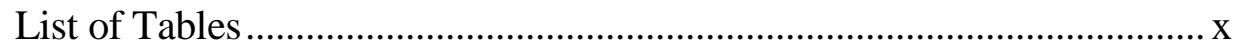

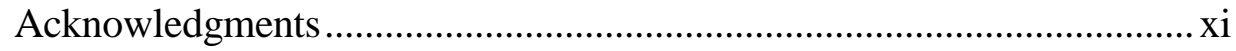

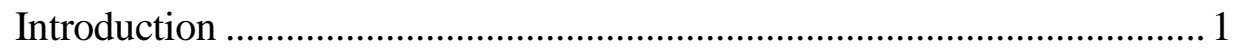

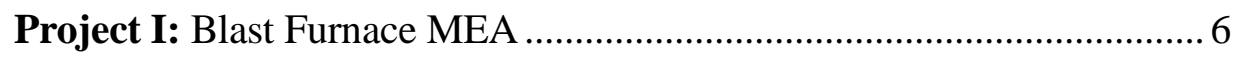

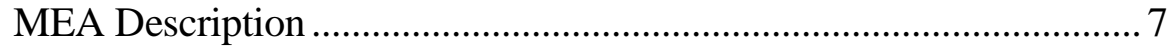

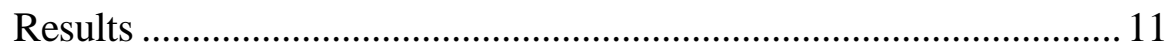

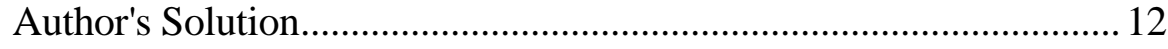

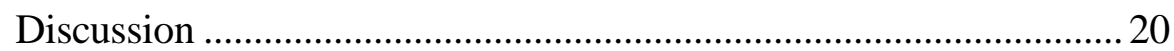

Project II: Strain Gauge MEA ….................................................... 22

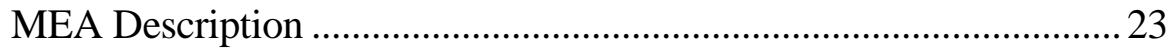

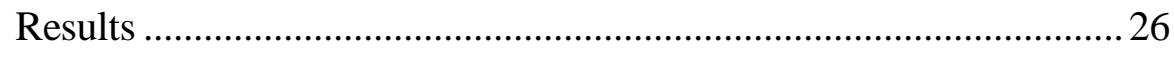

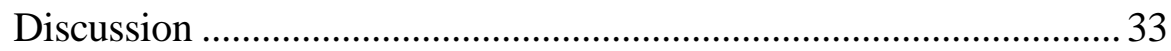

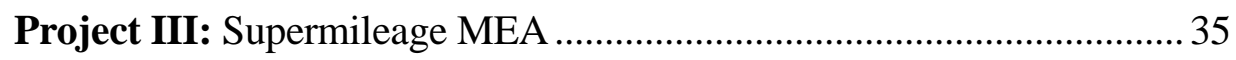

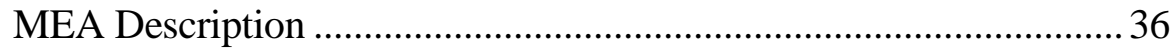

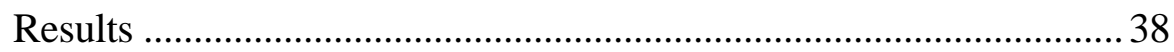

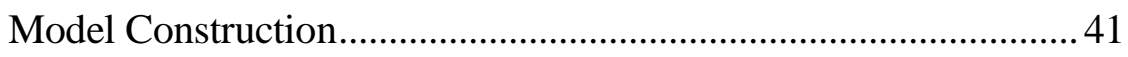

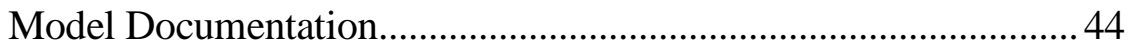

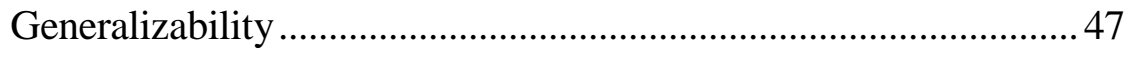

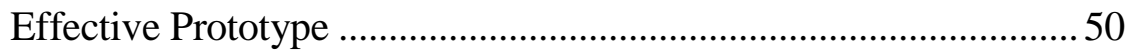




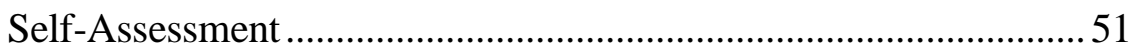

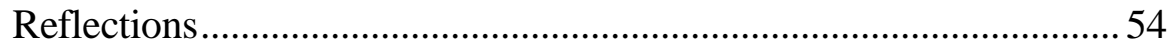

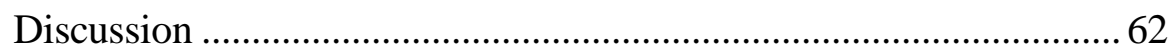

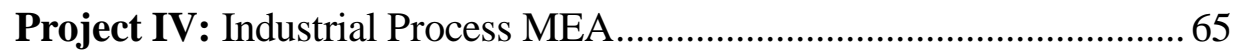

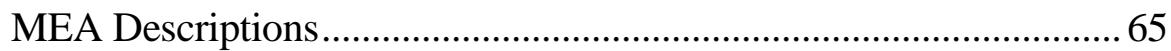

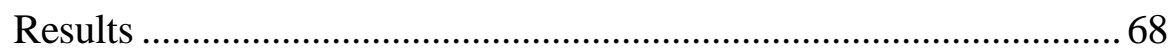

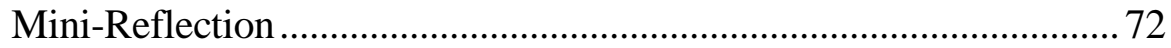

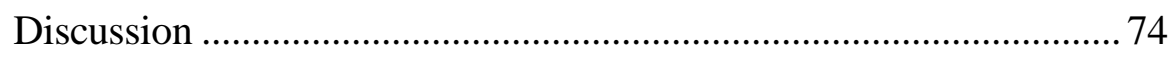

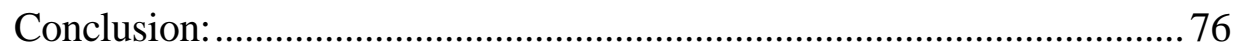

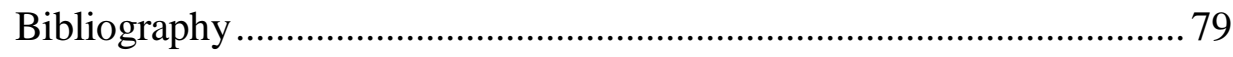

Appendix A: Data acquisition MEA …............................................... A

1 Original lab description ...........................................................

2 Evaluation Rubric ................................................................. A-2

3 Example Student Solution ...................................................... A-3

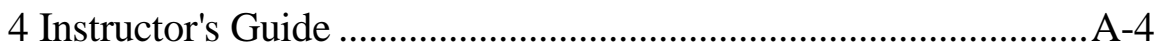

Appendix B: Strain gauge MEA .......................................................... B

1 Pre-Lab Material .................................................................. B-1

2 Pre-Lab Quiz ....................................................................... B-2

3 Soldering Instructions ......................................................... B-3

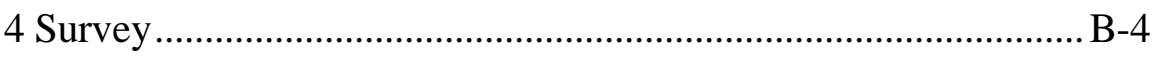

5 Student Example ................................................................. B-5 
Appendix C: Supermileage MEA ……………………………………....

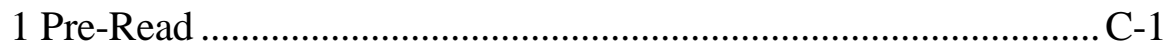

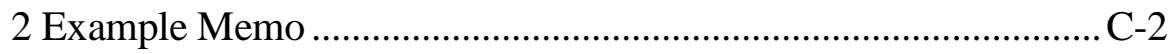

3 Reflection Example …………………………………………........

Appendix D: Industrial Process MEA …………………………………. D

1 Example Memo ……………………………………………..... D-1

2 Reflection Example ...................................................................... 


\section{LIST OF FIGURES}

Number

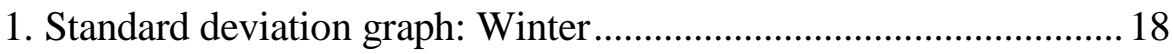

2. Standard deviation graph: Spring ................................................ 19

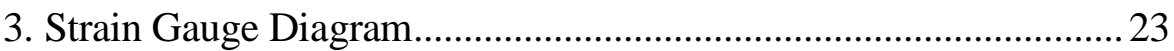

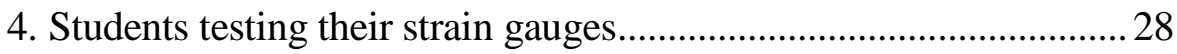

5. Students soldering their strain gauges ........................................... 29

6. Students working on the strain gauge MEA..................................... 30

7. Students working on their memorandums....................................... 32

8. Supermileage Pressure-Volume Graph ............................................. 35

9. Photograph of Supermileage Car...................................................... 37

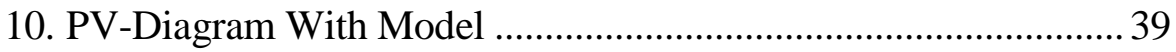

11. Supermileage Solution Tree: Spring ............................................ 42

12. Supermileage Solution Tree: Summer .......................................... 44

13. Supermileage Concepts Learned: Spring \& Summer .................... 56

14. Supermileage Suggestions to improve MEA: Spring .................... 57

15. Supermileage Suggestions to improve MEA: Summer ................. 58

16. Carnot/Rankine Cycle Examples.................................................69

17. Industrial Process Concepts Learned: Summer.............................. 73 


\section{LIST OF TABLES}

Number

1. DAQ devices

2. Blast Furnace MEA: 1st Run

3. Blast Furnace MEA Summary 21

4. Strain Gauge MEA: 1st Run 31

5. Strain Gauge MEA Summary …................................................... 34

6. Supermileage Document: Summer and Spring .............................. 46

7. Supermileage Deliverables: Summer and Spring .......................... 47

8. Supermileage Generalizability: Summer and Spring ...................... 48

9. Supermileage Effective Prototype: Summer and Spring ................ 50

10. Supermileage Calculation Errors: Summer and Spring ................. 52

11. Supermileage Reflection Questions: Spring and Summer............. 61

12. Supermileage MEA Summary ...................................................... 64

13. Industrial Process Mini-Reflection Questions.............................. 74

14. Industrial Process MEA Summary .............................................. 75 


\section{ACKNOWLEDGMENTS}

The author wishes to express sincere appreciation to mechanical engineering

student Frank Schreiber, and Professors Brian Self, Andrew Kean, and Glen Thorncroft for their assistance and guidance in the following research. This work was funded by the NSF CCLI Grant \#0717595: Collaborative Research: Improving Engineering Students’ Learning Strategies Through Models and Modeling. 


\section{Introduction}

Model-Eliciting Activities (MEAs) are tools used by educators to help them understand the problem-solving processes of students. These activities are done in small groups and encourage teamwork, critical thinking, and a deeper understanding of the solution process.

MEAs were developed in the mathematical community as a new way to teach students while assessing their abilities (Lesh ed., 2006). Case studies have shown that MEAs are particularly helpful in identifying students who excel at solving reality-based problems as opposed to conventional homework problems (Lohman, 2002). That is to say, MEAs give students who work better in real-life situations a chance to stand out in an academic setting. One research organization funded by the National Science Foundation (NFS HRD 0120794) called, "Small Group Mathematical Modeling for Improved Gender Equity (SGMM)," has been adapting Model-Eliciting Activities to undergraduate engineering education (Bowman et al., 2008). The SGMM research effort has focused on expanding the MEA methodology and framework to include new MEAs. The research contributes to discovering how students solve problems while also developing comprehensive research for undergraduate engineering education.

The following research is part of a collaborative effort between seven universities, including Cal Poly San Luis Obispo, Colorado School of Mines, Purdue University, University of Minnesota, University of Pittsburgh, Pepperdine, 
and the US Air Force Academy. This work focuses on the development and analysis of four MEAs that are meant to improve understanding of MEA methodology as well as to increase the number of MEAs available to engineering students.

Model-Eliciting Activities are constructed and analyzed based upon six principles. These principles help define the main goals of MEAs as well as provide the structure that makes MEAs successful learning and evaluation tools. (Lesh et al., 2000). Developed by teachers, parents, and community leaders, the six principles help educators learn about students while at the same time promoting real-life skills as well as academic ones. (Lesh et al., 2000). The six principles are described below:

1.) Model Construction: The students doing the MEA must develop a mathematical model or system representation that aids them in understanding the problem. A model is defined here as the descriptions, explanations, and constructions used by students when quantifying and interpreting a given scenario.

2.) Reality: The MEA must be set to a relevant engineering application. A helpful attribute of MEAs is that they are based on realistic problems that can be faced by modern engineers. Using this principle, students are able to experience problems that are relevant to their eventual career goals. 
3.) Generalizability: The resulting model should apply to other similar applications. The students must create their model so that it can apply to more problems than just the one at hand, or at least be easily modifiable for other situations.

4.) Self-Assessment: The students must be able to evaluate the quality of their own work. Self-assessment tools can include example solutions given to students to check their model, experimental data that they collect, or data provided to confirm their solutions.

5.) Model Documentation: The students must document the model that they develop as well as list any assumptions they employ. A memorandum addressed to a client is typically used to concisely present a description of a model and its results. Documentation is an important window into a student's problem-solving methods.

6.) Effective Prototype: An effective prototype ensures the involvement of key concepts usable in future work. The MEA should be centered around useful engineering tools and concepts that students can use in their future academic and professional careers

These six principles can be used to help new MEAs maintain an effective structure while fulfilling their full potential. New MEAs must adhere to the principles in order to maintain consistency within research and to ensure that they are valuable learning and assessment tools. 
Early development of Model Eliciting Activities included the creation of the six principles as guides for future creation of MEAs (Lesh, et al. 2000). As MEA research progressed, MEAs were employed as tools to teach students ethics (Shuman, Besterfiel-Sacre, 2009), promote teamwork in engineering (Moore, Diefes-Dux, Imbrie, 2007), and provide insight to student and instructor perceptions (Siewiorek, Shuman, Sacre, Goldstein 2011). Research that has studied the use of MEAs outside of a mathematical context has identified challenges in applying MEAs to other disciplines (Schofield, 2007). Instructors that employ MEAs, or attempt to create their own MEAs, need to ensure that they are extrapolating the MEA framework correctly. This research attempts to identify the presence of the six principles in new MEAs that are developed for undergraduate thermodynamic engineering courses. It is known that what instructors intend for students to learn and what students actually perceive do not always match up (Siewiorek, et al., 2007). Therefore, this research presents the MEA creation process from both an instructor's and a student's viewpoint.

This work will describe the development of four MEAs: two as material for laboratory periods in a thermal measurements course and two as group projects for an introductory thermodynamics course. The first two MEAs were based off of already existing laboratory content. As group activities, they were created to keep existing learning objectives while promoting team work and critical thinking. 
These MEAs will be analyzed purely from an instructor's viewpoint to provide a control for the remaining research. The remaining two MEAs were developed to supplement existing lecture material regarding thermodynamic processes and the concept of entropy in engineering applications. The students' solutions to these MEAs were analyzed in conjunction with in-depth reflection tools to gather as much detail regarding the students' problem solving process or processes as possible. From this research a helpful process to coordinate instructor intentions and student learning from the six principles of MEAs shall be determined. 


$$
\text { Project I: Blast Furnace MEA }
$$

In the Winter quarter of 2010, an MEA was implemented in a Thermal Measurements class (ME 236) for mechanical engineers. ME 236 is a hands-on lecture and lab that teaches undergraduate mechanical engineers about uncertainty, statistics, and probability in measurements. The following research improved upon one of the old labs that involved data acquisition systems (DAQs). Changing the lab was done for two reasons: first, this MEA would act as a control test to determine the effectiveness of MEAs with a physical lab component attached, and second, the new MEA utilized more of the available lab time. For these reasons an MEA was designed to focus on introducing students to data acquisition systems and on combining the uncertainties associated with taking large amounts of measurements.

The existing lab started with a 30-minute lecture regarding the function of data acquisition systems. Data acquisition systems take analog data in the form of electrical signals and convert them into a digital signal for input into a computer. After the lecture, the students went through an introductory LabView program and took data. LabView is computer software that allows for simple control and organization of incoming digital signals from DAQ hardware. For this experiment, the students used a thermocouple to take electrical readings of the ambient temperature. Using a thermocouple along with LabView, the students took 1,000 
temperature measurements in one second. Analysis was then done on the data to find the uncertainty associated with it.

The key goals of this laboratory were to introduce the students to data acquisition hardware and software while also reinforcing their knowledge of what they have been taught regarding uncertainty in measurements. In lecture the students have not yet been taught about combining different types of uncertainties, so this material was taught in the lab.

A brief memorandum was required that needed to address a long to-do list of graphs and calculations as seen in Appendix A-1. This process took about 30 minutes to complete. The three-hour period available for this particular lab allowed time for extended material to be included.

\section{MEA Description}

The new MEA that was designed to improve the existing lab was presented to the students as a memo from a steel making company. The detailed problem statement is listed below:

California Polytechnic State University

Date: January $26^{\text {th }}, 2010$

To: Professor Glen Thorncroft, ME Department

From: Paul van Bloemen Waanders, ME masters student

Subject: Details regarding help with DAQ statistics

I am working with a steel manufacturer who has asked for some statistics help. The client's data acquisition systems (DAQs) are very similar to the kind I used in my undergraduate ME program. I thought that you might be able to provide me with some assistance.

The client needs to replace their system that measures temperature in their blast furnace. They have a limited budget but would like to upgrade if 
they can. The quality of the steel they produce is directly dependent upon how accurately they measure their temperature. Their blast furnace can reach temperatures anywhere from $1600^{\circ} \mathrm{C}-2000{ }^{\circ} \mathrm{C}$ so they can only use high temperature measuring devices.

They need a procedure in order to decide on a measuring instrument, a DAQ system, and a sample rate for their blast furnace that will optimize uncertainty and cost. Since the DAQ system they currently use is very similar to the one in the lab, I thought that I could use it to verify my assumptions and test my final decision. Ideally my decision should be more accurate and/or cost less than their original system: a high temperature probe with a 16-bit DAQ system at 500 samples per second.

If you can help me I would greatly appreciate your input. Paul van Bloemen Waanders Cal Poly, Mechanical Engineering Department

The memo requests that the students aid the company with a statistics problem that the company needs an outside consultant to help solve. An e-mail describing the scenario was given to the students and can be seen below:

Dear Thermal Measurement Lab Students:

Attached is a memo from me to Professor Thorncroft asking for help on a statistics problem I had last quarter. You are going to help me by using the lab period next week (April $27^{\text {th) }}$ to solve this problem. This WILL count as a lab grade and you will be submitting your final procedures and calculations to me the following week.

Sincerely, Paul van Bloemen Waanders Mechanical Engineering Masters Student

The students also had a short pre-lab, shown below, due at the start of class:

Things to do before class on April $27^{\text {th }}$ :

-Read Appendix B in your lab manual on Data Acquisition systems $\circ$ Pay special attention to calculating resolution uncertainty (B.3). 
-Read the attached memo and answer the questions below:

1.) What is the client asking for? What are you expected to turn in?

2.) What are the different uncertainties associated with this problem?

3.) Given a voltage range of $-50 \mathrm{mV}$ to $+50 \mathrm{mV}$, what uncertainty can you expect from a 16-bit data acquisition system? What uncertainty can you expect from a 12-bit data acquisition system?

The e-mail and problem statement were meant to convince the students to treat this lab as a real-life problem. I am presented as the client who works for a steel manufacturing plant that needs a decision-based algorithm to replace old measuring equipment. The plant needs to choose between several measurement tools in order to accurately determine the temperature in its blast furnace. A blast furnace is used in the steel making industry almost continuously in order to melt raw materials. The temperature of these devices is sensitive and advanced data acquisition systems combined with infrared temperature measuring devices are used to monitor the temperatures.

The students are given a table with the various temperature measuring devices, data acquisitions systems and prices for each device, as seen in Table 1. The students generate a model of the system involving all of the possible methods of uncertainty or error in the system from the provided table. They then develop a procedure that will allow the client to decide which devices to use. The steel manufacturing plant will use this procedure for similar processes in order to further optimize their business. The model is confirmed first by applying it to a simplified system in the lab gathering actual data from a DAQ system. The students use data 
that they gather from the DAQ systems located in the classroom to analyze their assumptions and to determine the effect of standard deviation on their uncertainty analysis.

Table 1. DAQ devices - A table of measurement devices and data acquisition systems that was provided in the MEA

\begin{tabular}{|c|c|c|c|c|c|}
\hline & System name & $\begin{array}{c}\text { Sensitivity } \\
\text { (Voltage range) }\end{array}$ & $\begin{array}{l}\text { Approximate } \\
\text { Price }\end{array}$ & $\begin{array}{c}\text { DAQ systems, } \\
\text { \#-bits } \\
\text { (max sample } \\
\text { rate per } \\
\text { second) }\end{array}$ & $\begin{array}{l}\text { Approximate } \\
\text { Price }\end{array}$ \\
\hline 1 & $\begin{array}{c}\text { Thermocouple: } \\
\text { high } \\
\text { temperature } \\
\text { attachment* }\end{array}$ & $\begin{array}{c} \pm 5.0 \% \\
(-50-50 \mathrm{mV})\end{array}$ & $\$ 50$ & 8-bit, (10) & $\$ 1,000$ \\
\hline 2 & $\begin{array}{c}\text { High } \\
\text { Temperature } \\
\text { Probe } \\
\end{array}$ & $\begin{array}{c} \pm 1.0 \% \\
(-100-100 \mathrm{mV})\end{array}$ & $\$ 1,000$ & 12-bit (500) & $\$ 4,000$ \\
\hline 3 & Infrared Sensor & $\begin{array}{c} \pm 0.4 \% \\
(-50-50 \mathrm{mV}) \\
\end{array}$ & $\$ 4,000$ & 16-bit ( 1000) & $\$ 6,000$ \\
\hline 4 & $\begin{array}{c}\text { Infrared } \\
\text { Sensor: High } \\
\text { accuracy }\end{array}$ & $\begin{array}{c} \pm 0.2 \% \\
(-25-25 \mathrm{mV})\end{array}$ & $\$ 6,000$ & 24-bit $(10,000)$ & $\$ 9,000$ \\
\hline
\end{tabular}

The anticipated solution is that the students will find three sources of possible uncertainty: the resolution error from the data acquisition system, the resolution error from the measuring device, and the statistical error from the number of measurements. The model that the students create enables them to decide how to combine the resolution, statistical and instrumental uncertainty. The model also enables them to decide which device is most important for system accuracy. The students should be able to decide that the measuring device is the bottle neck for 
this particular system. The students also learn about the relationship between the number of data points taken and statistical uncertainty.

\section{Results}

The first run of the MEA was conducted in the Winter quarter of 2010 in one section of Thermal Measurements. A breakdown of the time spent can be seen in Table 2. The majority of the lab was spent getting the students to understand the problem and what their deliverables were. Once the students understood what they were expected to turn in, they did not have trouble coming up with the appropriate uncertainties and using the DAQ system to check their model. More time was needed toward the end of the lab to allow for questions and review but the students all succeeded in understanding what a DAQ system was and how the uncertainties could be combined to develop an overall uncertainty for a system.

The students' solutions were analyzed with a rubric that can be seen in Appendix A-2. The students were graded on their procedure, recommendation, justification and completeness. Their procedure needed to be clear and addressed to the client. The recommendation needed to be explicitly stated and justified using the procedure they developed. Lastly, the solutions needed to include hand calculations and any assumptions that were made in the procedure.

Through their solutions, each group of students demonstrated that they understood how the statistical uncertainty, measured resolution uncertainty, and data acquisition system uncertainty were determined. The use of a decision-based 
algorithm to determine the best system, from the table of available measuring devices, through the analysis of the standard deviation as a function of sample rate. Each student group was introduced to the data acquisition system and shown how to take data with it. The process for each student solution was to understand the problem, develop a model for each system and then follow the lab instructions to gather the required data. Most of the groups met later in the week to write up the lab or to think critically on how the data they gathered verified their model. An example of a group's solution is shown in Appendix A-3. The solution developed by the author of the MEA is listed below.

\section{Author's Solution}

\section{$1^{\text {st }}$ Task: Model Generation}

Step 1: Identify all contributing uncertainties to the measurement.

a. Resolution uncertainty - the error that is associated with the user reading the measuring device output.

b.Statistical Uncertainty -in any given sample of data there is an associated uncertainty with the averaging of those data points to determine a population mean. The uncertainty associated determining the mean for any given sample is statistical uncertainty.

This is given by $\mu=x \pm t s$

Where $\mu$ is the sample mean, $x$ is the calculated mean, $t$ is the student $\mathrm{t}$ distribution value and $s$ is the standard deviation.

c. Instrument uncertainty - the calibrated error that comes from the measuring device

Step 2: Root-Sum-Square all of the contributing uncertainties and identify the highest contributing uncertainty.

a. If the highest contributing uncertainty is statistical uncertainty, proceed to step 3

b. Otherwise choose the device with the lowest uncertainty in this area. If any are tied, choose the cheapest.

c. DONE

Step 3: Statistical Uncertainty

a. For statistical uncertainty, first check to see if the data is normal. 
a.Plot a histogram for the maximum sample of data and generate a standard deviation.

$$
\text { i. } \quad S=\sqrt{\frac{\sum_{i=1}^{N}\left(x_{i}-\bar{x}\right)^{2}}{n-1}}
$$

b. Use this standard deviation for the remainder of the calculations c.If the data is not normal than go back to step 2 and choose the next highest uncertainty contributor.

b. Choose a sample size in the middle of the available ones and calculate an uncertainty when estimating the population mean.

a.If the new uncertainty is less than the next highest uncertainty then choose a lower sample and try again.

i. If there are no smaller sample sizes proceed to step 2 and choose the next highest uncertainty contributor.

b. If the uncertainty is more than the next highest uncertainty then choose a larger sample and try again.

i. If there are no larger sample sizes or the uncertainty is now lower than the next highest uncertainty, choose the

\section{c. DONE} cheapest device that can handle the sample size used.

$2^{\text {nd }}$ Task: In-lab Testing

Step 1: Sources of Uncertainty

a. Resolution Error - The resolution error from the DAQ system is negligible because it is a 12-bit system. The resolution error from the thermocouple is $\pm 0.05^{\circ} \mathrm{C}$.

b. Instrument Error - The thermocouples have a calibrated accuracy to within about 1 degree, or $\pm 1.0^{\circ} \mathrm{C}$.

c. Statistical error - The lowest statistical error would come from two samples and lowest error would approach infinite sample size. A size of approximately 60 - 100 samples starts to resemble an infinite sample size in terms of uncertainty and standard deviation (from standard deviation graphs shown below).

$3^{\text {rd }}$ Task: Apply Model to clients application

Step 1: Sources of Uncertainty

a. Resolution Error - The resolution error ranges from 0.3 to 0.4

percent of total value. Since the infrared temperature sensors are for the blast furnace they will be experiencing temperatures approaching $1600^{\circ} \mathrm{C}$. Thus, their uncertainty arrives approximately at $\pm 6^{\circ} \mathrm{C}$.

b.Instrument Error - Assuming the DAQ system is separate from the measurement system the 12-bit DAQ will be a negligible amount with its 4096 bins while the 8-bit DAQ system will have only 255 bins allowing for $1600^{\circ} \mathrm{C} / 255= \pm 6.27^{\circ} \mathrm{C}$. 
c. Statistical error - Standard deviation for a given sample is $30.7^{\circ} \mathrm{C}$ and $t$ for 50 samples is 2.01 thus: $\mu=\bar{x} \pm \frac{t s}{\sqrt{n}} \Rightarrow \pm 8.72^{\circ} \mathrm{C}$.

Step 2: Root Sum Square the Uncertainties and decide the highest contributor.

a. Root sum square gives $\sqrt{6^{2}+6.27^{2}+8.72^{2}}= \pm 12.3{ }^{\circ} \mathrm{C}$

a. Highest contributor is statistical error.

\section{Step 3: Statistical Uncertainty}

a. Check to see if it's normal.

\section{Frequency}

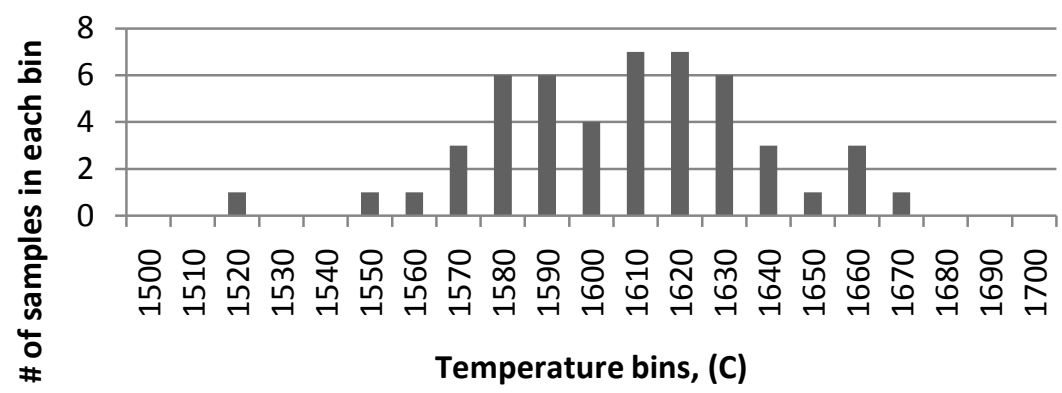

b. Data appears normal - the model says statistical uncertainty applies.

c. Choosing 500 as the sample size, $\mathrm{t}=1.96, \mathrm{~s}=30.7^{\circ} \mathrm{C}$.

a. $\mu=\bar{x} \pm \frac{t s}{\sqrt{n}} \Rightarrow \pm 2.69^{\circ} \mathrm{C}$, total uncertainty $= \pm 9.07^{\circ} \mathrm{C}$.

b. This is much lower than the next highest uncertainty, the model tells us to choose a smaller sample.

c. Choosing 100 as the sample size, $\mathrm{t}=1.98, \mathrm{~s}=30.7^{\circ} \mathrm{C}$.

d. $\mu=\bar{x} \pm \frac{t s}{\sqrt{n}} \Rightarrow \pm 6.08^{\circ} \mathrm{C}$, total uncertainty $= \pm 10.05^{\circ} \mathrm{C}$.

i. The model chooses the 100 sample system!

e.For completeness the 1000 system is considered.

i. $\mu=\bar{x} \pm \frac{t s}{\sqrt{n}} \Rightarrow \pm 1.90^{\circ} \mathrm{C}$

ii. 12-bit DAQ system $= \pm .02^{\circ} \mathrm{C}$, instrument uncertainty $\pm 6^{\circ} \mathrm{C}$.

iii. $\sqrt{6^{2}+0.02^{2}+1.9^{2}}= \pm 6.29^{\circ} \mathrm{C}$

iv. For $\$ 3,000$ a gain of $17^{\circ} \mathrm{C}$, for $\$ 4,000$ a gain of $18^{\circ} \mathrm{C}$ and for $\$ 8,000$ a gain of $22^{\circ} \mathrm{C}$.

f. While the 500 and 1,000 sample sizes are better, the 100 sample rate achieves great accuracy cheaper, thus the 100 sample Marathon FA series is the recommended system for this application. 
From the first run, we learned that we needed to clarify what was expected from the students before starting. It also became clear that more time was needed during the lab to finish the MEA. During the second run, conducted in the following quarter, we improved the experiment by giving students material beforehand that briefed them on the information provided in the memorandum. This was done to allow the students to talk to the client and ask directly what it was I wanted from them. The Professor of the class, Dr. Thorncroft, directed the first run in the Winter quarter. In the second run in the Spring, the client taught the class, hoping that having the client present would help the students identify their deliverables. In this run the same process was used as the previous run, however, material was provided before the class and more time was allotted to build the procedure.

Table 2. Blast Furnace MEA: 1st Run ME 236 Thermal Measurements Lab: 1st Run-through (2 - 3 - 2010) 8:00am 11:00am

\begin{tabular}{|l|l|}
\hline 8:00am & \multicolumn{1}{|c|}{ Time dedicated to lecturing on previous labs and any unfinished } \\
- & topics. Dr. Thorncroft took this time to give the students a quiz and \\
8:30am & lecture on the detail needed in graphs. \\
& \\
\hline
\end{tabular}




\begin{tabular}{|c|c|}
\hline $\begin{array}{l}\text { 8:30am } \\
- \\
\text { 9:00am }\end{array}$ & $\begin{array}{l}\text { The handout, which includes a detailed problem statement, was } \\
\text { given to the students and they were given several minutes to read it } \\
\text { through. We stopped them after about } 5 \text { minutes and allowed them to } \\
\text { ask questions about the reading in order to help them understand what } \\
\text { was going on. They all understood the main concept but needed } \\
\text { clarification on the smaller details. The questions asked by the students } \\
\text { as well as my responses included the following: } \\
\text { Q: "How does the plant use the information?" A: The plant uses } \\
\text { the temperature measurements to maintain the quality of their metal. } \\
\text { Q: "What controls the temperature? Is it a closed loop?" A: It is not } \\
\text { a closed loop; for this analysis we are focusing just on the measurement } \\
\text { of the data and not how it is used. } \\
\text { Q: "Why does the reading need to be so fast?" A: The client has } \\
\text { requested the upgrade and my analysis of it; the hope is for the faster } \\
\text { system to be more accurate. }\end{array}$ \\
\hline $\begin{array}{c}\text { 9:00am } \\
- \\
\text { 9:20am }\end{array}$ & $\begin{array}{l}\text { The students were told to brainstorm about how to solve the } \\
\text { problem in groups. Each group went to a different station and started } \\
\text { re-reading the problem. While more question were asked they were } \\
\text { answered if they were specific or the students were told to wait if the } \\
\text { questions were important so they could be addressed in class. The } \\
\text { students were only given enough time to briefly look through the MEA } \\
\text { and develop questions. }\end{array}$ \\
\hline $\begin{array}{c}\text { 9:20am } \\
- \\
\text { 10:00am }\end{array}$ & $\begin{array}{l}\text { The groups were brought back to their desks and asked to share the } \\
\text { questions they had. All of the questions were addressed and explained } \\
\text { thoroughly. } \\
\text { Q: "How do you combine uncertainties?" A: Root Sum Square. } \\
\text { Q: "Is the population normal?" A: That is something the client will } \\
\text { have to check. } \\
\text { Q: "How does the sampling rate affect uncertainty?" A: Predicting } \\
\text { population mean from a sample, population mean equals the sample } \\
\text { average plus or minus t over the root of the sample size. }\end{array}$ \\
\hline
\end{tabular}




\begin{tabular}{|l|l|}
\hline Q: "Do we use Z or T?" A: T is used because we are dealing with \\
samples. \\
Q: "How many samples per second should they use?" A: That \\
depends upon price, DAQ system and the associated uncertainty. 60 \\
would be a good number to test, large numbers are probably not needed. \\
Q: "How do you get the uncertainty in a DAQ?" A: This is the \\
topic of the lecture if not already known but the detailed answer is in the \\
lab book. The number of bits and the voltage range give you a reading \\
error. \\
11:00am \\
$\begin{array}{l}\text { Time ran short so the students were sent to collect data. They were } \\
\text { told to choose 5 sample sizes and take data. They were told to come up } \\
\text { with a standard deviation for each of the sample rates and the professor } \\
\text { would plot them. There was some confusion about the sample size and } \\
\text { samples per second; the students needed to change both sample size and } \\
\text { samples per second to the same value to change the samples taken per } \\
\text { second. The results of the standard deviation plot showed that standard } \\
\text { deviation varied greatly at below } 60 \text { samples but was more consistent } \\
\text { with larger samples. }\end{array}$ \\
\hline
\end{tabular}

The results of the second run were very similar to the first. Whether or not the additional preparation in the second run was helpful is not fully understood. No table is provided for the second run because similar questions were asked and answered. The pre-lab results showed that almost all of the students (14/16) understood who the client was as well as the simple calculations that drove the uncertainty in the DAQ system. To aid future users of this MEA, an instructor's guide was created and is seen in Appendix A-8. The instructor's guide coupled with the example solution and the author's solution should be ample information to successfully run this MEA. 
One aspect of the lab that could be further explored in future iterations was the standard deviation graph that was generated by the students. The students tested some of their uncertainty assumptions by capturing temperature data at various sample sizes. The students were told to pick random sample sizes and report their results so they could be plotted. Figures 1 and 2 are the data points for the winter and spring quarters.

\section{Standard Deviation Graph: Winter}

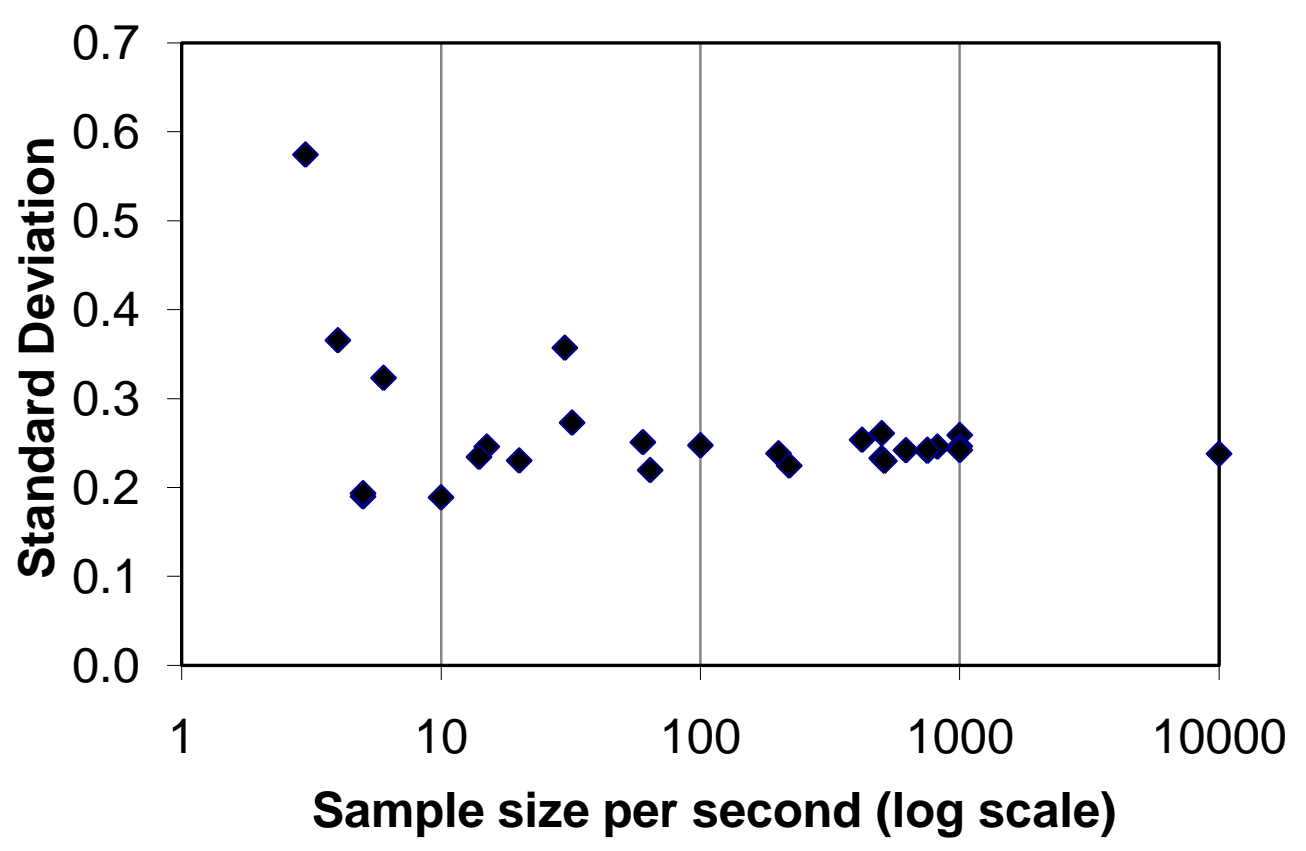

Figure 1: This graph shows data gathered for the standard deviation of a temperature sample in Celsius as a function of random sample rates in one second. These data were collected in the Winter quarter of 2010. 


\section{Standard Deviation Graph: Spring}

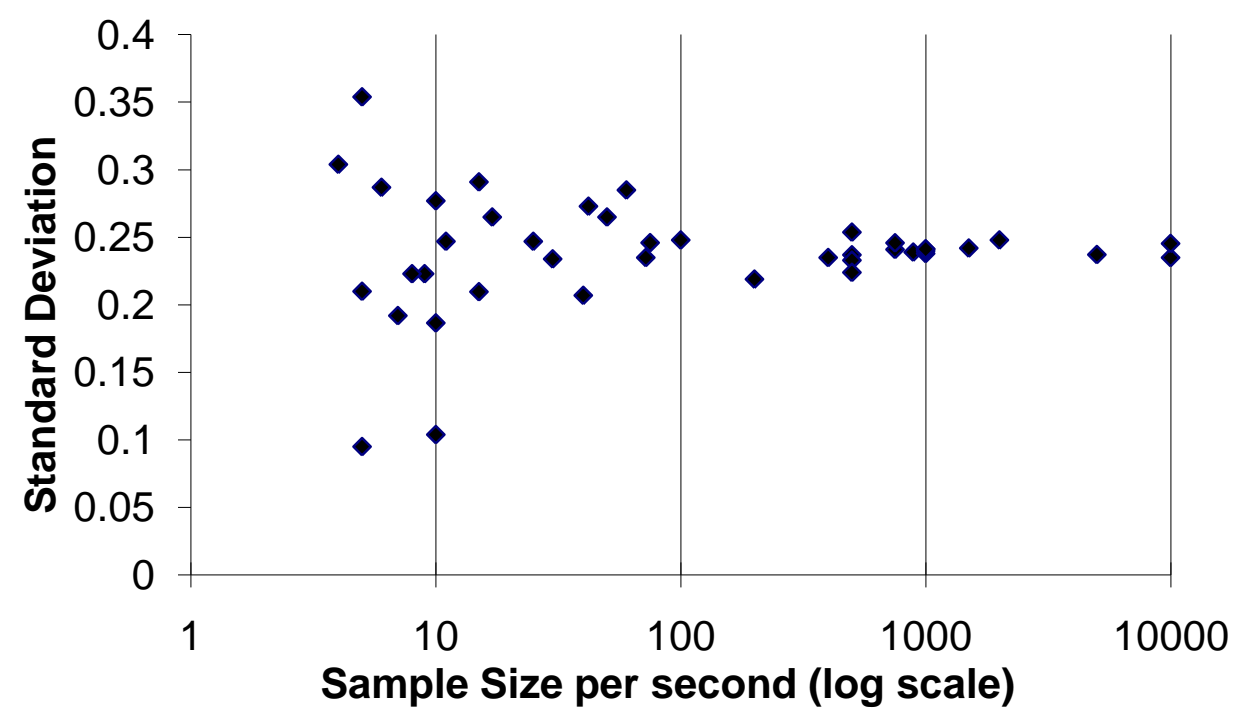

Figure 2: This graph represents the plotted standard deviation in Celsius as a function of sample size in one second. These data were produced randomly by the students in the Spring quarter of 2010.

These plots give a great visual confirmation that there is uncertainty associated with low samples sizes and less uncertainty with high samples sizes. This also shows that after a given sample rate (about 60 to 100) the standard deviation of the sample approaches that of the population. The students used this graph to help them decide whether higher sample rates would help their accuracy. All of the students were able to confirm that the sample sizes become a population approximately past 100 samples per second for this application. 


\section{Discussion}

The goal of this MEA was to create a three-hour MEA that encouraged students to work in teams, solve client driven problems, and create models while maintaining the learning objectives of the previous lab. From the adherence to the six principles of MEAs, this lab can be considered and effective MEA. The MEA helped to develop a new and more detailed lab for the Thermal Measurements class. Developing MEAs from existing labs is difficult and requires complete rewriting of the lab. While starting with a lab is simpler, it is difficult to ensure that the MEA principles are met without completely redesigning the existing content anyway. From this experience it is better to take a concept that you want to teach and design an MEA around it rather than forcing an existing lab into an MEA.

The previous lab was a short instruction-based list where the learning came mostly from the professor during the brief lecture before the lab. In comparison, the Blast Furnace MEA created a small project that the students were able to learn from on their own and be forced to think critically on a problem rather than follow instructions. The student's solutions showed that the MEA introduced the concepts of DAQ systems as well as combined uncertainties in a consistent manner. The standard deviation graphs were great visual aids that let the students see how sample sizes affected uncertainty. Overall this project achieved the goals that were set and successfully created a more thought provoking lab than the previous one. A detailed instructor's guide by the author is listed in Appendix A-4 to aid anyone 
who chooses to employ the MEA. The following table lists the six principles of MEAs and states the qualities of the developed MEA that meets each principle.

Table 3. Blast Furnace MEA Summary

- The six principles and how the Blast Furnace MEA fits them.

\begin{tabular}{|l|l|}
\hline $\begin{array}{l}\text { Model } \\
\text { Construction }\end{array}$ & $\begin{array}{l}\text { This MEA required the students to create a } \\
\text { mathematical model that represented the uncertainty in } \\
\text { the system in order to evaluate the uncertainty with } \\
\text { various tools. }\end{array}$ \\
\hline Reality & $\begin{array}{l}\text { Uncertainty analysis of measuring devices is an } \\
\text { important application in engineering. }\end{array}$ \\
\hline Generalizability & $\begin{array}{l}\text { The models developed were easily modifiable by } \\
\text { design and required less effort by the students to switch } \\
\text { devices and sample rates. }\end{array}$ \\
\hline Self-Assessment & $\begin{array}{l}\text { Data was taken from thermocouples at room } \\
\text { temperature to confirm a desired sample rate. The } \\
\text { students' models could be applied to the experimental } \\
\text { data to assess the quality of their model. }\end{array}$ \\
\hline $\begin{array}{l}\text { Model } \\
\text { Documentation }\end{array}$ & $\begin{array}{l}\text { Each memo was addressed to a client and the } \\
\text { deliverables were clearly identified. }\end{array}$ \\
\hline Effective Prototype & $\begin{array}{l}\text { Uncertainty analysis is useful engineering } \\
\text { knowledge that can be applied to the students' } \\
\text { professional careers. }\end{array}$ \\
\hline
\end{tabular}




\section{Project II: Strain Gauge MEA}

A very important component of the research at Cal Poly is the focus on hands-

on learning. Research has shown that physical experiments help clear up some of the misconceptions that students develop while learning new material (Bowman et al, 2008). During the last week of the quarter, no Thermal Measurements lab was scheduled; instead, the room was open for those students who had missed a lab or wished to catch up with work. Dr. Thorncroft, the professor in charge of the lab curriculum, saw this as a great opportunity to introduce a new project. Dr. Thorncroft had one section of his class try out a new lab that was a MEA with a focus on introducing strain gauges during the normally unscheduled class time.

Strain gauges are used to measure strain, which is the physical deformation of a material caused by an applied force. They consist of a small wire that is electrically conductive. In order to measure the strain in an engineering material, a strain gauge is physically bonded to its surface. A current is passed through the strain gauge and measured with a voltmeter made specifically for strain gauge measurement. As the engineering material undergoes strain the electrical resistance in the strain gauge changes proportionately, see Figure 3. The strain of an object can be used to indicate the external forces being applied it. In the case of a thinwalled pressure vessel, strain can be used to determine its internal pressure. 


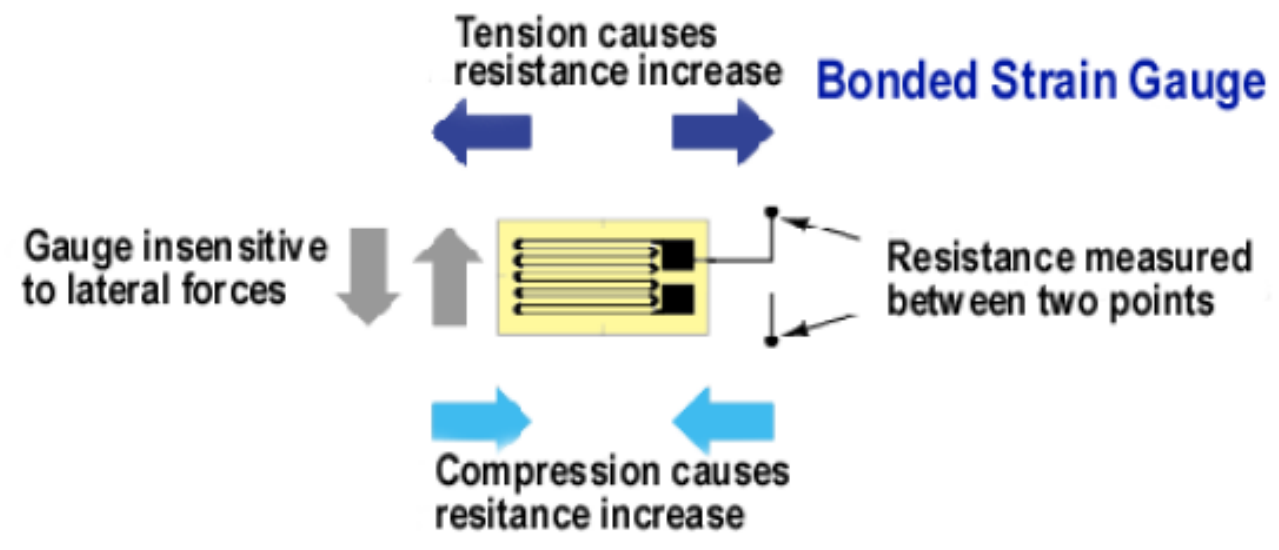

\begin{abstract}
Figure 3. Strain Gauge Diagram - A labeled diagram that illustrates the function of a strain gauge in regards to physical deformation and electrical resistance (image from www.sensorland.com, How they work: the strain gauge).
\end{abstract}

Strain gauges have thin, resistive wires, about 1/1000 inch in diameter, that are used to measure the infinitesimal strains produced in an engineering material. If accurate results are to be obtained from the tested specimen, a strain gauge must be applied to the surface smoothly and firmly normally with a special type of adhesive. Thermal expansion coefficients for the strain gauge and the test specimen need to be roughly equivalent or the reading can become inaccurate.

\title{
MEA Description
}

The strain gauge MEA memorandum below is written from the perspective of an employee of a fictitious soda company, Soda Simple, Inc. The pre- lab material is presented in Appendix B-1 and the problem statement is shown below: 


\section{Memorandum}

To: ME 236 Thermal Measurements Group, California Polytechnic State University

From: Roger Pedactor, Soda Simple, Inc.

CC: Paul van Bloemen Waanders, California Polytechnic State University

Date: June 1, 2010

Re: Testing Exploding Aluminum Cans

Soda Simple, Inc. would like to request your services in researching a dilemma that we have had. Our latest manufacturing process, employed a year ago, uses a new procedure to seal and pressurize the top of our aluminum soda cans. For the past month we have been getting complaints about our product failing at the seam when shaken too vigorously or when the temperature becomes too high. From various consumer reports we believe that this failure is a direct result from our new sealing procedure. The reports indicate that unusually extreme conditions rupture the connections at the top rim of the can, separating the top from the cylindrical body. In order to remedy the situation we need to determine the specific details of the failure.

Our quality engineers need to test the faulty soda cans and determine the different factors and conditions that lead to this particular failure. The pressure of the can at the time of the failure is of particular interest. For obvious reasons we cannot simply measure the pressure inside of the can at failure. One of the preferred methods of non-invasive pressure measurement is through the use of a strain gage. A standard soda can may represent a thin-walled pressure vessel, which means that the pressure is directly related to stress. This allows the strain gage to indicate the pressure inside the soda can without changing it.

We need an experimental test protocol that determines the failure conditions of our product within some engineering accuracy. This test protocol will be used by our quality control engineers on the faulty cans and should include all of the assumptions that are used. We will also need you to provide us with any verification data that you have which validates your procedure. We appreciate your efforts and would be grateful for your analysis as soon as possible. 
The strain gauge application for this MEA involves measuring the strain in an aluminum soda can, eventually predicting the internal pressure. The experimental setup was made originally for high school students but was easily adapted to a college setting (Dues, 2006). In this experiment, the soda can was treated as a cylindrical shell and the strain gauge was fixed to the middle in order to read the pressure in the can. Using a thin-walled pressure vessel assumption, the soda can's pressure is determined from a measured strain before and after the can is opened. A cylinder is considered thin-walled if its wall thickness to radius ratio, $\mathrm{t} / \mathrm{R}$, is much less than 1. The cylinder geometry and loading must also be symmetric and the internal pressure must be uniform. One important feature of the thin-walled pressure vessel assumption is that the end effects are ignored. The hoop stress, or stress tangent to the radius of the can, can be calculated using the equation below.

$$
\sigma_{H}=\frac{p D}{2 t}
$$

Where:

$$
\begin{aligned}
& \sigma_{H}=\text { Hoop Stress } \\
& p=\text { internal pressure } \\
& D=\text { Mean diameter of the cylinder } \\
& t=\text { Wall Thickness }
\end{aligned}
$$

The pre-strain is high due to the large pressure inside the can, allowing for the strain gauge to pick up the relatively small change in shape. In order to make this experiment suitable for college undergraduates, the experiment was changed to 
determine the pressure at material failure. The idea was to have the students develop a procedure that could be used to determine the conditions at which the can would fail. The desired procedure might include the following:

1. Step-by-step instructions
a. Apply strain gauge
b.Measure voltage
c. Apply thin walled pressure vessel assumptions
d.Calculate initial internal pressure
e. Carefully heat while safely measuring internal pressure
f. Record conditions at failure

\section{Model Documentation}

a. Assumptions list:

i. Thin-walled pressure vessel

ii. Perfectly uniform heating

The students were asked to develop a procedure but not to conduct them. The hands-on portion of the lab involved determining the pressure inside the soda can, rather than testing the strain and pressure during failure. An example of the students' solutions can be seen in Appendix B-5.

\section{Results}

This MEA was conducted in the Spring of 2010 in one section of Mechanical Engineering thermal measurements. The Spring section was given required reading 
before class and a quiz right before the MEA. The quiz was meant to be very simple and was taken directly from the required reading. A copy of the quiz is located in Appendix B-2.

The first question asks the students to visually identify the direction of stress in a surface element on a can. The stress in the soda can walls, as explained in the required reading, occurs in both the vertical and horizontal directions. The direction of stress is important for the students to understand because they are only measuring strain, which is directly related to stress through Hooke's Law, in the horizontal direction. In this particular application, only the horizontal strain is needed to determine the internal pressure of the soda can, however, the calculations are affected by which direction the strain is measured.

Only 3 out of 16 students did not identify the correct directions. The second question asks the students to briefly explain how a strain gauge works. Only 2 out of 16 students failed to identify the key concepts behind the strain gauge. The last question asks what the client is looking for, or what the students are responsible for turning in. In this MEA, the client is looking for a procedure to measure the internal pressure of the soda can without opening it. Only 2 out of 16 students failed to identify the appropriate deliverables. Only one student got all three questions wrong, indicating that the majority of the students did the required reading. This data shows with reasonable confidence that each of the four groups was properly prepared for the lab. 
After the quiz the class was introduced to the problem and then asked to brainstorm with their teams. After that, a short demonstration was given to show students how a strain gauge is properly applied. The procedure was performed by the students at the same time so that they could follow along and ask questions.

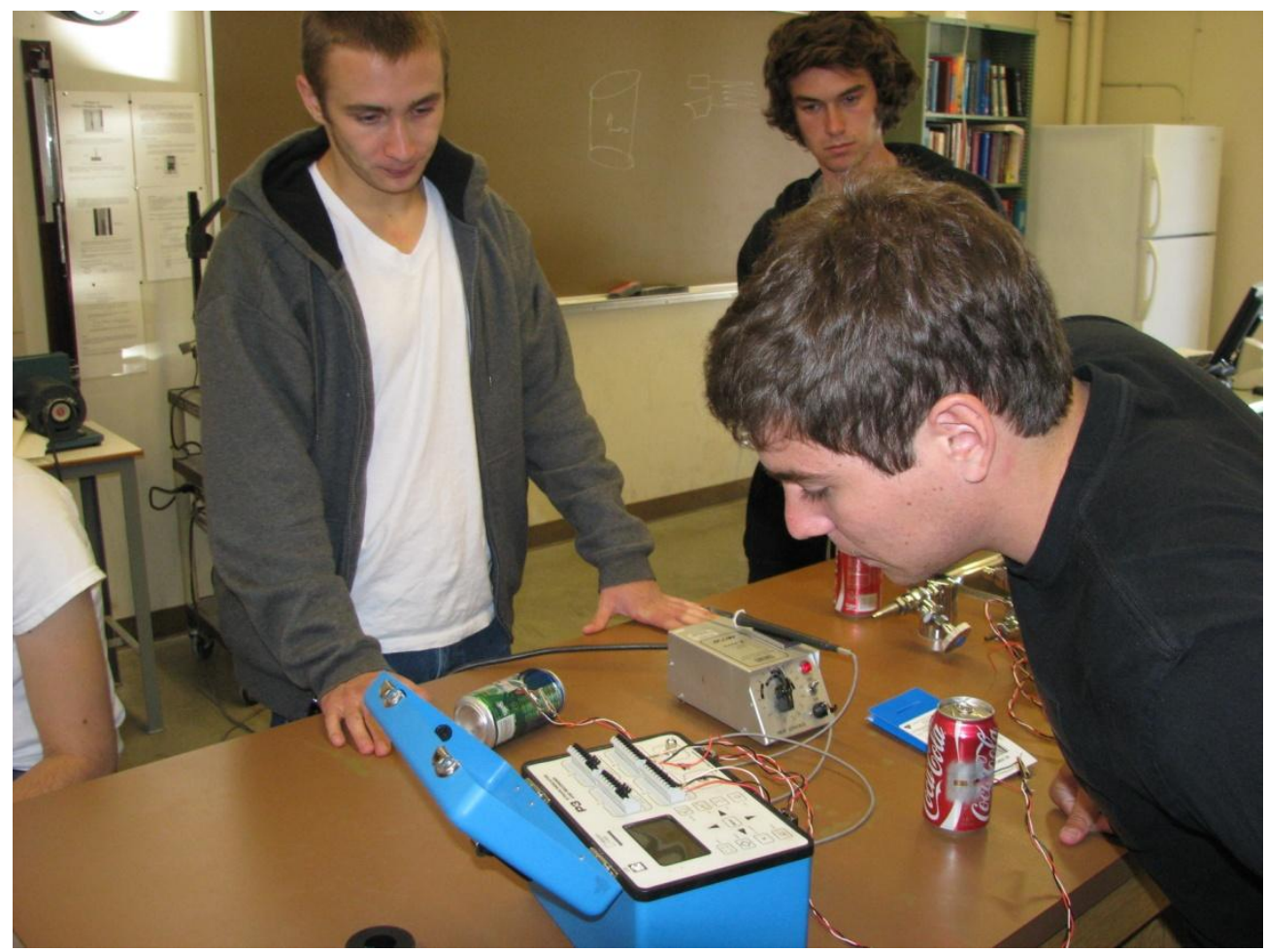

Figure 4. Students testing their strain gauges.

A procedure for soldering the strain gauge onto the can was demonstrated to help the students. This procedure is tabulated and included in Appendix B-3. Two demonstrations were done for two different groups in an effort to ensure there was enough space for the students to watch the demonstration. However, after going through the MEA there was clearly enough space in the classroom to go through the 
demonstration just once and ensure that all of the students could see. This would require more demonstration materials for the students but would be worth the time it saves. The full breakdown of the lab period can be seen in Table 3 .

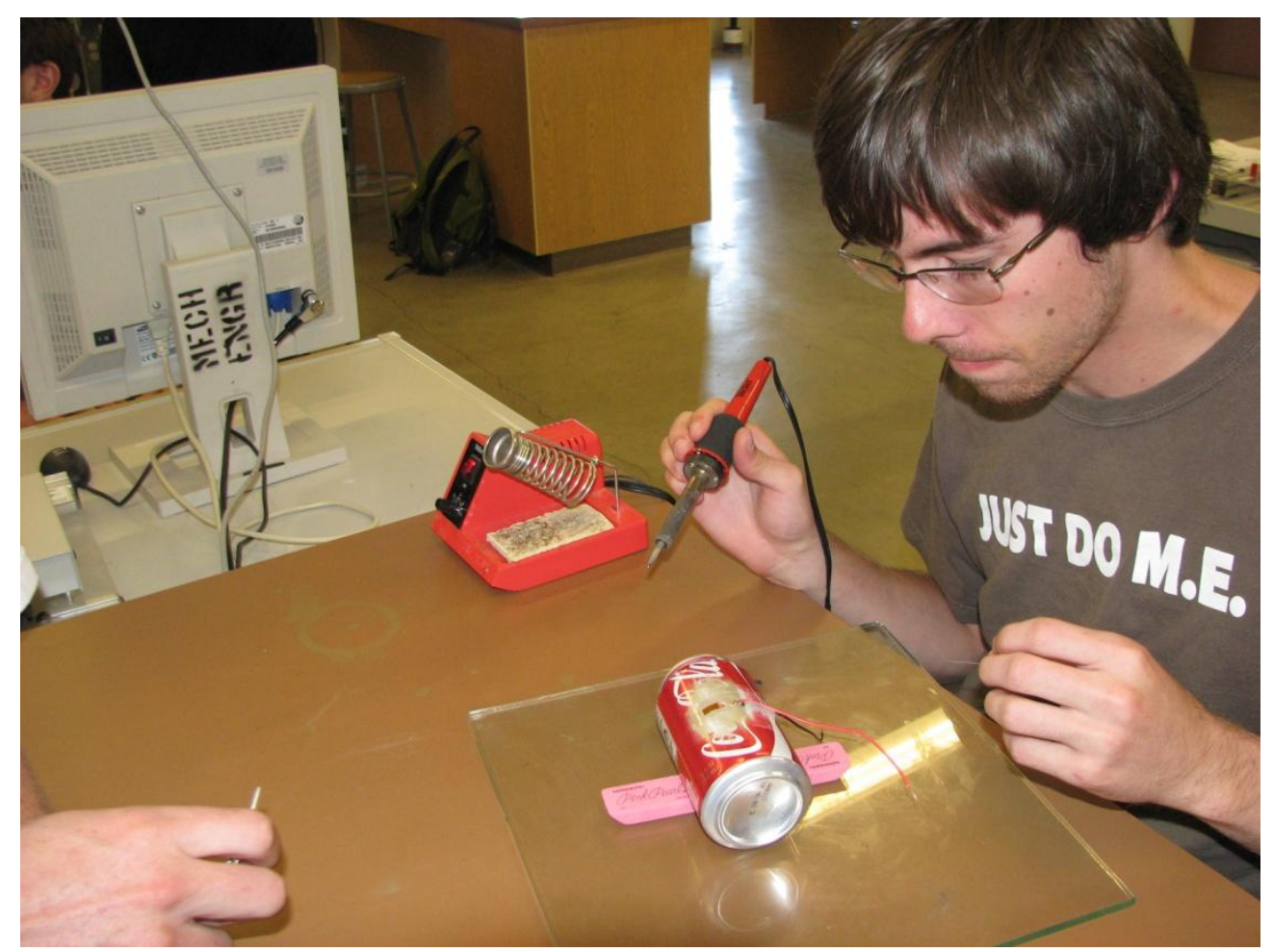

Figure 5. Student's soldering their strain gauges. 


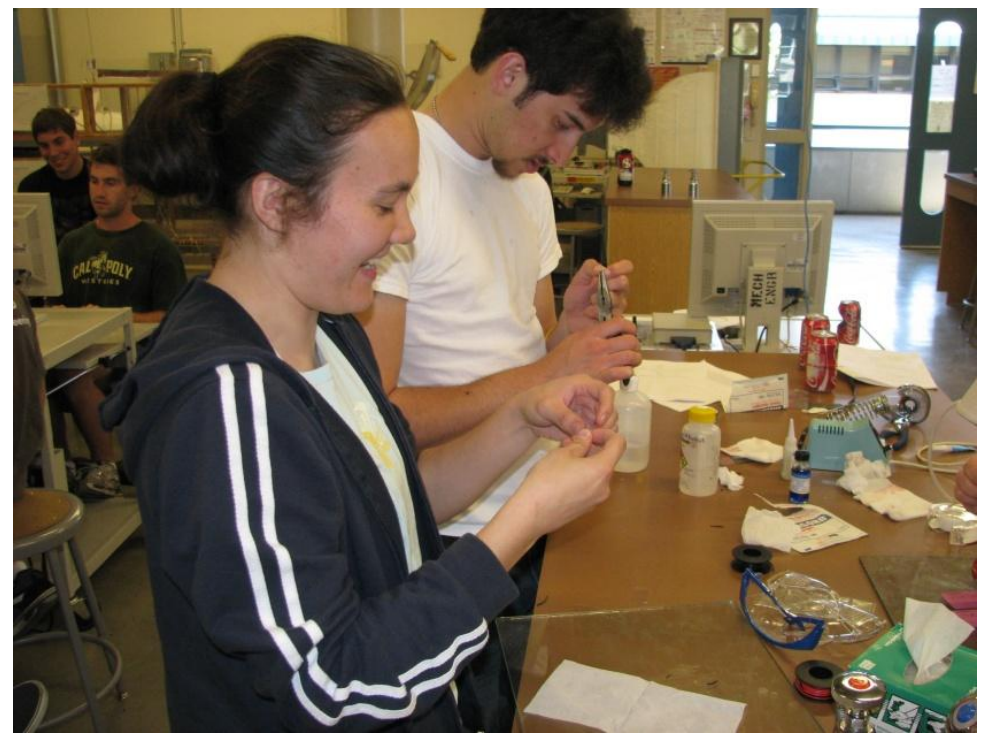

Figure 6. Students working on the strain gauge MEA.

A post survey was given to the students before they could leave in order to find the students' opinions of the lab. The questions asked are listed below:

-Was the Lab interesting/ motivating?

-Did the Lab help you learn the material?

-What could have made the lab better?

The first two questions were ranked from strongly disagree to strongly agree; this survey is listed in Appendix B-4. On a scale of $0-4$, question 1 received a total average of 3.3 and question 2 received an average of 2.7. This leads us to the question of why the students found the material interesting but thought it was less of a learning tool. The last question on the survey addresses this problem with the following comments by students: "less ambiguous directions," "what numbers 
should we be getting?," "should have tested the cans at failure," "better explanation of how a strain gauge works."

Table 4. Strain gauge MEA: 1st run First run of the Strain Gauge MEA - June 1 st, 2010

\begin{tabular}{|c|c|}
\hline 3:10 & $\begin{array}{l}\text { The students were given a straight-forward quiz on the pre-lab } \\
\text { information. Most students had read the information beforehand and } \\
\text { finished the quiz quickly; however, one or two students clearly did not } \\
\text { read the material and had to be given the pre-lab information. }\end{array}$ \\
\hline 3:15 & $\begin{array}{l}\text { The handouts were passed out and we went over the answers to the } \\
\text { quiz. Stresses on the walls of the can? Hoop-stress and longitudinal } \\
\text { stress. How does a strain gauge work? It changes in resistivity with } \\
\text { changes in length. What is the client asking for? The Soda Company is } \\
\text { asking for a procedure to determine the failure conditions of their faulty } \\
\text { soda cans. }\end{array}$ \\
\hline 3:30 & $\begin{array}{l}\text { The four groups were split in half and two of the groups were sent } \\
\text { to start brainstorming their procedure while the other two groups were } \\
\text { sent to watch the demo and created their strain gauge setups. }\end{array}$ \\
\hline $4: 00$ & $\begin{array}{l}\text { The groups switched; groups watching the demonstration started } \\
\text { working on their procedures while the remaining groups watched the } \\
\text { demonstration. The groups switched activities so now the groups who } \\
\text { were working on their procedure watched the demo and the groups who } \\
\text { were watching the demo worked on their procedure. Out of the } 4 \text { groups, } \\
2 \text { successfully soldered their cans and were able to generate simple } \\
\text { results. The other } 2 \text { groups failed in the soldering and were given pre- } \\
\text { made cans to measure and use. }\end{array}$ \\
\hline $4: 30$ & $\begin{array}{l}\text { I walked around answering questions about the procedure and } \\
\text { calculations but did not give the students any other direction. One group } \\
\text { clearly wished to leave early so they were given the post survey } \\
\text { separately. }\end{array}$ \\
\hline 5:00 & A second group finished. \\
\hline $5: 15$ & $\begin{array}{l}\text { Two groups stayed until 5:15 completing their procedures. Most } \\
\text { students had questions about the calculations and not about the } \\
\text { procedure. The most commonly asked question was whether or not they }\end{array}$ \\
\hline
\end{tabular}




\begin{tabular}{|c|l|}
\hline 5:30 & $\begin{array}{l}\text { could assume that the client knew how to apply a strain gauge. The } \\
\text { students wanted to know if they needed to describe the procedure I } \\
\text { demonstrated in class and I told them they did not have to. .. }\end{array}$ \\
$\begin{array}{l}\text { I reviewed the memos after everyone finished and found that most } \\
\text { people misinterpreted the instructions. They believed that I wanted step } \\
\text { group actually listed assumptions; no groups thought about } \\
\text { experimenting with temperature or came up with an actual procedure to } \\
\text { determine failure. }\end{array}$ \\
\hline
\end{tabular}

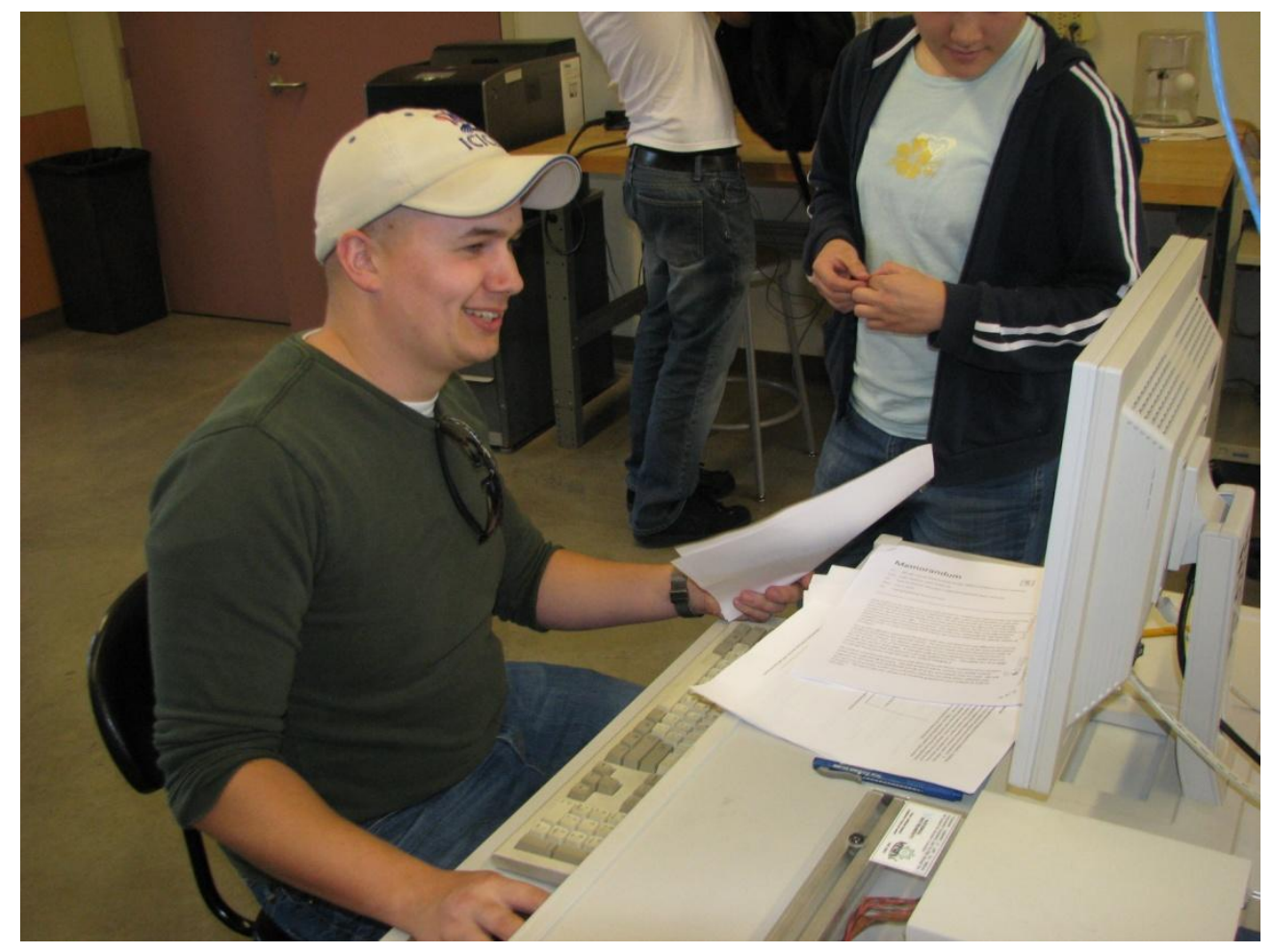

Figure 7. Student's working on their memorandum.

The results were not as detailed as I expected. The students were supposed to turn in a procedure to determine the conditions at soda can failure but most reports 
just described the soldering techniques. An example of a student's Solution is listed in Appendix B-5.

\section{Discussion}

The strain gauge MEA is a new hands-on MEA that shows tremendous promise. The goal of this experiment was to create an MEA that promoted the use of teamwork and critical thinking while introducing the students to the use of strain gauges. Although the MEA can be improved, it still provides a useful introduction to strain gauges during an otherwise unused time period. Table 5 shows the six principles of MEAs and how this project applies to each principle.

Although the students did not interpret the instructions as anticipated, they did get experience with a strain gauge and soldering iron. A Mechanical Engineering design professor approached me not long after the first run of the strain gauge lab, and told me that some of his students greatly benefited from the experience. His class included a physical experiment of strain gauges and the students who took the strain gauge MEA in this experiment had no trouble understanding the concepts in his class.

In the future, the following things should be considered:

1.) Clearly explain that the pressure cannot simply be measured from the strain gauge without intermediate calculations and assumptions.

2.) Have everyone submit their results and graph the results as they are submitted so they can be shared with the class. 
3.) Have the students analyze the uncertainty of each measurement they take.

4.) Only do one demonstration and have the students share the materials if there is any shortage.

5.) Include at least one example procedure to test the soda can at failure, even if it is only a demonstration.

Table 5. Strain Gauge MEA Summary A summary of the six principles and how they apply to the Strain Gauge MEA.

\begin{tabular}{|c|c|}
\hline $\begin{array}{l}\text { Model } \\
\text { Construction }\end{array}$ & $\begin{array}{l}\text { This MEA did not encourage the students to create } \\
\text { a very in-depth model of the soda can or the uncertainty } \\
\text { in the calculations. However, by redefining the } \\
\text { deliverables to require the students to analyze their } \\
\text { model from the perspective of the client, the content of } \\
\text { their models might improve. }\end{array}$ \\
\hline Reality & $\begin{array}{l}\text { The problem statement was presented as a client } \\
\text { based problem with conventional deliverables that could } \\
\text { be expected from any engineering consulting firm. } \\
\text { Failure analysis is also a very common engineering } \\
\text { application. }\end{array}$ \\
\hline Generalizability & $\begin{array}{l}\text { The strain gauge procedure only applied to the soda } \\
\text { can and did not apply to more general techniques. }\end{array}$ \\
\hline Self-Assessment & $\begin{array}{l}\text { Although the students saw the strain gauge } \\
\text { demonstration, they did not have any other guidelines to } \\
\text { check that they correctly solved the MEA. }\end{array}$ \\
\hline $\begin{array}{l}\text { Model } \\
\text { Documentation }\end{array}$ & $\begin{array}{l}\text { Each memo was addressed to a client however the } \\
\text { content could have been improved by some restructuring } \\
\text { of the wording in the problem statement. }\end{array}$ \\
\hline Effective Prototype & $\begin{array}{l}\text { The strain gauge and thin-walled pressure vessel } \\
\text { assumptions are relevant engineering concepts that are } \\
\text { used in professional settings. }\end{array}$ \\
\hline
\end{tabular}




$$
\text { Project III: Supermileage } M E A
$$

The Supermileage MEA comes from a student club at Cal Poly San Luis Obispo, although the problem and the memo are fictitious. The Supermileage club at Cal Poly San Luis Obispo designs a car that is made to get the most distance out

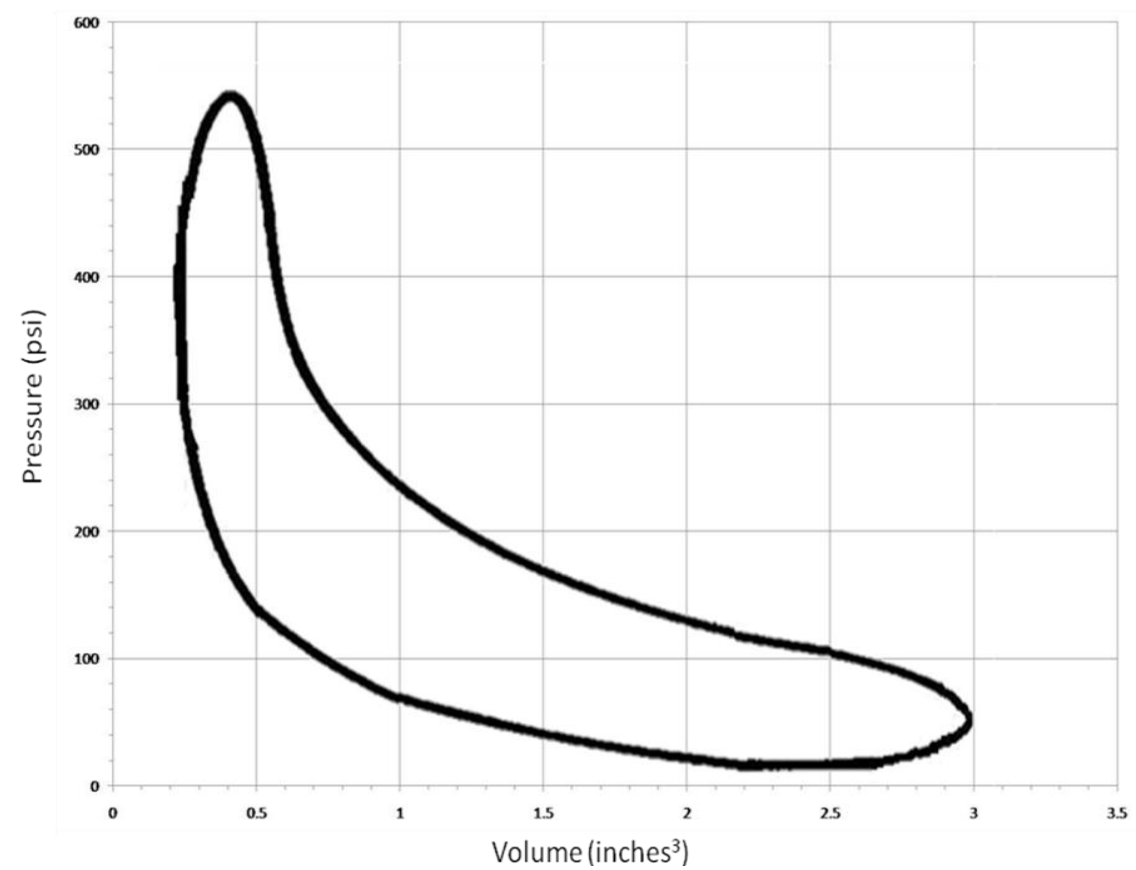

Figure 8. Supermileage Pressure-Volume Graph - The graph of an engine cycle presented as the measured pressure during a single cycle of the engine.

of a finite amount of gas, Figure 9. With this in mind, the students are asked to evaluate the pressure-volume data from a single engine cycle for the supermileage car. This MEA is introduced in the third week of the quarter in an introductory thermodynamics course to mostly third-year undergraduate engineering students. The students are told that they are to model this cycle with 4-to-6 simple processes 
in order to evaluate the thermal efficiency of the engine cycle as well as

recommend a way to increase its efficiency.

\section{MEA Description}

The problem statement is shown below and was presented to the students with the graph of the 'real' cycle plotted on a pressure and volume diagram seen in Figure 8.

Memorandum

To: Thermodynamic Analysis Team

From: Sharon Parker, Cal Poly Supermileage Team

Date:June 30, 2010

Re: Engine Performance Analysis

Each year, Cal Poly's Supermileage Vehicle Team competes in the Shell Eco-Marathon competition (http://www.shell.com/home/content/ecomarathon/americas/). Several years ago, we won the event when we drove our highly aerodynamic vehicle an amazing 1900 miles per gallon. We have not had as much luck recently, but hope you can help us turn that luck around.

Our vehicle is powered by a small displacement, but highly efficient, internal combustion engine. Prior to the competition, we instrumented our engine to measure combustion chamber pressure and volume. You can see sample results of our measurements on the next page. We measure pressure in the cylinder with a pressure transducer and we measure engine displacement (i.e. volume) with a Linear Variable Differential Transformer (LVDT). We are unfortunately not able to measure the work produced per cycle or the thermal efficiency of the engine directly.

We are writing to request your assistance with developing a thermodynamic model which accurately estimates the work produced by our engine per cycle, and determines the thermal efficiency of the engine. Please perform your primary analysis using the data we have provided. We plan to make frequent engine modifications out in the field which will change the cycle details, so please also make your model easy to adjust with additional p-V data. 
Hopefully with the help of your model, we will be able to see how making small changes to the cycle affects work produced and thermal efficiency. To keep the model easy to use, we ask that you: 1) treat the fuel-air mixture in the combustion chamber as simply air, 2) model combustion of the fuel as heat transfer into the system from the surroundings (i.e., even though this is an internal combustion engine, please model it as an external combustion engine), and 3) model the entire cycle with 6 or fewer distinct processes.

Please perform this analysis that our team has requested, and attach it to a memorandum. In your memorandum, please be sure to explain the key assumptions you have made in your analysis and state how you are choosing to model each process. Also in the memo, for the data we provided, please summarize your model calculations for each process (i.e., $\Delta \mathrm{U}, \mathrm{Q}$, and $\mathrm{W}$ ) and for the overall cycle (i.e., $\Delta \mathrm{U}, \mathrm{Q}, \mathrm{W}$ and $\eta$ ). Based on your analysis, what modifications to the cycle would you recommend to increase the performance of the engine? We would like your memo and model by early next week. Thanks for your attention to this matter.

Sincerely,

Sharon Parker,

Cal Poly Supermileage Team

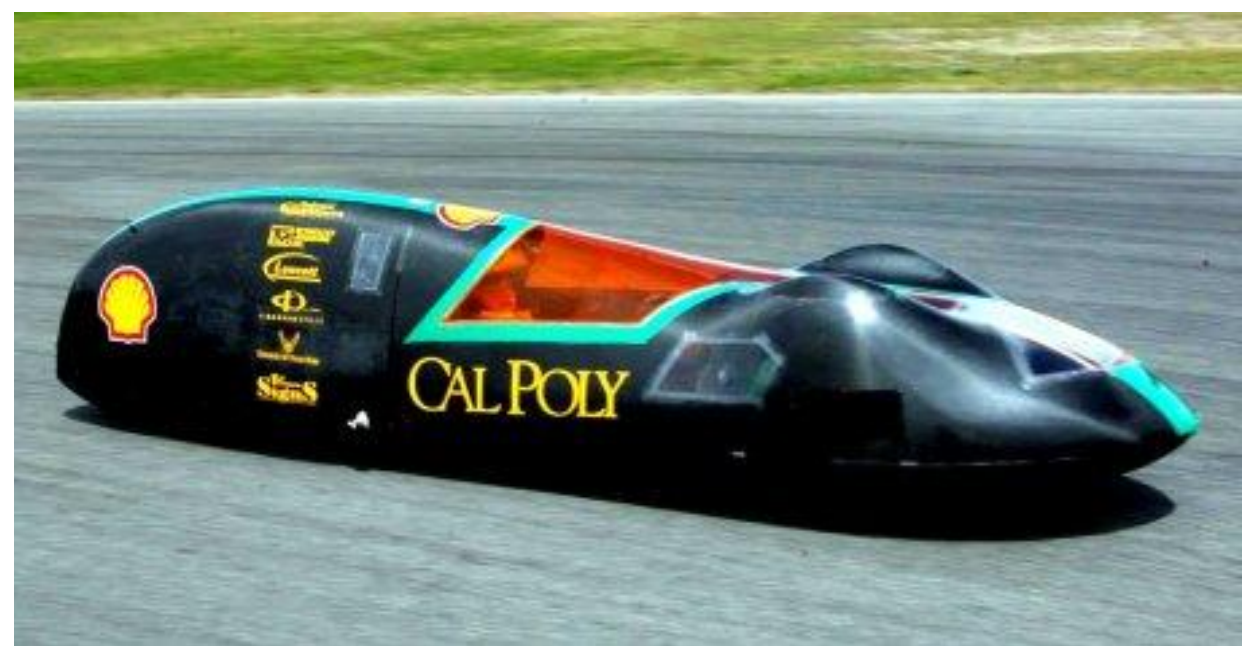

Figure 9: Photograph of Supermileage Car - A picture taken of the real Cal Poly supermileage vehicle. 
A pre-lab with helpful information for the students to learn beforehand is

provided in Appendix C-1. The graph in Figure 8 was generated from a theoretical model of a normal engine and sized onto the graph to allow for the lowest pressure to be atmosphere.

This MEA has so far been tested in six class sections, three in the Spring quarter and three in the Summer quarter of 2010. This MEA is designed specifically to reinforce the students' perceptions of how processes are shaped in a pressure-volume diagram. The hope is that the students will match the general shape of the provided curve with simplified processes they have learned earlier in the course. The students were given one week to develop a general model of the engine cycle. Each group was told to ascertain the thermal efficiency of the given cycle and to enable their model to evaluate the efficiency once the suggested changes to improve the engine had been employed.

\section{Results}

Modeling a combustion engine is a unique skill that is normally taught in a second thermodynamic course that describes various methods of modeling a heat engine. A combustion engine is one that uses a fuel to generate work by expanding a gas. The work from the gas is captured by a piston and, in this case, used to turn a crankshaft. The supermileage vehicle upon which this MEA is based upon is meant to have a high efficiency engine that can travel long distances with a small amount 
of fuel. The plot given to the students in Figure 8 represents the measured pressure inside of the cylinder as a function of volume. There are many standard ways to model an engine that are taught in an advanced thermodynamics class, however, because the MEA is introduced in the third week of the introductory thermodynamics course the students are told to attempt their own model.

The students start by taking the continuous graph given to them and assigning pressure-volume functions called processes to define each part of it. By doing this, the students can then integrate their functions with respect to volume to get the total work of the cycle, an example is shown in Figure 10.

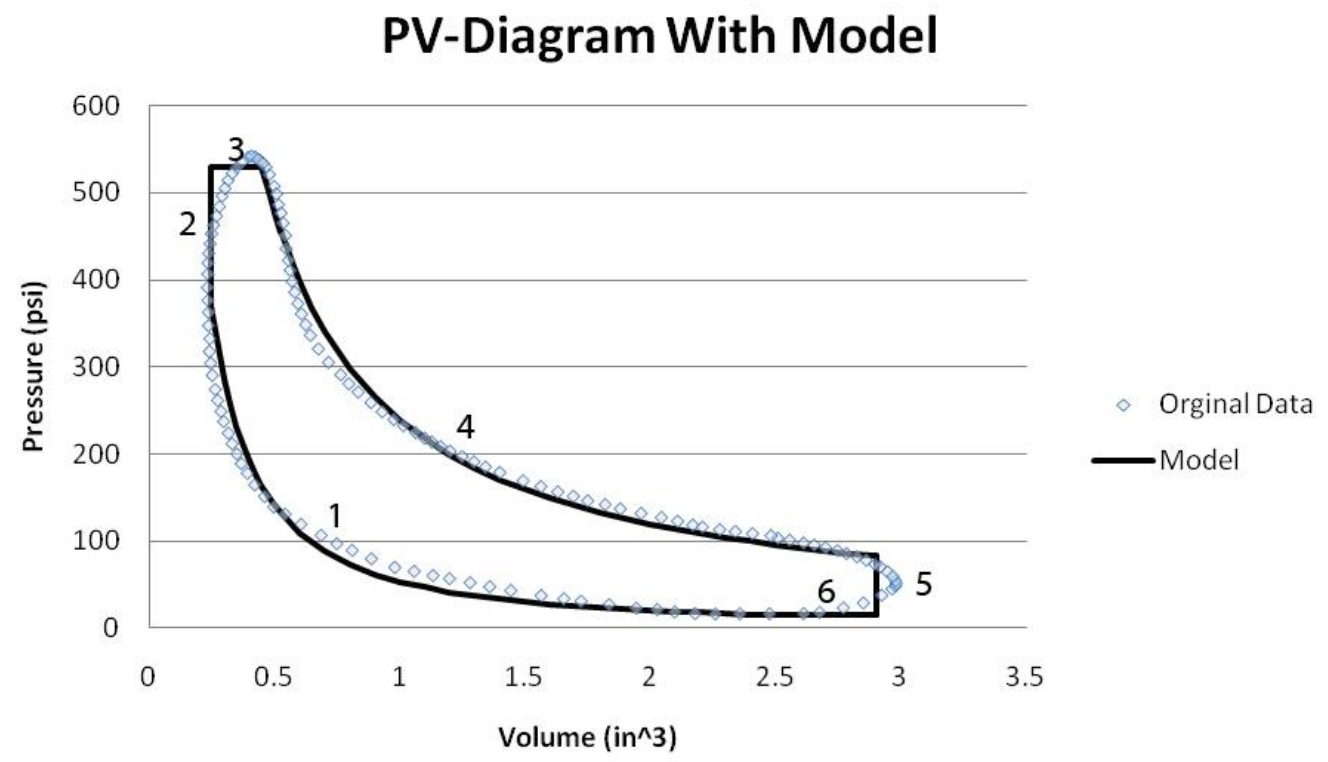

Figure 10. An example of a student's model of the given pressure-volume graph. 
- There are several processes that the students have available to them. The most basic are the constant volume, or isochoric process, and the constant pressure, or isobaric process. An isothermal process is defined by the relation $\mathrm{PV}=$ Constant, where $\mathrm{P}$ is pressure and $\mathrm{V}$ is volume. In the isothermal process the temperature of the working fluid is constant, thus by the ideal gas law PV $=\mathrm{nRT}, \mathrm{PV}=$ constant, where $\mathrm{n}$ is the number of moles, $\mathrm{R}$ is the universal gas constant and $\mathrm{T}$ is temperature. An adiabatic process is $\mathrm{PV}^{\mathrm{k}}=$ Constant, where $\mathrm{k}$ is the ratio of specific heats for the working fluid; air, in this case, has a k value of approximately 1.4. An adiabatic process is characterized by having no heat transfer in or out of the working fluid. Finally, any process that is defined $a \mathrm{PV}^{\mathrm{n}}=$ constant is a polytropic process in which $n$ is usually between 1 and $\mathrm{k}$.

Using these processes the students can develop a cycle that mathematically defines the graph given to them. In a standard combustion engine the combusted gas exits to atmosphere during some part in the cycle. This is represented by the lowest point in the graph, or atmospheric pressure defined as 14.7 psi (pounds per square inch). The students are not given this information beforehand so it is something that they have to observe on their own. Because the students are developing their own model, it is not required that they include an atmospheric point. The students' analysis should reveal whether or not adding an atmospheric point is important. 
The solutions that the students produced were evaluated and broken up into several major components. These components were selected to best show that the objective of the MEA was being achieved. In an effort to assess the effectiveness of this MEA, the solutions were evaluated based upon the six principles of ModelEliciting Activities.

\section{Model Construction}

In order to analyze the quality and form of the students' solutions it was necessary to separate the solutions into categories. Solution trees were created to help visualize the correlations between the different solutions and their methods. The main criterion for accuracy in a solution was the area inside the cycle or the total work of the system. An example of one of the students' memorandums is presented in Appendix C-2. The actual area inside of the graph was measured with a planimeter, a tool used to measure the area inside any two dimensional curve. This measured value was used to determine deviation in the students answers. The resulting number represents a percent error that was used as an indication of accuracy. It should be noted that several solutions had obvious mistakes or simple calculation errors that did not contribute to method-accuracy correlations. These solutions were not included in this analysis. The basic two groups that the students' models fell into were ones that included an isothermal process in their solutions and ones that did not. From all of the possible routes that could have been used to model the engine, included at least one isothermal process had the highest 
correlation to accurate answers. As seen in Figure 11, the number in normal parentheses ( ) is the number of solutions in that category. The numbers in the brackets [ ] are the minimum and maximum error in total work. The number to the left of the brackets is the average error for that category. For the first two categories it is observed that the solutions that included an isothermal process had a lower average error by $27 \%$ for the first set of solutions and $11 \%$ for the second set of solutions.

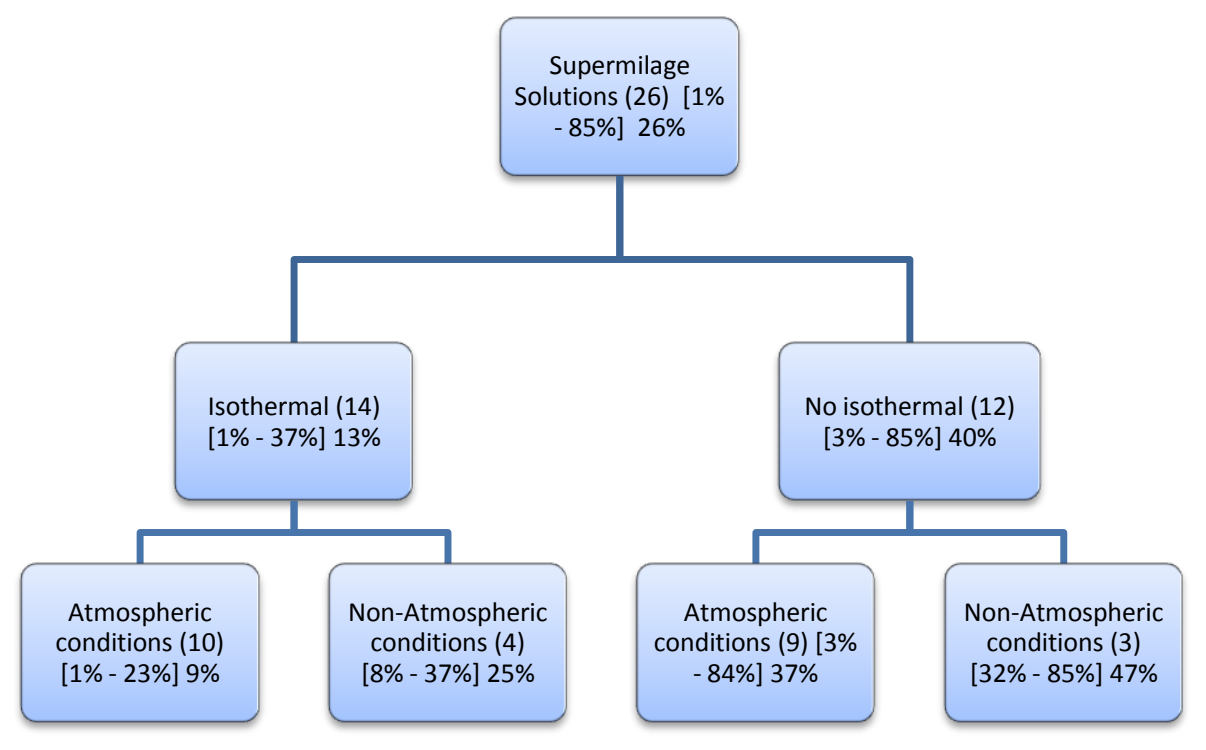

Figure 11. Supermileage Solution Tree: Spring - A breakdown of the analysis of the Spring solutions in all three classes combined. The tree is broken into groups that included an isothermal process and groups that included an atmospheric state point in their solutions. The boxes indicate total number of solutions in each bin, the range of calculated work output error from the actual value and the average error for each bin. 
The second type of grouping was whether or not the solution included a state point at atmospheric conditions. Using these categories the solutions were grouped and plotted to visualize the different solution paths that the students took. The results from this grouping of solutions can be seen in Figures 11 and 12. From the two figures it is observed that the average error is smaller when the students include an isothermal process and an atmospheric state. This could result because the groups that recognized a need for an atmospheric state were able to more smoothly model the cycle than those that did not. The isothermal process, depending on the starting and ending state points chosen, was generally seen to fit the curves of the provided graph more smoothly than the other possible processes. This could have resulted in the low error for the groups that included an isothermal process. 


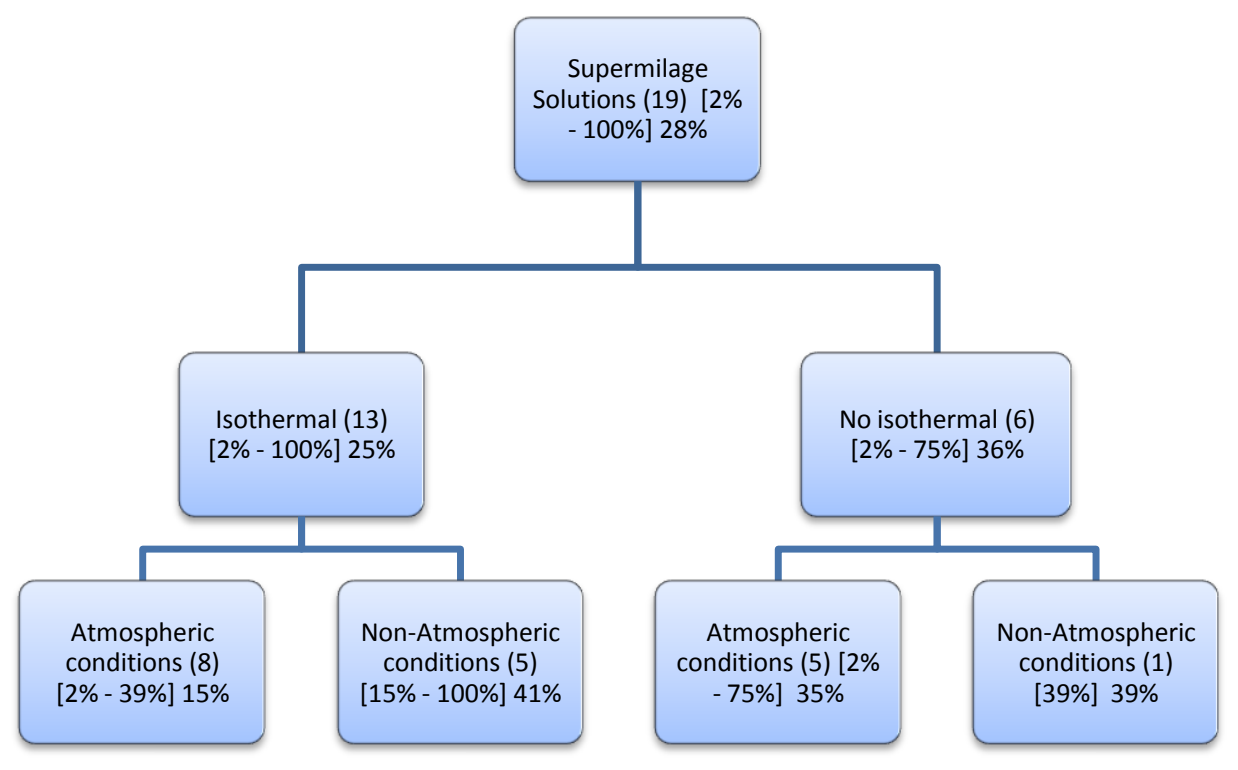

Figure 12. Supermileage Solution Tree: Summer - Another breakdown of the analysis of the Summer solutions in all three classes combined. The tree is broken into groups that included an isothermal process and groups that included an atmospheric state point in their solution. The boxes indicate total number of solutions in each bin, the range of calculated work output error from the actual value and the average error for each bin

\section{Model Documentation}

The documentation of the model is an important part of MEAs. In industry, it is very important for engineering colleagues to understand each other's work. Being able to communicate ideas through technical documents is an invaluable skill. MEAs cultivate this skill by requiring the students to document the technical models they create. Each group is expected to turn in a memorandum that is written to the client, in this case the fictitious Supermileage Club member Sharon Parker. The original problem statement asks them for the model in some digital 
form, the analysis of the cycle provided, and a simple recommendation to improve the efficiency of the cycle.

The first indication that the students understand that this activity is meant to emulate a real world scenario is who they choose to address in their memo Also very telling is the voice they choose to use throughout the memo. Table 6 summarizes the students' voice and who they addressed in their memo. The category "You" indicates that the students addressed the client in the memo by simply stating "You" without mentioning name or title. Similarly, "Dear Client" means that the client was addressed by name but only in the beginning of the Memo. "Supermileage" means that the students acknowledged that the Supermileage club was their client. "You, Supermileage" indicates that the students used both "You" and the Supermileage indicators in their memo. "None" means that no client was addressed and "Professor" means that the professor was addressed instead of the client. 
Table 6. Supermileage Document:

Summer and Spring - A list of the different voices used to address the client in the Summer and Spring groups' memos to the client.

\begin{tabular}{|c|c|c|}
\hline How the client was addressed & Summer & Spring \\
\hline You & $\mathbf{2 7 \%}$ & $\mathbf{3 1 \%}$ \\
\hline Dear Client & $\mathbf{0 \%}$ & $\mathbf{1 3 \%}$ \\
\hline Supermileage & $\mathbf{1 5 \%}$ & $\mathbf{2 5 \%}$ \\
\hline You, Supermileage & $\mathbf{1 9 \%}$ & $\mathbf{9 \%}$ \\
\hline none & $\mathbf{3 1 \%}$ & $\mathbf{2 2 \%}$ \\
\hline Professor & $\mathbf{8 \%}$ & $\mathbf{0 \%}$ \\
\hline
\end{tabular}

The deliverables of the project were also an important part of the documentation for the MEA. There were only three direct deliverables stated in the assignment: the model, the results and the recommendation. Table 7 summarizes for each quarter the percentage of students that included the corresponding deliverables. The tables also include the percentage of solutions that address a client in some way. 


\section{Table 7. Supermileage Deliverables:}

Summer and Spring - The percentage of solutions in the Summer and Spring that included the listed deliverables in their final memo.

\begin{tabular}{|c|c|c|}
\hline Deliverables & Summer & Spring \\
\hline Client & $\mathbf{6 1 \%}$ & $\mathbf{7 8 \%}$ \\
\hline Model & $\mathbf{9 6 \%}$ & $\mathbf{9 7 \%}$ \\
\hline Results & $\mathbf{6 2 \%}$ & $\mathbf{7 8 \%}$ \\
\hline Recommendation & $\mathbf{8 8 \%}$ & $\mathbf{9 4 \%}$ \\
\hline
\end{tabular}

From the previous tables, $61 \%$ of the solutions in the Summer and $78 \%$ in the Spring were addressed to a client, however the remaining students failed to address a client at all. $22 \%$ of the groups in the Spring and $38 \%$ in the Summer did not include the results of their model. Most of the solutions included the remaining deliverables: describing the model, listing assumptions while also providing a recommendation for increasing thermal efficiency.

\section{Generalizability}

The assignment asks the students to create their model such that the client, the Supermileage Club, will be able to use it when analyzing future engine cycles. This is required to encourage the students to make their models simple to modify, or "generalizable". This also indicates to the students that the client expects their model to be useful and help them solve future engineering problems. For this MEA there is a trade-off for making the model more generalizable. If the students use 
values that need to be looked up in their model, it limits the ability of the model to be used as a tool. In order to make the model more flexible, complex approximations can be made that lessen the accuracy of the model and are more difficult to employ. For example, calculating the heat lost to the surroundings requires looking up values of internal energy and specific heats in a textbook. Without complex equations, which some students did use, the model requires the user to alter the model parameters in order to use it accurately. In Table 8, several generalizable traits are listed along with the percentage of groups that employed them.

Table 8. Supermileage Generalizability: Summer and Spring - The methods used in group solutions that made the model more generalizable for the Summer and Spring sessions in 2010.

\begin{tabular}{|l|c|c|}
\hline \multicolumn{1}{|c|}{ Generalizability } & Summer & Spring \\
\hline $\begin{array}{l}\text { The model has clearly indicated space for } \\
\text { input }\end{array}$ & $\mathbf{6 5 \%}$ & $\mathbf{7 6 \%}$ \\
\hline $\begin{array}{l}\text { The user does not need to alter the model } \\
\text { when using new input values }\end{array}$ & $\mathbf{8 5 \%}$ & $\mathbf{8 4 \%}$ \\
\hline The user does not need to look up values & $\mathbf{1 2 \%}$ & $\mathbf{3 1 \%}$ \\
\hline $\begin{array}{l}\text { Work is recalculated automatically when new } \\
\text { inputs are used }\end{array}$ & $\mathbf{7 0 \%}$ & $\mathbf{7 4 \%}$ \\
\hline $\begin{array}{l}\text { Internal Energy is recalculated automatically } \\
\text { when new inputs are used }\end{array}$ & $\mathbf{5 0 \%}$ & $\mathbf{2 9 \%}$ \\
\hline
\end{tabular}


The least popular method of creating a good generalizable model was using equations to generate the values of specific heat based upon temperature. Specific heats do not change very much over temperature unless the gas that is being worked with is getting very hot, which was the case in this MEA. Most students chose to look up the specific heats and have the client do the same thing when applying the model to a different cycle. This is an easy and accurate way to get those numbers. Other groups held the specific heats constant and regarded the resulting error as negligible by choosing a specific heat that was based on an average of the beginning and ending state temperatures. A third, smaller selection of groups chose to look up the equation for determining specific heats based upon temperature and include that in the model. The students in this third group took into account that their model would apply to more applications if they used a general equation for the specific heats instead of simply holding it constant. Deciding between either a specific and simple model or an complex and broad model is something engineers struggle with every day.

Since the numbers in Table 8 are low, it is clear that making the model generalizable was a low priority for most groups. The important thing is that the groups recognized the issue and placed input areas for new data while recalculating work so the model remained updated. Recalculating the internal energy, U, required the students to do more research into different methods of calculating internal energy other than simply looking the values up. 


\section{Effective Prototype}

An important objective to confirm is whether or not the students are learning the concepts. This objective is important because MEAs are only useful tools if they are helping the students to learn, not preventing them from learning. The concepts in this MEA are intended to help students with common problematic areas in the thermodynamic curriculum. Table 9 shows the percentage of students that included the following basic thermodynamic concepts in their model: The Ideal Gas Law

$$
(\mathrm{PV}=\mathrm{nRT})
$$

Integrated Work

$$
\left(\text { Work }=\int \mathrm{Pdv}\right) \text {, }
$$

and the First Law of Thermodynamics (Cengel, 2008).

$$
(\partial \mathrm{U}=\partial \mathrm{Q}-\partial \mathrm{W})
$$

Table 9. Supermileage Effective

Prototype - A summary of the Summer and Spring groups that included the following basic but essential thermodynamic concepts correctly.

\begin{tabular}{|c|c|c|}
\hline Effective Prototype & Spring & Summer \\
\hline Ideal Gas Law & $\mathbf{9 7 \%}$ & $\mathbf{9 6 \%}$ \\
\hline Integrated Work & $\mathbf{9 1 \%}$ & $\mathbf{1 0 0 \%}$ \\
\hline 1st law & $\mathbf{9 7 \%}$ & $\mathbf{1 0 0 \%}$ \\
\hline
\end{tabular}


The numbers show that the main thermodynamic concepts are being employed correctly by the majority of the students. Only a handful of solutions, at most $9 \%$, fail to include the essential concepts. It is important to note that the Ideal Gas Law, the First Law of Thermodynamics, and the concept of integrated work are very important concepts in thermodynamics. Students who did not finish the course with these concepts in hand would be seriously lacking in their engineering education.

\section{Self-Assessment}

One missing part of this MEA is the ability for students to easily evaluate their own work. Of the required deliverables, only thermal efficiency of the engine was something the students could look up to check their answers. Although the work output of the given cycle is measureable, it takes up valuable time for the groups to confirm that they have appropriate work. Simple mistakes like unit conversion or basic misunderstandings can be found through some sort of check that could be provided by the teacher. The average calculated efficiency was $43 \%$ and the measured work was $34 \mathrm{ft}-\mathrm{lbs}$; these values might be given to the students so that they have something with which they can compare their calculated values. Another possibility is to have the next iteration of this MEA to include the students average results from this iteration. Table 10, below, shows the percentage of groups that made the most common two mistakes or did not include a model. 
Table 10. Supermileage Calculation Errors: Summer and Spring - The common errors that were found in the Spring and Summer quarters solutions.

\begin{tabular}{|l|c|c|}
\hline Calculation errors & Spring & Summer \\
\hline Unit conversion & $\mathbf{1 0 \%}$ & $\mathbf{6 \%}$ \\
\hline $\begin{array}{l}\text { Confusing the heat energy into the engine as the } \\
\text { total heat energy in and out of the system }\end{array}$ & $\mathbf{3 \%}$ & $\mathbf{9 \%}$ \\
\hline No model & $\mathbf{1 0 \%}$ & $\mathbf{6 \%}$ \\
\hline
\end{tabular}

Having $6 \%-10 \%$ of the groups not turn in a model is concerning. Some postMEA surveys indicated that some groups ran out of time and at least one simply did not understand that a working model was required. Even more concerning is that $3 \%$ to $9 \%$ of the students thought that the total heat transfer into the system was calculated as the summation of all of the heat transfer in and out of the system. The calculation in question was essential for determine the thermal efficiency of the system, which is the summed total work from the system over the heat delivered into the system.

One aspect of the solutions that is worthy to note is that some of the solutions included processes that were simply equations to fit the line instead of the processes that they had learned. At first, this was thought to be a significant factor for accuracy but the results showed no direct correlation. One third of all the groups 
chose to employ at least one process that they had not learned about in class. Of the students that chose defined thermodynamic processes, the average of the total error in work output was $33 \%$ while those that chose new or otherwise made up processes had an average of $14 \%$ error. Simply put, the students that followed directions and employed only processes that they learned were more likely to have more error in their model. This method of modeling may steer the students away from one of the main objectives which is to help the students become familiar with known thermodynamic processes.

Another point that can be seen from the difference in modeling known processes, such as isothermal, isobaric, isentropic, adiabatic, etc., rather than undefined polytropic processes with arbitrary exponential values is the contrast in thermal efficiency. The thermal efficiency is a ratio of the total work produced to the amount of heat transferred into the system. The solutions that included known processes came out with an average efficiency of $43 \%$. The accuracy of thermal efficiency is largely dependent on how the state points are chosen. The group solutions that used at least one undefined process came up with efficiencies that were an average of $56 \%$. The actual efficiency of the engine is unknown because the amount of heat transfer depends on the method used to model the system. The use of unknown processes rendering higher efficiencies is an interesting observation. If this in fact is a correlation then the association with higher 
efficiencies with undefined processes again could lead the students away from the objective of helping them with known processes.

\section{Reflections}

Every student was given an in-depth reflection questionnaire after the assignment. These reflections are used to allow the students to analyze their own work as well as to let the professors get a glimpse of how the students are solving these activities. The reflection asks the students about the process they used to solve the MEA as well as their own feelings towards their contributions and solutions. A full example of the reflection questionnaire can be seen in Appendix C-3. For the summer session, one question was added because of the demonstration that was given in the middle of the assignment. This question asked if the students thought that collecting PV data on their own would be beneficial.

The reflection covers many areas, however the topics of interest for this particular MEA are in the concepts that the students feel they learned. Question 10 in the reflection exercise asks the students to identify the concepts that they feel were important to this particular MEA. Among the possible concepts are processes, cycles, the first law of thermodynamics, modeling polytropic processes, thermal efficiency, ideal gases, and evaluating energy for an ideal gas. All of these concepts could have been present in the problem depending upon how the students chose to set it up. What we are looking for is for the students to indicate processes as the main learning concepts of the MEA. 
One of the reflection questions deals with the concepts that the students felt they learned the most. They were given a list of eight concepts and were told to underline the ones they felt they learned through the process of solving the MEA. Each of the eight concepts is involved in the MEA somewhere and someone who did the MEA alone would likely indicate all of them. It is common in group projects to split up the work; one group member might deal just with the thermal efficiency, while another focuses only on the first law. The idea is that the question will reveal which concepts are learned by everyone and which ones are learned only by a few. Figure 13 show the results of all the reflections and which concepts are most selected. The graphs show that Processes, Evaluating energy for an ideal gas, and Modeling a Polytropic Process were indicated as the most learned concepts. This means that the original goal of creating an MEA to focus on processes was most likely achieved. An interesting result is that the graphs from the two different quarters look the same and have very similar percentages. The only difference between the presentations of the two quarters was a demonstration of pressure volume data gathering on the second day of the assignment. The consistency of the results of this MEA could indicate that this is a solid method for teaching the highly ranked concepts reliably. 


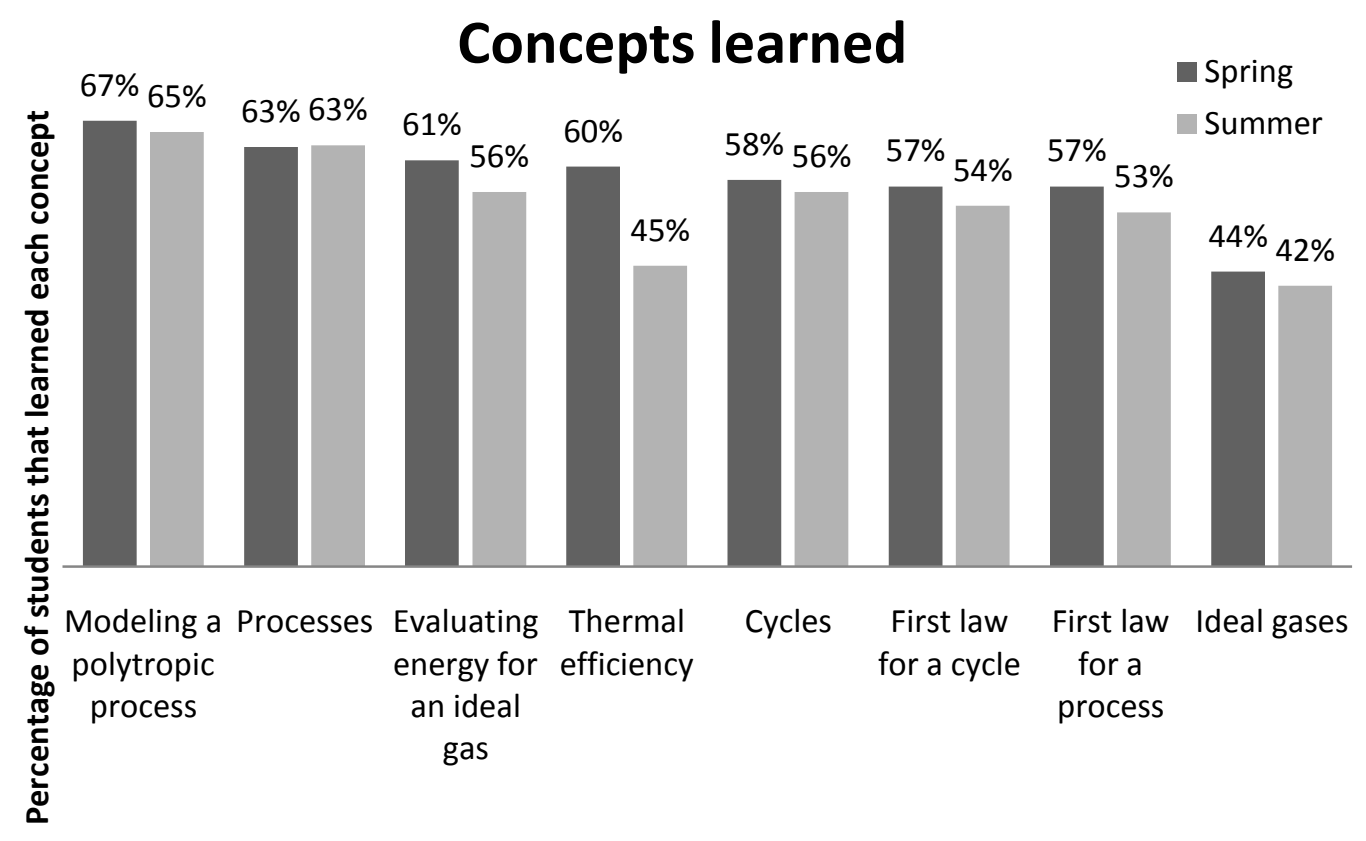

Figure 13. Supermileage Concepts Learned: Spring \& Summer - The percentage of students during the Spring and Summer quarters in 2010 that indicated that they learned each of the listed concepts 


\section{Supermileage Suggestions to improve MEA: Spring}

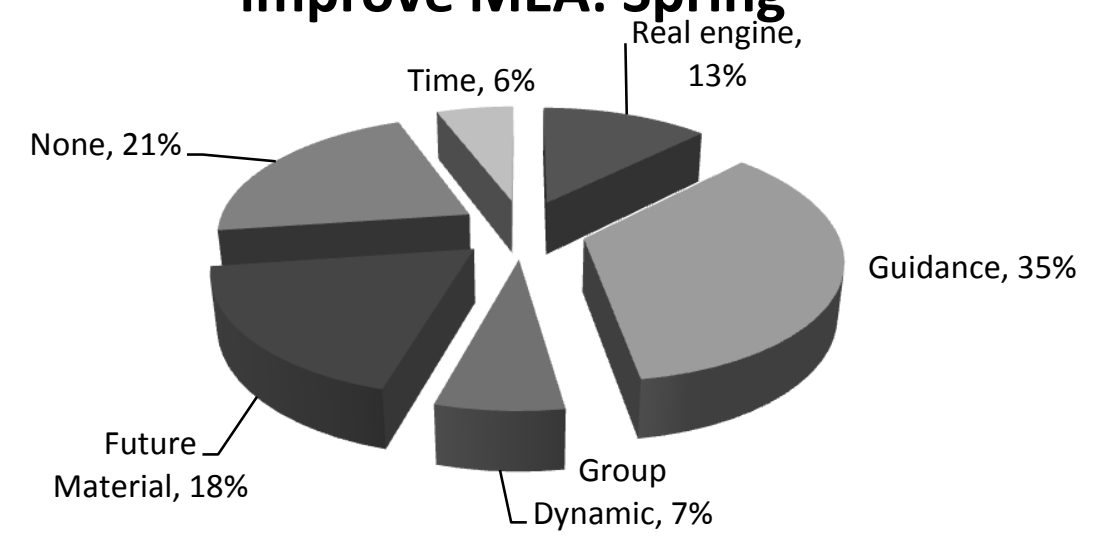

Figure 14: This is a list of the six suggestions that the students listed as ways to improve the supermileage MEA in the Spring session.

The first step in analyzing the reflections was to take a small sample and read through them to determine where the revealing information is. After dissecting several of the reflections it became clear that only some questions in the reflection were useful for this research. The time and graphs of the critical points in the MEA were interesting but failed to reveal the effectiveness of the MEA. However, the students were asked to reveal how much involvement they had in each critical step of the solving process. These numbers provided an excellent reference for the other answers. In one example, a student claimed that he did not believe that the MEA helped him learn, however he reported his level of involvement in each process as very low. It does not necessarily prove that the MEA would have helped him but it does provide a possible explanation as to why he did not gain much from the 


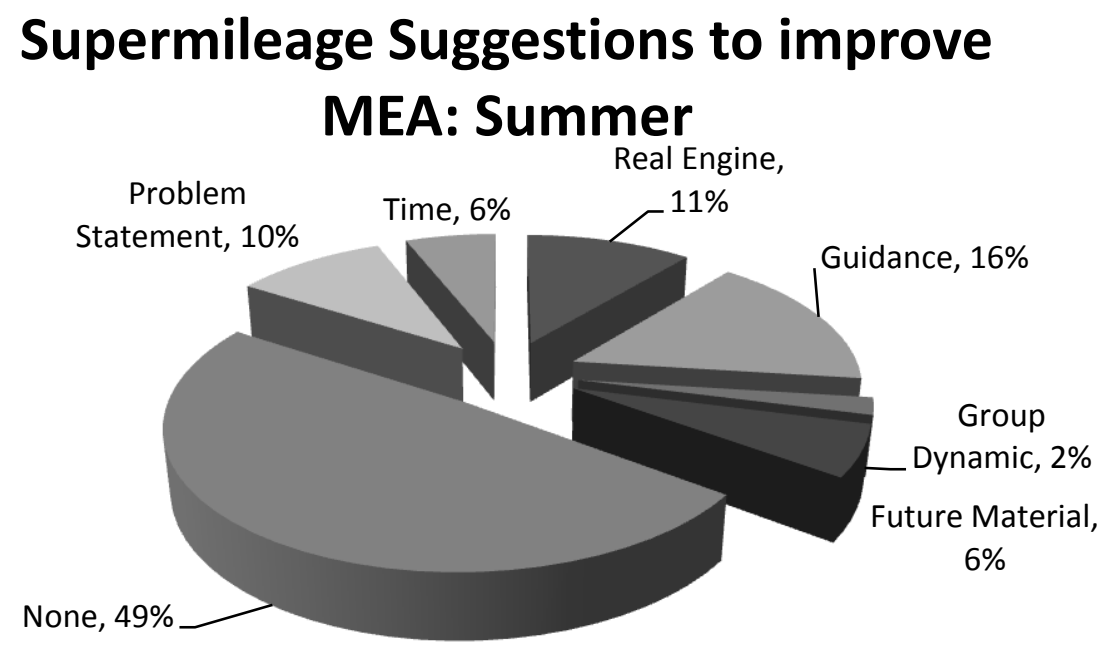

Figure 15: This is a list of the seven suggestions that the students listed as ways to improve the supermileage MEA in the Summer session.

experience. The most telling question was the last one; it asked the students how the MEA could have been improved. Figures 14 and 15 have the breakdown of the most common answers. The listed categories are time, Real Engine, Guidance, Group Dynamic, Future Material, and none. Time indicates that the students felt rushed and needed more time. Real engine indicates that the students felt that they would have benefited from an explanation regarding real engines and the processes that define them. Guidance indicates that the students wanted more help in solving the problem. Group Dynamic indicates that the grouping somehow negatively affected their ability to learn and complete the MEA. Future material indicates that the MEA required the use of material that had not been covered and that the activity 
would be better if that material was omitted. Lastly, none indicates that the student either did not put anything or stated that the MEA was fine the way it was. In the prescreening there were three responses that were prominent: The students needed more guidance in the beginning, they wanted some comparison to the strokes of an engine and the PV graph they were given, and they requested that the MEA not include material that they had not covered yet. The students that requested more guidance specifically mentioned that they had no idea how to begin the solution process and struggled because they did not know how to approach the problem. The students that requested a real engine comparison did not struggle with the MEA so much as struggled with the concepts of the diagram. The students that complained about uncovered material specifically mentioned the internal energy and how it related to the thermal efficiency of the cycle. Most of the students were confused about how internal energy was evaluated given a varying temperature, which is taught later in the course.

After evaluating the spring and summer reflections a significant improvement can be seen between the first and second attempts. The requests for improvement decrease and the amount of students that believe that the MEA is fine as is increases to almost $50 \%$ from the spring to the summer. This could be related to the fact that the summer students most likely have more free time to work on the MEA. It could also be due to the fact that there was a demonstration of pressure-volume curves in a piston cylinder in the summer and it appeared to help a great deal or that the 
implementation and explanation of the activity might have gone more smoothly the second time around. It should be kept in mind that these are the opinions of the students and do not necessary indicate that the MEA would improve if employed.

Several of the questions in the reflection exercise were not analyzed for this paper. Although all of the questions reveal something about the MEA and the students' solution process, the purpose of the assessment for this application was to improve the MEA and ensure that it is serving its purpose. Tables 11 and 12 list the remaining questions on the reflection questionnaire. These questions asked the students to rank their responses either $0-4$, strongly disagree, disagree, neutral, agree, strongly agree or $0-3$, none, low, medium, and high; the scale is listed for each question. 
Table 11. Supermileage Reflection Questions: Spring and Summer Summary of the quantitative questions that are asked in the reflection exercise for Spring.

\begin{tabular}{|c|c|c|}
\hline Spring & Summer & Average Student Data: \\
\hline & & Level of Involvement (0-3) \\
\hline 2.53 & 2.52 & Critical point 1 \\
\hline 2.48 & 2.38 & Critical point 2 \\
\hline 3.31 & 3.11 & Satisfied with their final solution (0-4) \\
\hline 2.56 & 2.84 & Enjoyed the experience $(0-4)$ \\
\hline \multirow[t]{3}{*}{2.9} & & $\begin{array}{l}\text { Would benefit from a hands on } \\
\text { demonstration }(0-4)\end{array}$ \\
\hline & 3.15 & Benefit from demonstration $(0-4)$ \\
\hline & 1.86 & $\begin{array}{l}\text { Would benefit from a personal hands } \\
\text { on lab }(0-4)\end{array}$ \\
\hline
\end{tabular}

The first question shows that the students were satisfied with their answers but somewhat less so in the summer. The level of involvement score reflects what the students felt they contributed in each critical point in the solution process. These answers remain consistent showing that students feel that they contribute more in the beginning than in the end. Perhaps this has something to do with the fact that students who asked for more guidance asked for it in the beginning where they were struggling more. More students indicated that they enjoyed the MEA in the Summer than the Spring. Lastly, the questions pertaining to the lab demonstration indicated that the demonstration was helpful. Even though the students rated a 
potential hands-on demonstration as 2.9 out of 4 , they rated the benefit from the lab as 3.15 out of 4. This is an interesting result showing that students might not be the best people to ask about what they might need. With that in mind, the last question asked if they thought they would benefit from taking the pressure volume data themselves rather than having the instructor do the demonstration. It ranked 1.86 which is just below neutral.

\section{Discussion}

Physical experiments and "Learn By Doing" are something that Cal Poly San Luis Obispo has always made sure to focus on in its curriculum. Research shows that students with misconceptions can be helped by a physical experiment that clarifies the concept in question (Miller, Identifying and repairing. . .). A polytropic process can have a polytropic index or exponent of almost any value. The objective of this MEA is to associate those exponent values in a polytropic process to some sort of physical process. Specifically, the students become more familiar with processes they already know something about like isothermal or adiabatic processes. If the students focus on processes just because the processes best fit a line, they will miss one of the central learning objectives.

One of the goals of this MEA is to allow the students to think critically on their own about what processes are involved in an engine and how those processes appear on a PV diagram. The MEA does satisfy this goal as seen in the reflections, although what it is missing is some closed loop feedback that the students can use 
to test whether or not their solution is working. To start, it needs to be made clear that only processes of a certain form should appear in an engine cycle. The main reason for doing this is to make sure that the intended goal of the MEA is realized. This might make it easier to grade as well, while ensuring that students learn about processes that they will use in the remainder of the course. A second modification would be to include the measured total work of the cycle. This is something that the client is not looking for directly, so it might be easy to provide and will allow the students to check their work. As long as it is clear that the students are providing the client with the model as a deliverable, then they can use that number as a guide. Another option is to provide an efficiency range so that the students can check their answer without giving the answer away. In all of the solutions $22 \%$ of the groups had some miscalculation or wrong idea that led them astray. The most common misconception was that the heat transfer into the system was the total heat transfer, which is not the case. The heat transfer into the system is only the positive heat transfers. Because of this, some of the solutions had incorrect thermal efficiencies so it might be beneficial to provide a method of assessment regarding the efficiencies since that will help with of some of the errors.

Even though some students struggled with units and heat transfer misconceptions, a similar number of them wrote in the reflection that they understood they did something wrong. The reflections showed that the majority of the students learned the important concepts and enjoyed the MEA in some way. 
Enjoying the MEA is not a requirement of MEA's although it does make the job of teaching simpler if the students are more excited to learn. Table 12 summarizes the Supermileage MEAs adherence to the six principles.

Table 12. Supermileage MEA

Summary - A summary of the six

principles and how the Supermileage

MEA addresses each one.

\begin{tabular}{|l|l|}
\hline $\begin{array}{l}\text { Model } \\
\text { Construction }\end{array}$ & $\begin{array}{c}\text { This MEA requires the students to create a model of } \\
\text { an engine in an open-ended fashion. }\end{array}$ \\
\hline Reality & $\begin{array}{l}\text { The clients are a team on campus which allows the } \\
\text { students to identify the need as one they might actually } \\
\text { encounter. }\end{array}$ \\
\hline Generalizability & $\begin{array}{l}\text { The models developed can be easily modified to } \\
\text { apply to other power cycles and are not necessarily } \\
\text { tailored the specific graph that is given. }\end{array}$ \\
\hline Self-Assessment & $\begin{array}{l}\text { Other than data that could be looked up there was } \\
\text { no provided information that the students could use to } \\
\text { confirm their model. }\end{array}$ \\
\hline Model & $\begin{array}{l}\text { Each memo was addressed to a client and the } \\
\text { Deliverables were clearly identified in most cases. } \\
\text { Students provided a model in Excel or Matlab as well as } \\
\text { the document explaining their model which aided in } \\
\text { evaluating them. }\end{array}$ \\
\hline Effective Prototype & $\begin{array}{l}\text { Familiarity with common simple processes will aid } \\
\text { the students in more advanced thermodynamic courses } \\
\text { and any profession that uses gaseous cycles. }\end{array}$ \\
\hline
\end{tabular}




$$
\text { Project IV: Industrial Process MEA }
$$

The last MEA that was given to the Introduction to Thermodynamics class was based upon an industrial process. The main goal was to create an MEA that helped to teach entropy-related concepts and the 2nd law of thermodynamics.

\section{MEA Description}

The new MEA introduces an industrial plant that is dumping hot water into a nearby river; the problem statement is shown below:

To: ME 302 Thermodynamics Analysis Team, California Polytechnic State University

From: Jennifer Conover, Industrial Process Designs, Inc.

CC: Andrew Kean, California Polytechnic State University

Date: May 24, 2010

Re: "Thermodynamic Property Evaluation Handout" Request

Industrial Process Designs is writing you today to request your assistance with a current project of ours. We have been hired by a client to develop an environmentally friendly method to take advantage of waste-heat that is available in their industrial facility. Their requirements are such that $50 \mathrm{lbs} / \mathrm{s}$ of water at $900 \mathrm{psi}$ is cooled from a saturated vapor to a saturated liquid. Currently, they flow water from a nearby river though this condenser, resulting in an $8.4^{\circ} \mathrm{F}$ rise in the temperature of the overall river. This $\Delta \mathrm{T}$ of the river water is no longer allowed under CalEPA regulations, and we have been hired to reduce the temperature rise of the river water to less than $5^{\circ} \mathrm{F}$.

One of our engineers has proposed the following solution. Instead of simply dumping all the waste-heat into the river, it might be possible to build a steam power plant which converts some or all of the waste-heat into mechanical energy. This would reduce how much energy ends up heating the river and producing valuable electricity at the same time. It is not practical to directly use the industrial facility process water, so instead we envision using a heat exchanger to transfer the energy from the facility process water to the water of the steam power plant. In other words, one heat exchanger would be a condenser to the facility water and the boiler to a new steam power plant. 
We would like to hire you to do some "best-case" feasibility calculations for this power plant.

We are interested in the analysis of the following three scenarios right now, but keep in mind that these requirements will likely change, so ease of adjustability to your calculations is appreciated.

Option 1: Utilizes a very large (i.e., expensive) heat exchanger which requires only around $10-20{ }^{\circ} \mathrm{F}$ temperature difference between the facility water and the power plant water to achieve the necessary heat transfer. This scenario has the power plant condenser at ambient pressure.

Option 2: Utilizes a smaller heat exchanger which requires around 100$150{ }^{\circ} \mathrm{F}$ temperature difference between the facility water and the power plant to achieve the necessary heat transfer. This scenario would also have the power plant condenser at ambient pressure.

Option 3: Utilizes the same heat exchanger as Option 1, but instead of the power plant condenser at ambient pressure, we are interested in the benefits of condensing at well below ambient pressure.

For each of these three scenarios, please analyze the details of the four processes that comprise your steam power plant cycle. Specifically, we would like tables summarizing your results for each state (p, T, h, s, etc), each process $(\Delta \mathrm{p}, \Delta \mathrm{T}, \Delta \mathrm{h}, \Delta \mathrm{s}$, etc.), and for the overall three cycles (mass flow, efficiency, work produced, $\$$ generated with electricity, $\Delta \mathrm{T}$ of river water, etc.).

Please include these results in a memorandum, which also clearly explains your approach to performing these calculations. A description of the strengths and weaknesses of your analysis is appreciated. Based on your analysis, will we be able to achieve our goal of only a $5{ }^{\circ} \mathrm{F}$ temperature rise of the river? If you analysis wasn't a best-case analysis, would that change any of your conclusions? Thank you for your prompt attention to this matter.

This river is small and the dumping causes the river to increase several degrees. The client noticed this and wants to try and solve this problem in an efficient manner. The client proposes that there could be a power plant that utilizes 
the energy being dumped into the river through a standard heat cycle. The client shows three ways in which this could be done and asks the students to analyze each method to determine the best case scenario.

The students are asked to clearly state their processes with the states of entropy and internal energy for each method. By doing this the students should discover that there is only a finite amount of energy related to the temperature difference and the differences in each method simply deal with the amount of entropy they produce. The students are also asked to analyze the given options using ideal assumptions and also remark on the validity of those assumptions.

A drawback to this MEA is that it does not explicitly ask the students to create a model to determine the answer. Because this MEA follows the supermileage MEA and another MEA not analyzed by this research, it is possible that the students will discover on their own the benefits of first creating the model and then analyzing the system. The stepwise options were created to force the students to go through the process of thinking critically about the heat lost and the consequences of making slight changes to a power cycle.

The MEA is designed to be more iterative than previous MEAs. The students have an initial calculation of the heat transfer from the facility water to the river. This heat transfer calculation is for the boiler of the new designed power cycle. Using this heat input the students can develop a design for a power plant with an appropriate thermal efficiency, work output and heat transfer out of the condenser. 
The students can then go through each of the three options and determine which one is the best way to utilize the energy that goes into the heating the river.

\section{Results}

There are several different ways to go about modeling a power plant. The most common solution found were a simple Carnot Cycle, (or an ideal Rankine Cycle), a normal Rankine Cycle, an ideal Rankine Cycle with a superheated state or a normal Rankine Cycle with a superheated state, see Figure 16 (Cengel, 2008). The most efficient of these is the Ideal Rankine Cycle or Carnot Cycle although the answers given varied widely. The problem statement asked the students for tables of data and not for their model or calculations so a few of the solutions did not include any form of calculations or explanation for the numbers given. Despite this, enough of the data were given to discern the approach and possible mistakes that many of the solutions contained.

An ideal Rankine Cycle, or Carnot Cycle is a completely idealized cycle. The cycle starts at a saturated gas state under the vapor dome. The working fluid, in this case air, is expanded adiabatically (completely insulated) until it reaches the low pressure state, usually atmospheric. The air is then condensed at a constant pressure. This condensed fluid is then compressed adiabatically to reach the same density that it started with. The fluid is then heated at a constant pressure to reach the original state again. 

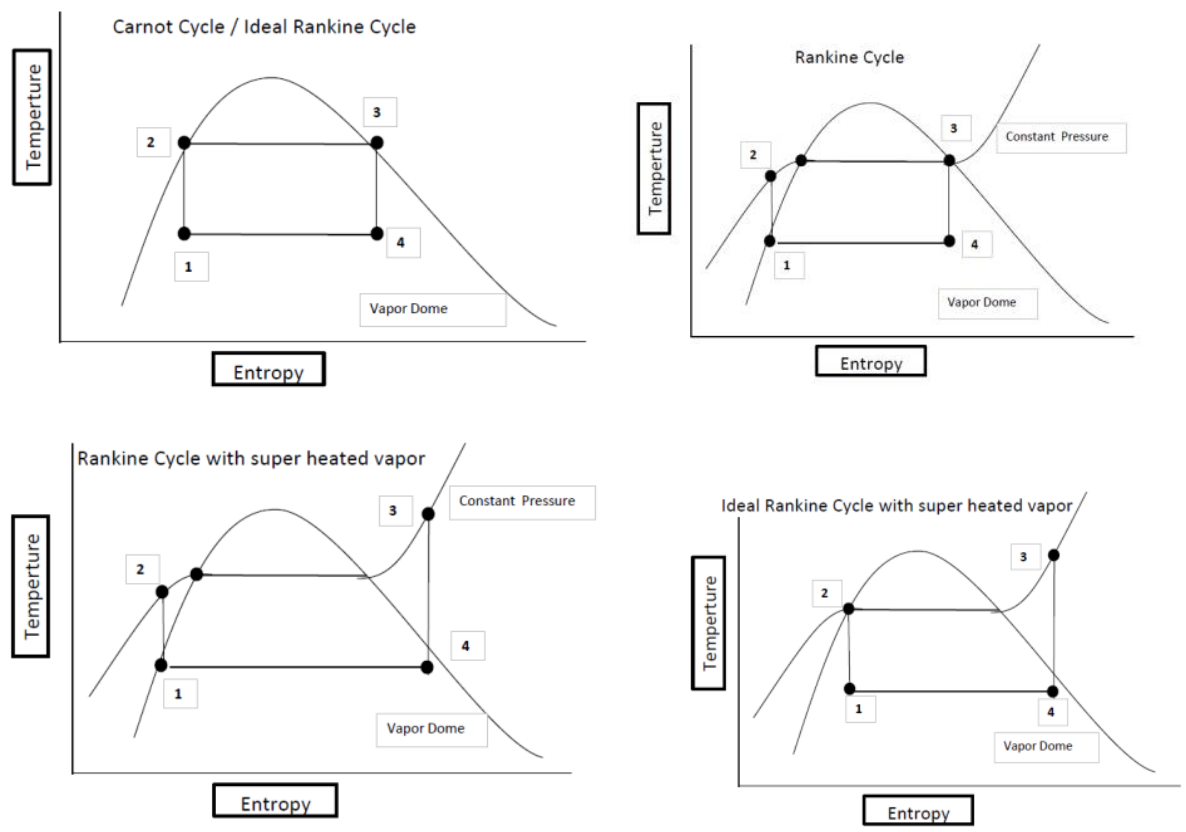

Figure 16. Carnot/Rankine Cycle Examples - Clockwise from Upper left: A Carnot Cycle/ideal Rankine Cycle, A Rankine Cycle, A Rankine Cycle with a superheated vapor state, and an ideal Rankine Cycle with a superheated vapor state (Cengel, 2008).

This cycle is used mostly because it is a simple model to calculate and looks like a rectangle under the vapor dome. This, however, is a simplified version of a real cycle and is much more efficient than a normal cycle. The students that chose this cycle almost all got high efficiencies that satisfied the requirements of the problem.

A normal Rankine Cycle is basically the same except for the condensing process which is extended to a lower quality state. This forces the compression process to leave the vapor dome. When the heating process begins it has to follow the edge of the vapor dome along a constant pressure line until it reaches the 
original state back through the vapor dome. This cycle is a slightly more realistic way to model a steam cycle.

One widely interpreted topic was the temperature difference required by the available options. The suggested heat exchangers from the problem statement indicate that they require a certain range of temperature in order to be functional. Option one says 10 to 20 degrees Fahrenheit for a more expensive heat exchanger and option two says 100-150 degrees Fahrenheit for a smaller and cheaper one. This is simpler for the solutions that involved a Carnot cycle because there is only one temperature in the applicable process. However with a Rankine cycle the temperature changes depending on when the process starts. If there is a superheated state in the Rankine cycle then the process temperature will change on the order of 200 degrees Fahrenheit. The uncertainty comes in what temperature is needed to be within the range of the specifics for the heat exchanger: the highest temperature, some average of the processes temperatures or perhaps the entire range of temperatures. The most common interpretation for this is the highest temperature in the superheated vapor state as the defining temperature. This leads to these solutions being more inefficient than others that used the saturated value at the appropriate pressure as an average of the temperature.

An interesting outcome is revealed from the analysis of the methods the students used for their models. If the problem is modeled as a simple Carnot Cycle with ideal states and simple processes the desired temperature drop required in the 
problem statement is possible. However, if the model is done with a more detailed steam cycle like the superheated Rankine Cycle, the temperature drop of the river becomes more than is desired. The changing temperature drop in the river based upon the type of model employed means that if the cycle is idealized it appears that the goal is reachable. However, if a more complex cycle is used to model the problem then it becomes more uncertain that the goal is possible.

The third option in the available scenarios involves a much lower than atmospheric conditions pressure for the condenser. This increases efficiency and was expected to be the best and only option that would satisfy the requirements. Three out of the thirty two solutions evaluated chose a higher than three psi pressure for this state. Most students chose around 1 psi although the problem simply says below atmospheric, which is $14.7 \mathrm{psi}$ in standard conditions. Those solutions modeled the plant with a Carnot cycle and concluded that the third option would not be sufficient. This shows how sensitive the calculations are for simple assumptions and could be misinterpreted very easily.

One result revealed from the analysis is the format of the memorandum. The intent of a memorandum document is to contain all of the research, analysis, results, and discussion in a simple summary format. The students are not given any indication on how they are to format the memo other than the memo given to them to describe the problem. This is not part of the requirements for the MEA, but the formatting that the students choose to use helps to identify if they understand that 
they are writing to a client or a teacher. An example of a student memo can be found in Appendix D-1. These MEAs are meant to expose students to the possibilities of real situations where this type of analysis and report would be necessary.

The required memorandum in this MEA, being the last of three given in the quarter, was anticipated to have shown improved writing and client identification. While the available deliverables remained somewhat the same, the client identification was lacking. Some students chose to write the memo like a brief formal report avoiding first or second person pronouns. These types of memos had very little technical explanations describing their models. While this is not incorrect, the point of having the students document their work is so they can have experience communicating with clients or peers.

\section{Mini-Reflection}

At the end of the MEA the students were told to fill out a small reflection exercise to help determine the success of the MEA, see Appendix D-2. In one of the questions the students were asked to identify the available concepts that they might have learned during the MEA. Figure 17 shows the percentage of students that indicated that they learned the concept listed. Only the concepts that were selected by $50 \%$ or more of the students are listed in Figure 16. The remaining concepts and their corresponding percentages are: specific heats 15\%, Entropy generation $13 \%$, closed systems $24 \%$, Second Law 48\%, mass balance $40 \%$, 
property evaluation $49 \%$ and the Kevin-Planck Statement 26\%. The most identified concepts were Carnot cycles, Steam Power Plants, and Condensers and boilers. While the most recognized concepts were not intended to be the main focus, they still add value to the thermodynamic curriculum. On a $0-4.0$ scale, Table 13 shows the average response of the students regarding the MEA. The majority of the students indicated that they were satisfied with their solution. The majority also indicated that they considered their time well spent while working on the industrial process MEA.

Concepts Learned: Summer

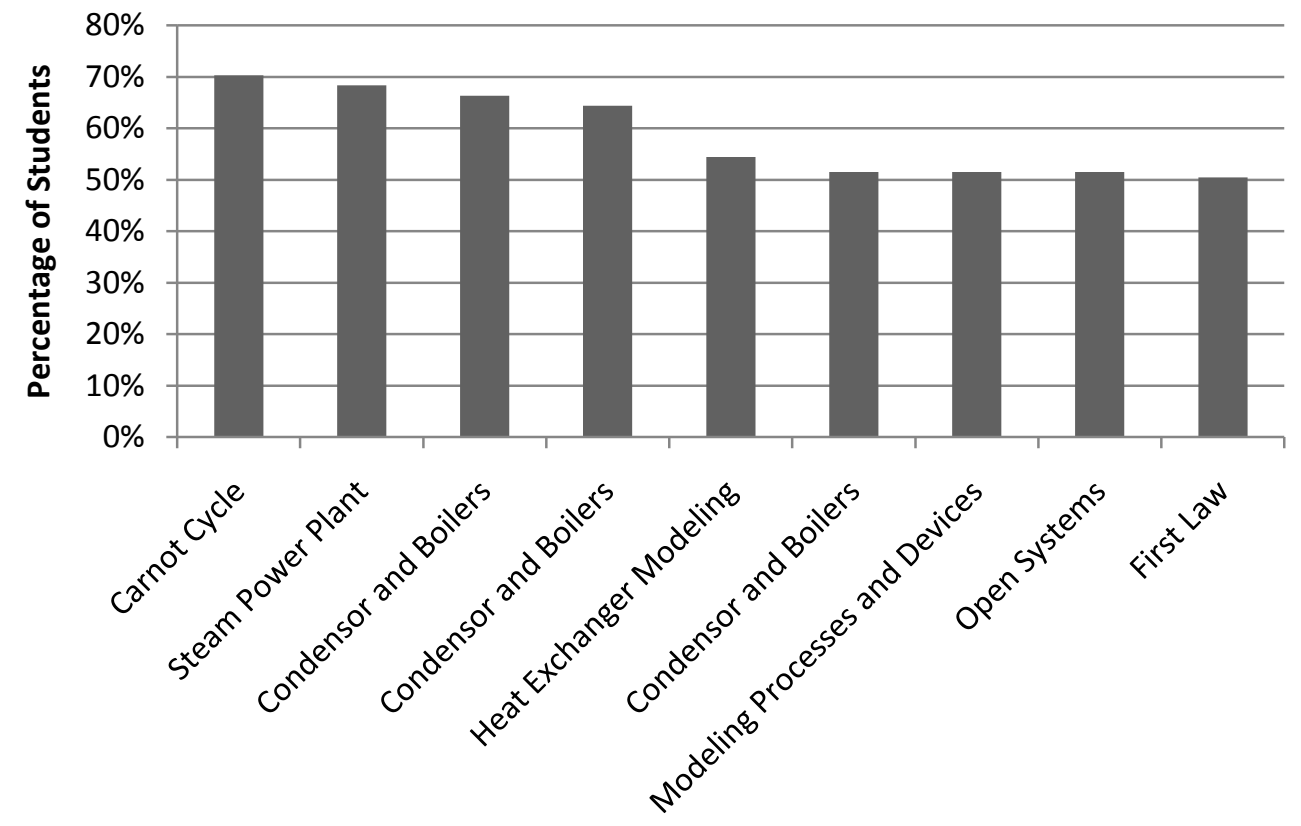

Thermodynamic Concepts

Figure 17. Industrial Process Concepts

Learned: Summer This graph shows the concepts that $50 \%$ or more of the students indicated they learned. 
Table 13. Industrial Process MiniReflection Questions - This table summarizes the results from the questions in the industrial process mini-reflection. The results are on a $0-4$ scale that represent strongly disagree, disagree, neutral, agree, and strongly agree respectively.

\section{Questions in Mini-Reflection Exercise}

Average Score

\begin{tabular}{|l|c|}
\hline Satisfied With Solution & $\mathbf{3 . 3 0}$ \\
\hline Enjoyed the MEA & $\mathbf{2 . 8 1}$ \\
\hline Time Well Spent & $\mathbf{3 . 1 6}$ \\
\hline
\end{tabular}

\section{Discussion}

One noticeable achievement in this MEA analysis is the quality of the students' solutions in the end of the quarter. There are three thermodynamic MEAs that have been given to the students throughout the quarter, one of which is not mentioned in the previous sections.

This MEA was created with two primary thoughts in mind: to have the students think critically about the assumptions they made and to provide them with a more iterative process approach to help guide them in the problem. The analysis of this MEA shows that having the solution depend on the assumptions is a risk for many of the students. There were more solutions that had mistakes than those that 
did not. Although the students were aware that these ideal assumptions swayed the results, they remained confident that their analysis was sufficient to justify its practicality. Table 14 shows the six principles and how the Industrial Process MEA applies to each one.

Table 14. Industrial Process MEA - The six principles and a short summary on how the industrial process MEA adheres to each of them.

\begin{tabular}{|l|l|}
\hline $\begin{array}{l}\text { Model } \\
\text { Construction }\end{array}$ & $\begin{array}{c}\text { This MEA required the students to create a } \\
\text { mathematical model of a power plant. }\end{array}$ \\
\hline Reality & $\begin{array}{l}\text { Waste dumping is a familiar environmental concern } \\
\text { of major nuclear plants that can be taken seriously as an } \\
\text { engineering problem. }\end{array}$ \\
\hline Generalizability & $\begin{array}{l}\text { The models developed must be able to apply to } \\
\text { each scenario and thus helps the students to broaden the } \\
\text { scope of their models. }\end{array}$ \\
\hline Self-Assessment & $\begin{array}{l}\text { There was no obvious way for the students to verify } \\
\text { if they got the correct answer besides directly asking the } \\
\text { professor. }\end{array}$ \\
\hline $\begin{array}{l}\text { Model } \\
\text { Documentation }\end{array}$ & $\begin{array}{l}\text { Each memo was addressed to a client and the } \\
\text { deliverables were clearly identified in most cases. }\end{array}$ \\
\hline Effective Prototype & $\begin{array}{l}\text { The development of power cycles and the concept } \\
\text { of usable energy is very prominent in modern } \\
\text { engineering and can be very useful when attempting to } \\
\text { optimize the energy efficiency of new energy-related } \\
\text { technology. }\end{array}$ \\
\hline
\end{tabular}




\section{Conclusion}

Model-Eliciting Activities can be useful tools that are slowly developing a place in engineering curricula. The intention of the above projects was to provide insight into the analysis of MEAs by using the six principles to evaluate student solutions. The six principles of MEAs were used as guidelines to match the instructor's objectives for each MEA with the students' solutions. These six principles - model construction, reality, generalizability, self-assessment, model documentation, and effective prototype - create a foundation for MEAs which promotes critical thinking and thought revealing student solutions (Lesh, et al., 2000).

The first two projects were analyzed from the perspective of the instructor in order to show how the instructor's anticipated results varied from the students' responses. The Blast Furnace MEA was developed from an existing lab activity and it successfully employed the six MEA principles. The students asked thoughtprovoking questions and "discovered" correlations between statistical uncertainty and sample sizes during a physical experiment. The physical experiment also acted as a self-assessment tool which allowed the students to evaluate the model they created. The students treated the activity as a real situation and turned in descriptive memorandums that described their models and listed their assumptions.

In contrast, the Strain Gauge MEA did not encourage the development of an in-depth model. The MEA required more time than the class period provided and 
the physical experiment did not allow the students to check their procedures for determine failure. By analyzing the MEA with the six principles in mind, the missing elements from the activity were determined. Although both of the MEAs met their learning objectives, in their current forms the Blast Furnace MEA was a more useful learning tool than the Strain Gauge MEA. The six principles allowed each MEA to be separated into categories and evaluated for their effectiveness.

The last two projects were developed more carefully with the six principles in mind. To evaluate the relative success of these activities, it was necessary to analyze the students' solutions and their reflection exercises. For the Supermileage MEA in project III, the students' solution paths were plotted into categories. Analyzing each category revealed correlations between a solution path and model accuracy. The reflections also provided insight into the students' level of involvement relative to the concepts they learned. The six principles were used as anticipated except for the self-assessment principle. There was no mechanism in place to ensure that the students created an accurate model aside from the guidance of the Professor.

The Industrial Process MEA, in a similar manner to the Supermileage MEA, satisfied all of the principles except for the self-assessment principle. Although the instructor anticipated that the students could evaluate the quality of their models on their own, the students felt that they did not have enough information to verify their results. 
These MEAs were successful in fulfilling all of the required learning objectives and most of the MEA principles. However, upon further inspection of the students' solutions, there were missing elements that might have made the developed MEAs more successful. Analyzing the students' solutions provided insight into the common misconceptions of students as well as the suggestions they had for improving the activities. However, the main goal of this research was to ensure that MEA structure was maintained not solely from the instructor's perspective, but also from the deliverables of the students. Using the six principles as analysis tools has shown that even carefully conceived MEAs might omit some of the basic principles that make them effective learning tools.

Future work for MEA analysis may include evaluating the six principles and their effects on engineering students as opposed to the mathematical community. The six principles of MEAs reveal how well a developed activity meets the principles of MEAs in engineering. However, the six principles need to be assessed from an engineering perspective before they are used as analysis tools. MEAs are great evaluation and learning tools and I have greatly benefited from creating and implementing them. In my opinion the engineering discipline could benefit greatly from implementing more MEAs in its curriculum. 


\section{BIBLIOGRAPHY}

[1] Bowman, Keith J.; Diefes-Dux, Heidi A.; Zawojewski, Judith S.

Models and Modeling in Engineering Education: Designing Experiences for All Students. Sense Publishers, 2008.

[2] Bullen, F. and D. Knight, The board and strategic value of the Freshman Engineering Experience-FEE. International Journal of Engineering Education, 2006. 22(6): p. 1241-1251

[3] Cengel, A. Y., Boles, A. M. Thermodynamics: An Engineering Approach. 6th ed. McGraw-Hill, 2008

[4] Chamberlin, Scott A. How does the Problem-Based Learning Approach Compare to the Model-Eliciting Activity Approach in Mathematics Instruction? International Journal of Mathematics Teaching and Learning, 2008

[5] Dues, J. F., Soda Can Mythbusting. College of Technology at New Albany, Purdue University, 2006

[6] Edward, N., Evaluations of introducing project-based design activities in the first and second years of engineering courses. European Journal of Engineering Education, 2004. 29(4):p p.491-503. 
[7] Fong, L. Enhancing Dynamics courses with Model Eliciting Activities, Mechanical Engineering Master's Thesis from Cal Poly San Luis Obispo, California Polytechnic State University, 2009

[8] Hmelo-Silver, C.E. and H.S. Barrows, Goals and Strategies of a Problem-based Learning Facilitator. The Interdisciplinary Journal of Problem-Based Learning, 2006. 1(1).

[9] Lesh, R., ed. Research design on applications and modeling in mathematics education. ICMI Study 14: Applications and Modeling in Mathematics Education, ed. E. H. Henn \& W. Blum. 2006: Dortmund (Germany). 102-106

[10] Lesh, R., Hoover, M., Hole, B., Kelly, A., Post T., (2000) Principles for Developing Though-Revealing Activities for Students and Teachers. In A. Kelly, R. Lesh (Eds.), Research Design in Mathematics and Science Education. (pp. 591-646). Lawrence Erlbaum Associates, Mahwah, New Jersey.

[11] Lohman, M. and M. Finkelstein, Designing cases in problem-based learning to foster problem solving skill. European Journal of Dental Education, 2002. 6(3): p 121-127

[12] McKay, M. and McGrath, Real-World Problem-Solving Using Real-Time Data. International Journal of Engineering Education 
[13] Miller, R., Streveler, R. A., Yang, D., Santiago Roman, A. Y., Identifying and Repairing Students Misconceptions in Thermal and Transport Science AIChE Annual Meeting, Tennessee, November 10, 2009

[14] Moore, T. J., Diefes-Dux, H. A., \& Imbrie, P.K., Spontaneous groups versus long-term teams: An investigation using complex problem solving in a first-year engineering course. 2007 ASEE National Conference, Honolulu, HI 2007

[15] Patton, M. Q.(1990). Qualitative evaluation and research methods. Newbury Park, CA: Sage Publications

[16] Self, Brian. National Science Foundation: Collaborative research: Improving Engineering Students’ Learning Strategies through Models and Modeling. August 31, 2007.

[17] Schofield, M., The Model Eliciting Activities Concept: Challenges in Extrapolation to Non-Mathematical Contexts. ICTMA Conference Strand 'Modeling and Design Sciences' 2007

[18] Shuman, LJ., Besterfield-Sacre, M., "E-MEAs: Introducing an Ethical Component to Model Eliciting Activities", 2009 ASEE Annual Conference \& Exposition, Austin TX, June 2009.

[19] Siewiorek, N., Shuman, LJ., Scare, M. B., Goldstein, R. "Comparison of Instructor Perceptions and Student Reflections on Model Eliciting 
Activities" 2011 Proceedings of the ASEE Annual Conference and Exposition, Vancouver, British Colombia.

[20] Strauss, A., \& Corbin, J. (1998). Basics of qualitative research:

Techniques and procedures for developing grounded theory (2nd ed.).

Thousand Oaks, CA: Sage Publication 
APPENDIX A: Blast Furnace MEA Supplemental Material 
Introduction to Data Acquisition and Analysis

Group Assignment: DUE IN TWO WEEKS

This is a group assignment, not a full, formal report. Present the following information:

1. Construct a Run-Sequence Plot (Sequential Plot) of the temperature data, following all formatting standards. (Do not plot the data using symbols; this is another example of a situation where plotting experimental data with lines INSTEAD OF SYMBOLS is a good idea.) Below it, write a brief paragraph describing/discussing the results.

2. Develop and plot a histogram (frequency distribution) of the data (develop in Excel - no hand-drawn histograms). Note: Once you have determined the number of bins and their widths, you can use an Excel function called FREQUENCY to calculate the frequencies in each bin. The procedure is as follows:

a. Go to the first cell to the right of the column containing the bins, and type '=frequency(' . Do NOT press ENTER.

b. The function FREQUENCY requires two arrays: the column of experimental data, and then the column of bins. Using your mouse, click and drag to select all the temperature measurements, then type in a comma (,). Then select the column of bins with your mouse. Finally, type in the right parentheses ')' and press ENTER.

c. You now have a completed function to the right of the top bin cell. However, in order to apply this function to the entire set of bins, you cannot simply copy the function, because the FREQUENCY function is an array function, and not just a cell function. To apply this function to the entire set of bins, first highlight all the cells to the right of the bin column. Press F2, then CTRL+SHIFT+ENTER. The frequencies should now appear next to all the bins. (Recall that each value is the number of observations that are less than or equal to the value of the bin, but greater than the bin before it).

Beneath the plot, write a brief paragraph describing/discussing the results.

3. Construct a Lag Plot of the data. You may need to ask your instructor about this. Beneath the plot, write a brief paragraph describing/discussing the results.

4. Discuss whether the data are normally distributed. (Do not construct a normal probability plot.) DISCUSS your results (WHY are/aren't the data normally distributed? And why is it important that the data be normally distributed?)

5. Create a box plot for the data. Excel does not have a function to do this conveniently, so ask your instructor for advice on this. Beneath the plot, write a brief paragraph describing/discussing the results.

The following tasks require hand calculations. Use engineering paper, and present this work thoroughly and with sufficient detail that any professional colleague could understand and follow your work.

6. Using hand calculations, identify any outliers; discard any extreme outliers.

7. Using hand calculations, estimate the "true" temperature during that time and at that location. For statistical uncertainty, assume $95 \%$ confidence.

8. If we had taken only ONE data point during that second instead of 1000 , how well would that single measurement represent the temperature during that second? Use hand calculations, and again assume $95 \%$ confidence.

9. Note that the DAQ system reads temperature from a T-type thermocouple with a resolution of $0.03{ }^{\circ} \mathrm{C}$; in addition, the manufacturer reports that the thermocouple is 
calibrated to $\pm 1{ }^{\circ} \mathrm{C}$. How would these uncertainties affect the overall uncertainty in the measurement of the true temperature? Use hand calculations and discuss briefly.

Do NOT turn in a spreadsheet showing all 1000 temperature measurements, since this would be too large a spreadsheet to read. Instead, simply include the five-number summary of data that you need in order to complete Task 5 above. 

Procedure - The memo needed to contain an easy to read procedure that helped the client solve the problem they had.

Incomplete Poor Gverage Good Great

Recommendation - The memo needed to contain some recommendation for an upgraded system using the included procedure.

\begin{tabular}{llll}
\hline Incomplete & Poor & Average & Good
\end{tabular}

Justification - There needed to be clear reasons for any assumptions or recommendations that were made.

\begin{tabular}{llll}
\hline Incomplete & Poor & Average & Good
\end{tabular}

Completeness - The memo needed to contain all of the calculations and assumptions that were made.

Incomplete Poor Average Good Great


Date: April 29, 2010

To: Paul

From:

Subject: Procedure, results, and recommendation for DAQ system

\section{Procedure}

The following is a procedure to find the overall uncertainty when given a measurement device with a certain sensitivity and a DAQ system with a certain bit resolution. There are three uncertainties that contribute to the total uncertainty of the system, they are: the reading uncertainty of the measuring device which is given by the manufacturer and describe as plus or minus a percentage of the temperature being measured, the reading uncertainty of the DAQ system which can be found using a simple formula, and the statistical uncertainty which we determined in an experiment. These three together give the total uncertainty of the system.

1. The reading uncertainty of the measuring device is given with the device and has already been determined by the manufacturer. It will be given as plus or minus a certain percentage of the temperature that is being read by the device. For example, if you are using a High Temperature Probe with a $\pm 1.0 \%$ reading uncertainty to read a temperature of $1800^{\circ} \mathrm{C}$, the uncertainty will be plus or minus $1.0 \%$ of $1800^{\circ} \mathrm{C}$ or $\pm 18.0^{\circ} \mathrm{C}$. This means that the measure device will read to within $\pm 18.0^{\circ} \mathrm{C}$ of the true temperature.

2. To find the reading uncertainty of the $D A Q$, you take the voltage range of the measuring device and divide it by the number of possible combination of bits. To find the possible combinations of bits, you take 2 and raise it to the number of bit DAQ system that you are using (this is also given on the device). This equation will give you the resolution the DAQ system and the measuring device, to get the uncertainty you simply divide this by 2 . For example, if you are using a thermocouple with a voltage range of $\pm 50 \mathrm{mV}$ and a 16 -bit DAQ system to measure a given temperature, you would take $\frac{100 \mathrm{mV}}{2^{16}}$ which gives a resolution of $\pm 0.0015 \mathrm{mV}$. Then, to get the uncertainty you divide the resolution by 2 , which is $\frac{ \pm 0.0015}{2}$ giving an uncertainty of $\pm 0.00075 \mathrm{mV}$. See Table 1 for the reading uncertainties of the possible measurement devices with different DAQ systems.

3. The statistical uncertainty of a thermocouple was determined by a simple experiment using that thermocouple and a DAQ system with a variable bit resolution. We tested the thermocouple with a range of different bit systems to find the statistical uncertainty for each one. We varied the bit resolution by changing the sample rate or the maximum number of sample that are taken each second. For each sample rate, we found the standard deviation of the data which represents the statistical uncertainty. These values are given in a Table 2.

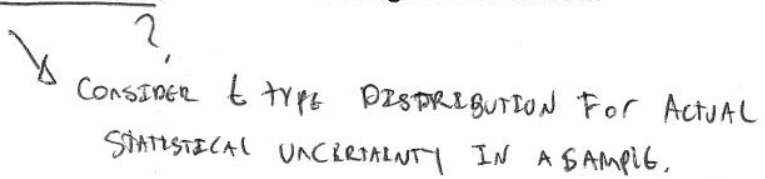




\section{Results}

Table 1. Reading uncertainty for different DAQ systems paired with different measuring devices

\begin{tabular}{|c|c|c|c|c|c|}
\cline { 3 - 6 } \multicolumn{2}{c|}{} & \multicolumn{4}{c|}{ DAQ System, \# of bits (max sample rate per second) } \\
\cline { 3 - 6 } & 8-bit (10) & 12-bit (500) & 16-bit (1000) & 24-bit (10000) \\
\hline $\begin{array}{c}\text { Measuring Device: } \\
\begin{array}{c}\text { Thermocouple: } \\
\text { High Temperature } \\
\text { Attachment }\end{array}\end{array}$ & $\pm 5.0 \%( \pm 50 \mathrm{mV})$ & \pm 0.1953 & \pm 0.0122 & \pm 0.00075 & \pm 0.00000298 \\
\hline $\begin{array}{c}\text { High Temperature } \\
\text { Probe }\end{array}$ & $\pm 1.0 \%( \pm 100 \mathrm{mV})$ & \pm 0.3906 & \pm 0.0244 & \pm 0.00153 & \pm 0.00000596 \\
\hline $\begin{array}{c}\text { Infrared Sensor } \\
\text { Sigity }\end{array}$ & $\pm 0.4 \%( \pm 50 \mathrm{mV})$ & \pm 0.1953 & \pm 0.0122 & \pm 0.00075 & \pm 0.00000298 \\
\hline $\begin{array}{c}\text { Infrared Sensor: } \\
\text { High Accuracy }\end{array}$ & $\pm 0.2 \%( \pm 25 \mathrm{mV})$ & \pm 0.0977 & \pm 0.0061 & \pm 0.00038 & \pm 0.00000149 \\
\hline
\end{tabular}

Table 2. Statistical uncertainty for thermocouple and DAQ system using varying sample rate resolutions

\begin{tabular}{|c|c|}
\hline $\begin{array}{c}\text { Sample Size (samples } \\
\text { per second) }\end{array}$ & $\begin{array}{c}\text { Standard Deviation } \\
(\mathrm{mV})\end{array}$ \\
\hline 10 & \pm 0.104 \\
\hline 500 & \pm 0.254 \\
\hline 750 & \pm 0.246 \\
\hline 1000 & \pm 0.241 \\
\hline 10000 & \pm 0.245 \\
\hline
\end{tabular}


Table 3. Pricing of different pairs of DAQ systems with different measuring devices and recommended combination.

\begin{tabular}{|c|c|c|c|c|}
\hline & \multicolumn{4}{|c|}{ DAQ System, \# of bits (max sample rate per second) } \\
\hline & 8-bit (10) & 12-bit (500) & 16-bit (1000) & 24-bit (10000) \\
\hline Measuring Device: & \multicolumn{4}{|c|}{ Price paired with each measuring device (\$) } \\
\hline $\begin{array}{l}\text { Thermocouple: } \\
\text { High Temperature } \\
\text { Attachment }\end{array}$ & 1050 & 4050 & 6050 & 9050 \\
\hline $\begin{array}{c}\text { High Temperature } \\
\text { Probe }\end{array}$ & 2000 & 5000 & 7000 & 10000 \\
\hline Infrared Sensor & 5000 & 8000 & 10000 & 13000 \\
\hline $\begin{array}{l}\text { Infrared Sensor: } \\
\text { High Accuracy }\end{array}$ & 7000 & 10000 & 12000 & 15000 \\
\hline
\end{tabular}

\section{Recommendation}

Based on our results, we believe that the High Temperature Probe with the 16-bit DAQ system would be the best set up for these reasons:

1. You already employ the 16 -bit DAQ system, so you would only need to buy the High Temperature Probe which would cost a total of $\$ 1,000$.

2. The difference in uncertainty between the 16 - bit and the 24 -bit DAQ systems is $\pm 0.003 \mathrm{mV}$, which is not worth the extra $\$ 3,000$.

3. Upgrading to the High Temperature Probe will decrease the reading uncertainty of the measuring device from $\pm 5.0 \%$ to $\pm 1.0 \%$ while only costing you $\$ 1,000$. You could decrease to $\pm 0.4 \%$, a relatively insignificant amount, by buying the Infrared Sensor but it would cost you $\$ 4,000$. 


\section{Conclusion}

Based on results from the experiment that we conducted, we found that the uncertainty of the DAQ system approaches a constant value as the sample rate increases. Figure 1 (shown below) shows that sample rates larger than 500 samples per second have effectively the same uncertainty. Your system currently produces 1,000 samples per second, therefore upgrading to the 24-bit DAQ system which can (produce 10,000 samples per second) is definitely not worth spending $\$ 9,000$. Since you already have the 16-bit DAQ system, but would like to upgrade, changing the measuring device will be the only way to do this. This leaves you with three possible upgrades that you can choose from: the High Temperature Probe, the Infrared Sensor, and the high accuracy Infrared Sensor. We believe that choosing the High Temperature Probe will provide the upgrade in accuracy that you seek, while staying within your limited budget.

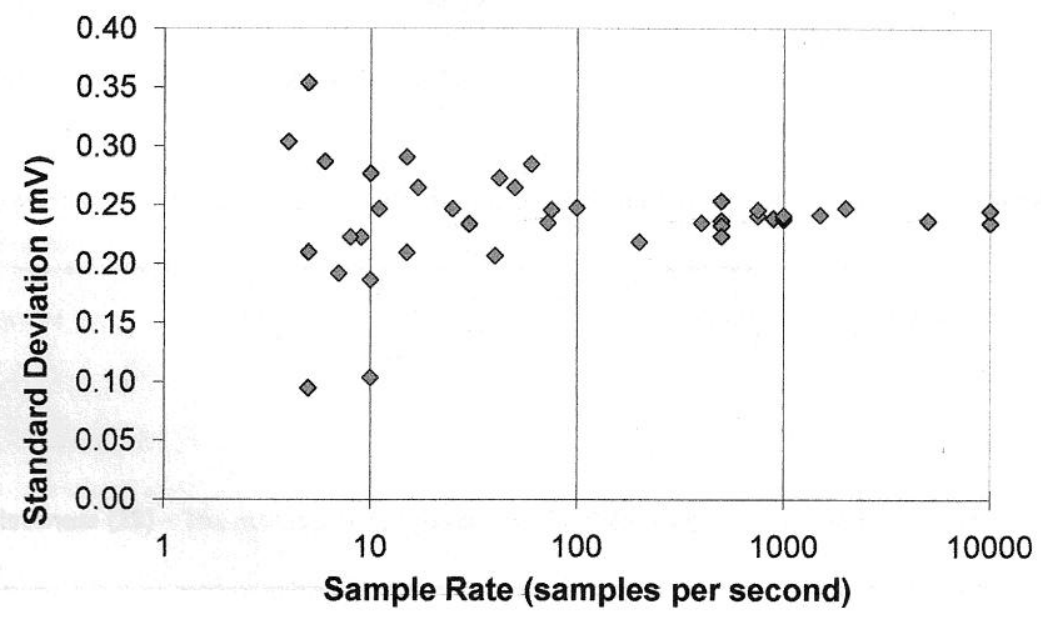

Figure 1. Variance of the Standard Deviation of a sample depending on the sample rate 
Evaluation Rubric for ME 236 Memorandums to Client

Procedure (25) - The memo needed to contain an easy to read procedure that helped the client solve the problem they had.

$\begin{array}{lll}\text { Incomplete } & \text { Poor Average } & \text { Good } \\ \text { STEP BY STEP PROCEDUrE } & \end{array}$

Recommendation (25) - The memo needed to contain some recommendation for an upgraded system using the included procedure.

Incomplete Poor Good Grate

Well reasoned Recommenpaison

Justification (25) - There needed to be clear reasons for any assumptions or recommendations that were made.

$\begin{array}{lll}\text { Incomplete } & \text { Poor } & \text { Average }\end{array}$

RERERGNGES

Completeness (25) - The memo needed to contain all of the calculations and assumptions that were made.

Incomplete Poor Good Great

NEXT TIME NEED TO SHOW CAICUIATTONS

Grade $100 / 100$

For actual UnCERTAIN HY

IN COMBINED SYSTEM AT I EAST

ONCE. 
ME 236 - Thermal Science Laboratory

Instructors' Guide

Pre-lab:

Reading on DAQ and Analog to digital converters. The reading should explain that the signal is converted through the use of digital bins and a 12-bit Data Acquisition System (what we are using in the lab) means relatively low uncertainty $\sim 0.1 \%$ while a lower bit DAQ will add to uncertainty. Refer to http://communication.howstuffworks.com/analog-digital3.htm for more information.

\section{Introduce the scenario:}

The instructor will introduce the problem as a real problem presented to him from a local steel manufacturing company. We want to have the students think critically and in an open ended fashion on the problem. Providing a potentially real project might help them do so.

The scenario is that the steel company needs help deciding which DAQ system to employ for each process they use. The different measuring devices each have the same uncertainty but different sampling capabilities. The goal for the students is to create a system that the customer can use to apply to each process to aid them in deciding which DAQ they need.

\section{Generating the model:}

The students will then be in about 5 teams of 3 or 4 . They will be given 15-20 minutes to analyze the situation on their own. They will be provided an e-mail correspondence from the customer to the professor explaining the situation. The professor needs to provide information that is requested from the students as much as possible.

The class will then go over their respective models together with assumptions and suggestions written on the board. Ideally the students will come up with things that haven't been thought of. An example of the model they come up with is attached in the Solution.

\section{Testing the Model:}

The students will test their model by using the in-class DAQ system and thermocouples to model the system at request of the professor. With these tools they will need to verify that the data is normal and whether a DAQ system is needed to measure the ambient temperature in the air. The Instructions for using the DAQ system will be provided by the lab manual.

While using the DAQ to test their model for different sample sizes they should do two things:

1. Plot one of the data sequences into a histogram to check to see if it is normal

2. Plot the standard deviation calculations over a range of sample sizes to find a minimum sample size that correctly approximates standard deviation of the population within acceptable uncertainty. 
They should realize that the uncertainties in the thermocouple outweigh the uncertainties in the statistics regardless of how many samples taken. This result is specific for this in-lab test and that should be pointed out. With increased accuracy in the measurement device the statistical error becomes more important and a DAQ system would be needed to decrease uncertainty.

Using the Model:

After the model has been tested using the in-class DAQ system the students need to apply it to the application the "customer" has provided. Their model should allow the students to come up with a statistical error ranging from .3\% to negligible given number of samples, and a sample minimum of approximately 30 samples to obtain a reasonable standard deviation. Given the good accuracy of the temperature measuring system and the 16-bit DAQ system used the students should find that a middle DAQ system of approximately 100 samples per second to satisfy the approximate uncertainty needed for this process. Although a 30 sample per second system would work as well.

Post Lab:

The students should cover the following points somewhere in the lab.

1. Standard deviation of 1 sample is a very difficult approximation thus the statistical uncertainty is difficult to find given no other data.

2. Statistical uncertainty goes to negligible fast for systems with average to high uncertainty but cannot be discarded when dealing with very accurate systems.

3. Approximately 30 samples are required before standard deviation is a good approximation of population standard deviation.

4. DAQ systems are Analog to Digital Converters that bin Analog voltages and that results in the histogram becoming lumpy if too many samples are taken too fast. 
APPENDIX B: Strain Gauge MEA Supplemental Material 


\section{Thin Walled Pressure Vessel - The Soda Can}

A pressure vessel is a standard engineering application that appears frequently in industry. Anything from power plant boilers to scuba tanks can be engineered using pressure vessel assumptions. A standard sized soda can is a good example of a simple thin walled cylindrical pressure vessel. With this assumption there are two stresses: The longitudinal stress shown in figure 1, also called the axial stress, and the hoop stress shown in figure 2, also called the circumferential stress. Because of the large size of the pressure force in relation to most other applied forces the stress that the wall of the can experiences is only a function of pressure and the size of the can. Using this relationship and Hooke's law to relate strain in the wall to stress, the pressure can be calculated from the measured strain.

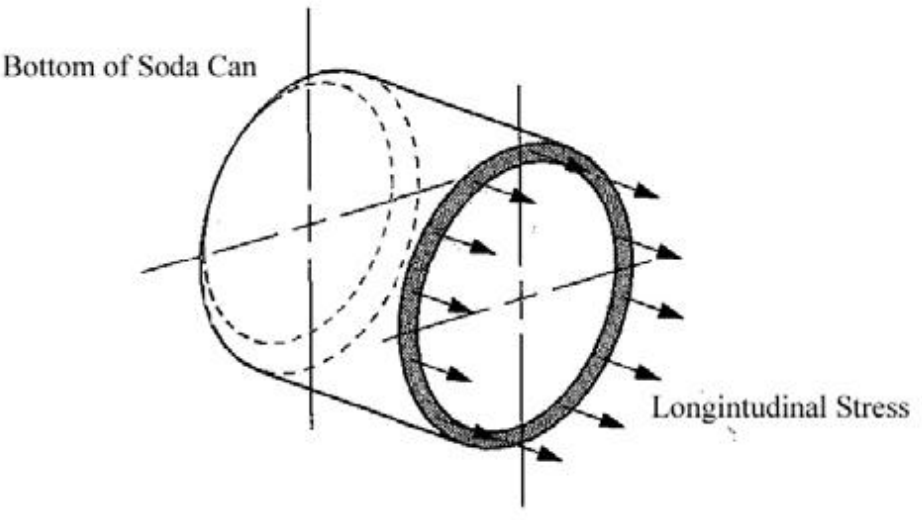

Figure 1: Depiction of the longitudinal stress in the thin wall pressure vessel

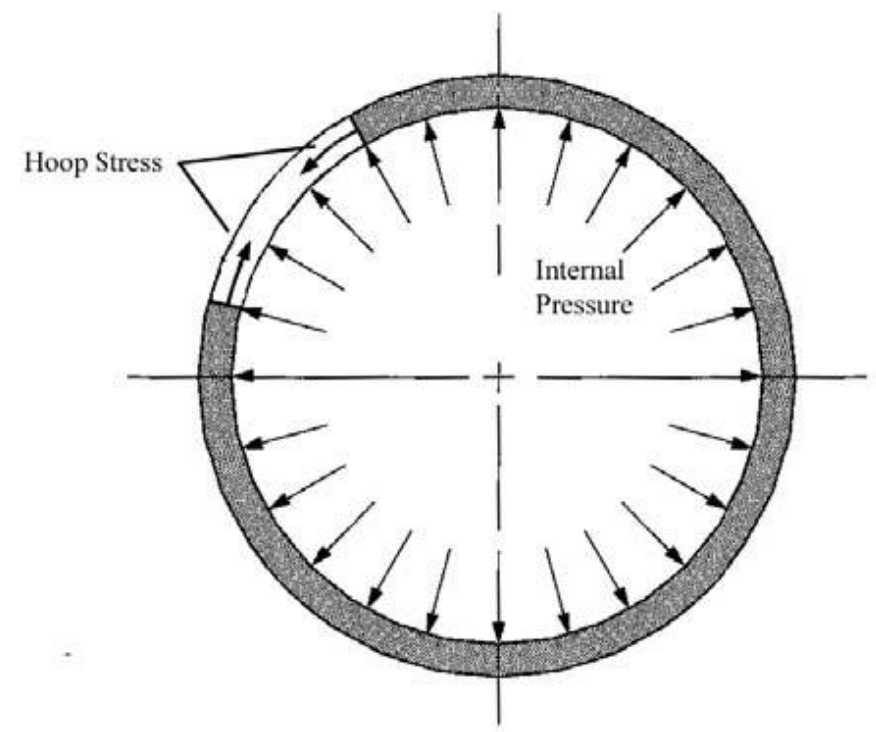

Figure 2: Representation of the hoop stress for a thin wall pressure vessel. 
The longitudinal stress in a thin walled cylinder can be calculated from:

$$
\sigma_{L}=\frac{p D}{4 t}
$$

Where:

$$
\begin{aligned}
& p-\text { internal pressure (psi) } \\
& D-\text { mean diameter of cylinder (in.) } \\
& t-\text { wall thickness (in.) }
\end{aligned}
$$

Likewise, the hoop stress for the thin walled cylinder is calculated from:

$$
\sigma_{H}=\frac{p D}{2 t}
$$

using the same variables. This means that:

$$
\sigma_{H}=2 \sigma_{L}
$$

Assuming that:

- The material is homogeneous and isotropic,

- The can is loaded only within its elastic range,

- A biaxial state of stress exists in the can,

Then Hooke's law states that stress in the can is proportional to the strain. For a biaxial state of stress, this proportionality can be expressed as:

And

$$
\sigma_{L}=\frac{E\left(\varepsilon_{L}+v \varepsilon_{H}\right)}{\left(1-v^{2}\right)}
$$

$$
\sigma_{H}=\frac{E\left(\varepsilon_{H}+v \varepsilon_{L}\right)}{\left(1-v^{2}\right)}
$$

where:

$E$ - modulus of elasticity or Young's modulus (psi)

$v$ - Poisson's ratio

$\varepsilon_{H^{-}}$hoop strain (in./in.)

$\varepsilon_{L}-$ longitudinal strain (in./in.)

Using equations the Hooke's law equations and the fact that the hoop stress is twice the longitudinal stress results in: 
And

$$
\sigma_{L}=\frac{E\left(\varepsilon_{H}\right)}{(2-v)}
$$

$$
\sigma_{H}=\frac{E\left(\varepsilon_{L}\right)}{(1-2 v)}
$$

Thus the pressure can be calculated directly from the measured strains by substituting these equations back into the original stress equations to get:

$$
p=\frac{4 t E \varepsilon_{H}}{D(2-v)}
$$

And

$$
p=\frac{4 t E \varepsilon_{L}}{D(1-2 v)}
$$

Once we have these equations, then the internal pressure in the can may be directly calculated from the measured longitudinal and hoop strains. 
The Strain Gauge: From www.sensorland.com

The strain gauge has been in use for many years and is the fundamental sensing element for many types of sensors, including pressure sensors, load cells, torque sensors, position sensors, etc.

The majority of strain gauges are foil types, available in a wide choice of shapes and sizes to suit a variety of applications. They consist of a pattern of resistive foil which is mounted on a backing material. They operate on the principle that as the foil is subjected to stress, the resistance of the foil changes in a defined way.

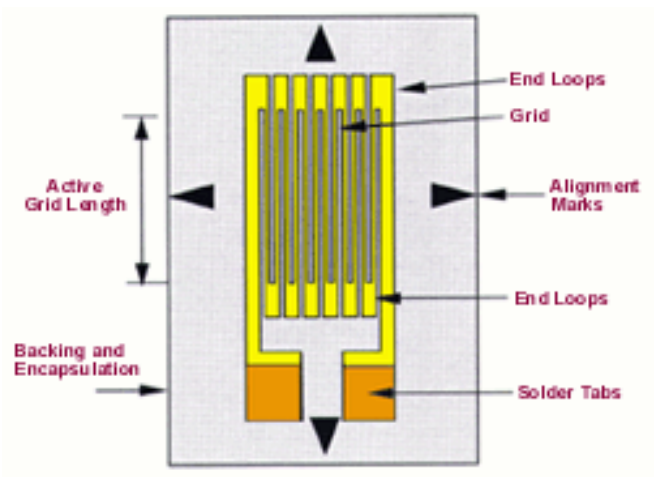

The strain gauge is connected into a Wheatstone Bridge circuit with a combination of four active gauges (full bridge), two gauges (half bridge),

or, less commonly, a single gauge (quarter bridge). In the half and quarter circuits, the bridge is completed with precision resistors.

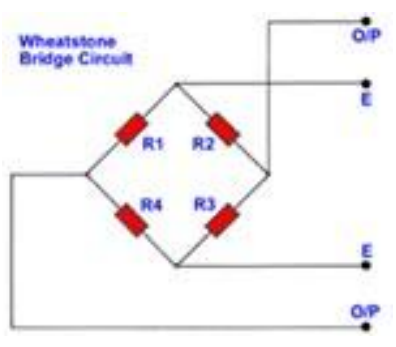

The complete Wheatstone Bridge is excited with a stabilised DC supply and with additional conditioning electronics, can be zeroed at the null point of measurement. As stress is applied to the bonded strain gauge, a resistive changes takes place and unbalances the Wheatstone Bridge. Top

This results in a signal output, related to the stress value. As the signal value is small, (typically a few millivolts) the signal conditioning electronics provides amplification to increase the signal level to 5 to 10 volts, a suitable level for application to external data collection systems such as recorders or PC Data Acquistion and Analysis Systems. 


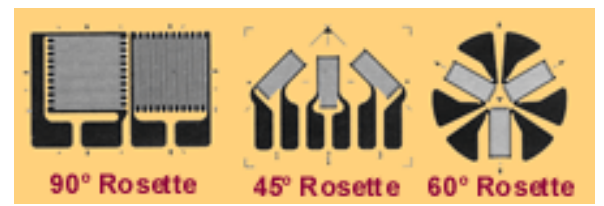

Some of the many Gauge Patterns available

Most manufacturers of strain gauges offer extensive ranges of differing patterns to suit a wide variety of applications in research and industrial projects.

They also supply all the necessary accessories including preparation materials, bonding adhesives, connections tags, cable, etc. The bonding of strain gauges is a skill and training courses are offered by some suppliers. There are also companies which offer bonding and calibration services, either as an in-house or on-site service.

\section{More about the Strain Gauge...}

If a strip of conductive metal is stretched, it will become skinnier and longer, both changes resulting in an increase of electrical resistance end-to-end. Conversely, if a strip of conductive metal is placed under compressive force (without buckling), it will broaden and shorten. If these stresses are kept within the elastic limit of the metal strip (so that the strip does not permanently deform), the strip can be used as a measuring element for physical force, the amount of applied force inferred from measuring its resistance.

Such a device is called a strain gauge. Strain gauges are frequently used in mechanical engineering research and development to measure the stresses generated by machinery. Aircraft component testing is one area of application, tiny strain-gauge strips glued to structural members, linkages, and any other critical component of an airframe to measure stress. Most strain gauges are smaller than a postage stamp, and they look something like this:

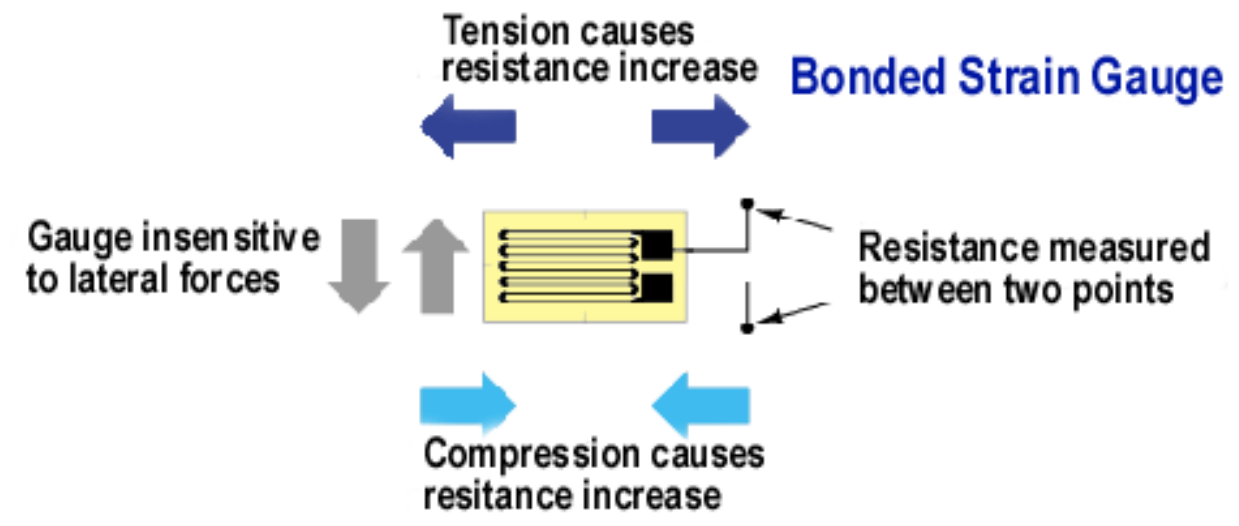

A strain gauge's conductors are very thin: if made of round wire, about $1 / 1000$ inch in diameter. Alternatively, strain gauge conductors may be 
thin strips of metallic film deposited on a nonconducting substrate material called the carrier. The latter form of strain gauge is represented

in the previous illustration. The name "bonded gauge" is given to strain gauges that are glued to a larger structure under stress (called the test specimen) The task of bonding strain gauges to test specimens may appear to be very simple, but it is not. "Gauging" is a craft in its own right, absolutely essential for obtaining accurate, stable strain measurements. It is also possible to use an unmounted gauge wire stretched between two mechanical points to measure tension, but this technique has its limitations.

Typical strain gauge resistances range from 30 Ohms to $3 \mathrm{kOhms}$ (unstressed). This resistance may change only a fraction of a percent

for the full force range of the gauge, given the limitations imposed by the elastic limits of the gauge material and of the test specimen. Forces great enough to induce greater resistance changes would permanently deform the test specimen and/or the gauge conductors themselves, thus ruining the gauge as a measurement device. Thus, in order to use the train gauge as a practical instrument, we must measure extremely small changes in resistance with high accuracy.

Such demanding precision calls for a bridge measurement circuit. Unlike the Wheatstone bridge shown in the last chapter using a null-balance detector and a human operator to maintain a state of balance, a strain gauge bridge circuit indicates measured strain by the degree of imbalance, and uses a precision voltmeter in the center of the bridge to provide an accurate measurement of that imbalance: 


\section{Memorandum}

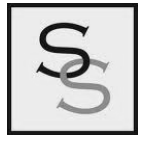

To: $\quad$ ME 236 Thermal Measurements Group, California Polytechnic State University

From: Roger Pedactor, Soda Simple, Inc.

CC: Paul van Bloemen Waanders, California Polytechnic State University

Date: June 1, 2010

Re: $\quad$ Testing Exploding Aluminum Cans

Soda Simple, Inc would like to request your services in researching a dilemma that we have had. Our latest manufacturing process, employed a year ago, uses a new procedure to seal and pressurize the top of our aluminum soda cans. For the past month we have been getting complaints about our product failing at the seam when shaken too vigorously or when the temperature becomes too high. From various consumer reports we believe that this failure is a direct result from our new sealing procedure. The reports indicate that unusually extreme conditions rupture the connections at the top rim of the can, separating the top from the cylindrical body. In order to remedy the situation we need to determine the specific details of the failure.

Our quality engineers need to test the faulty soda cans and determine the different factors and conditions that lead to this particular failure. The pressure of the can at the time of the failure is of particular interest. For obvious reasons we cannot simply measure the pressure inside of the can at failure. One of the preferred methods of non-invasive pressure measurement is through the use of a strain gage. A standard soda can may represent a thin walled pressure vessel, which means that the pressure is directly related to stress. This allows the strain gage to indicate the pressure inside the soda can without changing it.

We need an experimental test protocol that determines the failure conditions of our product within some engineering accuracy. This test protocol will be used by our quality control engineers on the faulty cans and should include all of the assumptions that are used. We will also need you to provide us with any verification data that you have which validates your procedure. We appreciate your efforts and would be grateful for your analysis as soon as possible. 
Quiz on Pre-Lab

1.) What stress does the wall of a thin walled cylindrical pressure vessel experience due to pressure? (no equations, a picture with labeled arrows please)

2.) Describe how a strain gauge works in one or two sentences.

3.) In the memo, who is the client and what do they need? 
Procedure for Soldering on the strain gage:

Inventory:

1 Carbonated, unopened Soda can

Sandpaper

Stranded wire

Wire cutters

Wire strippers

Scotch tape

Two erasers (as holders)

2 Terminal Pads

One Strain gage

Super glue

1. Use the sand paper to sand off the side of the can, clean off the area so there is no dust there. Lay the can on its side using the erasers as stoppers.

2. Cut two of the Terminal pads so that they are separated. Using the scotch tape, pick up the terminals, apply some superglue, and rest it on the side of the can. (remove the tape if able)

3. Cut two finger length strips of wire and strip the ends so that they wire is showing. Separate one of the wires and cut the rest of the leads short.

4. Tape the wires down in a position on top of the terminal pads. Using a soldering iron, heat the pad and the wires and apply some solder. The wires will have trouble staying down so have an assistant use a tool to hold the wire down as the solder cools. Make sure the long wire is within reaching distance of the other wire.

5. Stick the strain gage onto a strip of scotch tape, apply some super glue ensuring that the entire pad is covered. Place the strain gage HORIZONTALLY on the Soda Can. This is to ensure that Hoop stress is measured. 
Post Lab - (Circle One)

1.) The lab was interesting/motivating

\begin{tabular}{llll}
\hline Strongly Disagree $\quad$ Disagree Neutral & Agree & Strongly Agree \\
2.) The lab helped me learn the material & & \\
\hline Strongly Disagree $\quad$ Disagree $\quad$ Neutral & Agree & Strongly Agree
\end{tabular}

3.) What could have made this lab better? 

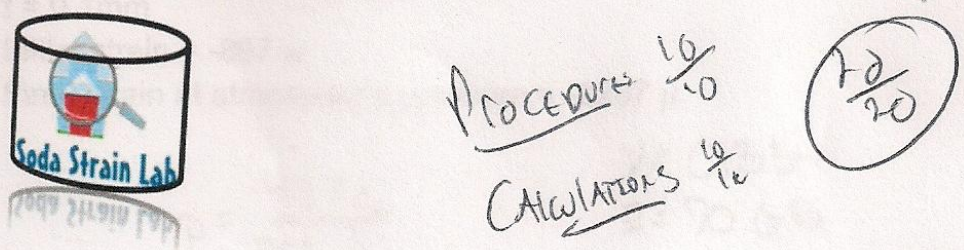

\section{Recommendation Report}

Date: June 1, 2010

To: Roger Pedactor, Simple Soda, Inc.

From: Erik Morton $\mathrm{s}, \mathrm{m}$

Kimberley Silken

Esteban Ruiz

Nathan Ruiz

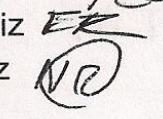

Subject: Requested Testing Procedure for Exploding Aluminum Cans

Introductory Summary:

In response to your request, we tested exploding aluminum cans using strain gauges and this recommendation report highlights the experimental procedure we suggest to use based on our acquired data.

\section{Details:}

I. Measure initial strain

1. Conform strain gauge to the can horizontally

2. Take and record strain reading from indicator while the said can is still closed

II. Measure final strain by opening the can and recording the indicator reading

III. Measure wall thickness

1. Drain can

2. Use Calipers to obtain a wall thickness value

IV. Use the strain relationship equation: $p=\frac{4 t E \varepsilon_{H}}{D(2-v)} \quad$ with the material properties of aluminum to solve for the pressure

\section{Conclusion:}

Observations and analysis of our data suggest that the use of strain gauges to measure the pressure inside the aluminum cans at the point of failure is relatively accurate.

Attachment: Experimental Data 
Data and Observations:

$$
\mathrm{t}=0.1 \mathrm{~mm}
$$

Initial strain $=-897 \mu$

Final strain at atmospheric pressure $=-2287 \mu$

$$
\begin{array}{lll}
P=\frac{4 t E C_{H}}{D(2-\nu)} & \nu=0.334 & t=0.1 \mathrm{~mm} \\
& E=70 G P a & D=16.54 \mathrm{~mm} \\
P=\frac{4(0.1 \mathrm{~mm})\left(70 \times 10^{9} \mathrm{~Pa}\right)\left(-1390 \times 10^{-6}\right)}{(16.54 \mathrm{man})(2-0.334)} & \varepsilon_{H}=-1390 \mathrm{r}-(-2287) \mu & \\
P=1.412 \mathrm{MPa} &
\end{array}
$$


APPENDIX C: Supermileage MEA Supplemental Material 
For our first Model Eliciting Activity (MEA), you will work in groups of four to develop a computational model to analyze performance of a fuel-efficient engine (i.e., work produced, thermal efficiency, etc.). I will assign students to groups. Please bring your textbook to class and note that the MEA will be easier once you have worked on HW2. In preparation for this MEA, it is worth summarizing all of the types of processes that we will commonly encounter in the early part of this course. We can model many of these processes with our polytropic process relationship, $\mathrm{pV}^{\mathrm{n}}=$ constant, with the value of the polytropic exponent, $n$, determining the shape of the curve (higher $n$ means a steeper curve on the $\mathrm{p}-\mathrm{v}$ diagram). Based on our discussion so far, the following processes should be familiar: constant pressure (isobaric, $n=0$ ), constant temperature (isothermal, $n=1$ ), adiabatic (no heat transfer, $\mathrm{n}=\mathrm{k}$ ), and constant volume (isochoric, $\mathrm{n}=\mathrm{infinity}$ ). There are infinite possibilities for the value of $n$, but these common values are shown in this figure from Chapter 6 :
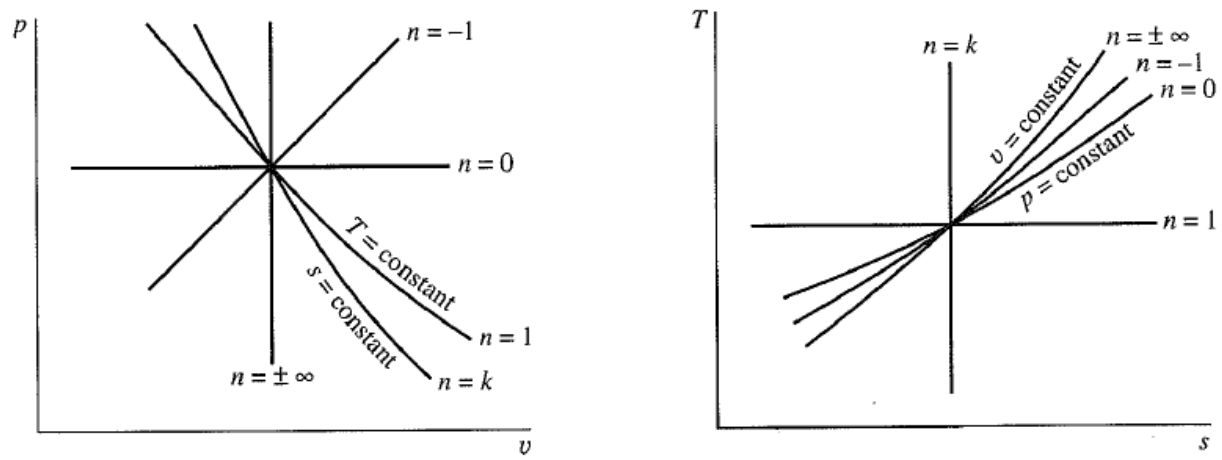

Fig. 6.10 Polytropic processes on $p-v$ and $T-s$ diagrams.

For now, we need only focus on the p-v diagram. We will tackle the Temperature-Entropy (T-s) diagram later in the course. But I should clarify that on the $\mathrm{p}-\mathrm{v}$ diagram, the curve corresponding to $\mathrm{n}=\mathrm{k}$ is for an isentropic process, which we will learn later occurs when a process is both adiabatic and reversible. Here $\mathrm{k}$ is the ratio of two specific heats we will commonly use. That is, $\mathrm{k}=\mathrm{c}_{\mathrm{p}} / \mathrm{c}_{\mathrm{v}}$ where $c_{p}$ is the specific heat at constant pressure and $c_{v}$ is the specific heat at constant volume. See Table A-20 for values of $c_{p}, c_{v}$, and $k$.

As part of this MEA, you will have to analyze the internal energy of air (as an ideal gas). We will learn in Chapter 3 that for ideal gases, the internal energy is a function of only the temperature of the gas, as suggested in equation 3.40:

$$
\mathrm{u}\left(\mathrm{T}_{2}\right)-\mathrm{u}\left(\mathrm{T}_{1}\right)=\int_{\mathrm{T} 1}^{\mathrm{T} 2} \mathrm{c}_{\mathrm{v}}(T) d T
$$

There are several ways to evaluate this integral as described in Sections 3.13 and 3.14. Please read through these sections in preparation for our MEA. Also, please answer the following questions:

1) Is an adiabatic process the same as an isothermal process? Why or why not?

2) To what type of systems and processes does $W_{\text {rev }}=\int_{V_{1}}^{V_{2}} p d V$ apply?

3) When evaluating the integral above, is it more accurate to assume constant specific heats or to let the specific heat change with temperature? When evaluating the integral above, which method(s) appear best suited for a computer program and which method(s) appear best suited for hand calculations? 


\section{MEMORANDUM}

TO: $\quad$ SHARON PARKER

FROM: (NAMES OMMITTED)

SUBJECT: RE: THERMODYNAMIC ANALYSIS TEAM

DATE: $\quad$ APRIL 19, 2010

Dear Sharon,

Attached in this memo is part of our Thermodynamic analysis for the Cal Poly Supermieage team. Overall, we used a total of 6 processes to model the cycle, and after our analysis we were able to learn more about this power cycle.

In order to analyze the data from the graph that was presented, there were many key assumptions we had to make. To begin the analysis we assumed point A, the start of process one, was at a temperature of 59 degrees Fahrenheit and at a pressure of 14.7 psi (to represent standard atmospheric conditions). Using the tables in the back of the Thermodynamics textbook, the value of $\mathrm{C}_{\mathrm{v}}$ was determined to be .171 and this value was used for all cycles. As instructed, the air-fuel mixture was treated as only air, the process was analyzed as reversible and the cycle was treated as an external combustion instead of an internal combustion engine.

The following is a breakdown of the processes we chose to model the data from the Supermileage's engine testing:

- Process 1 is an adiabatic process with $\mathrm{k}=1.401$

- Process 2 is a constant volume process

- Process 3 is a constant pressure process

- Process 4 is an isothermal process

- Process 5 is a constant volume process

- Process 6 is a constant pressure process

Calculations were completed as follows:

(Process 1) Work: W = - Delta U

Delta $U:\left(\mathrm{C}_{\mathrm{v}}\right) \times($ mass $) \times($ Delta $\mathrm{T})=$ Delta $\mathrm{U}$

Q: Zero, because it is an adiabatic process

(Process 2) Work: Zero, because it is a constant volume process

Delta U: $\left(\mathrm{C}_{\mathrm{v}}\right) \times($ mass $) \times($ Delta $\mathrm{T})=$ Delta $\mathrm{U}$

$\mathrm{Q}: \mathrm{Q}=\mathrm{U}+\mathrm{W}$ 
(Process 3) Work: $\int \mathrm{p} \mathrm{x} \mathrm{dV} \mathrm{(From} \mathrm{V}_{3}$ to $\left.\mathrm{V}_{4}\right)=\mathrm{W}$

Delta $U:\left(\mathrm{C}_{\mathrm{v}}\right) \times($ mass $) \times($ Delta $\mathrm{T})=$ Delta $\mathrm{U}$

$\mathrm{Q}: \mathrm{Q}=\mathrm{U}+\mathrm{W}$

(Process 4) Work: $\mathrm{P}_{4} \times \mathrm{V}_{4} \times \ln \left(\mathrm{V}_{5} / \mathrm{V}_{4}\right)=\mathrm{W}$

Delta U: $\left(\mathrm{C}_{\mathrm{V}}\right) \times$ (mass) $\times($ Delta $\mathrm{T})=$ Delta $\mathrm{U}$

$\mathrm{Q}: \mathrm{Q}=\mathrm{U}+\mathrm{W}$

(Process 5) Work: Zero, because it is a constant volume process

Delta U: $\left(\mathrm{C}_{\mathrm{v}}\right) \times$ (mass) $\times($ Delta $\mathrm{T})=$ Delta $\mathrm{U}$

$\mathrm{Q}: \mathrm{Q}=\mathrm{U}+\mathrm{W}$

(Process 6) Work: $\int \mathrm{p} x \mathrm{dV}\left(\right.$ From $\mathrm{V}_{6}$ to $\left.\mathrm{V}_{1}\right)=\mathrm{W}$

Delta U: $\left(\mathrm{C}_{\mathrm{v}}\right) \times$ (mass) $\mathrm{x}($ Delta $\mathrm{T})=$ Delta $\mathrm{U}$

$\mathrm{Q}: \mathrm{Q}=\mathrm{U}+\mathrm{W}$

The following is a graph of the model procesess in black on top of the orignal data provided from the engine testing. The number on the graph represent the different processes.

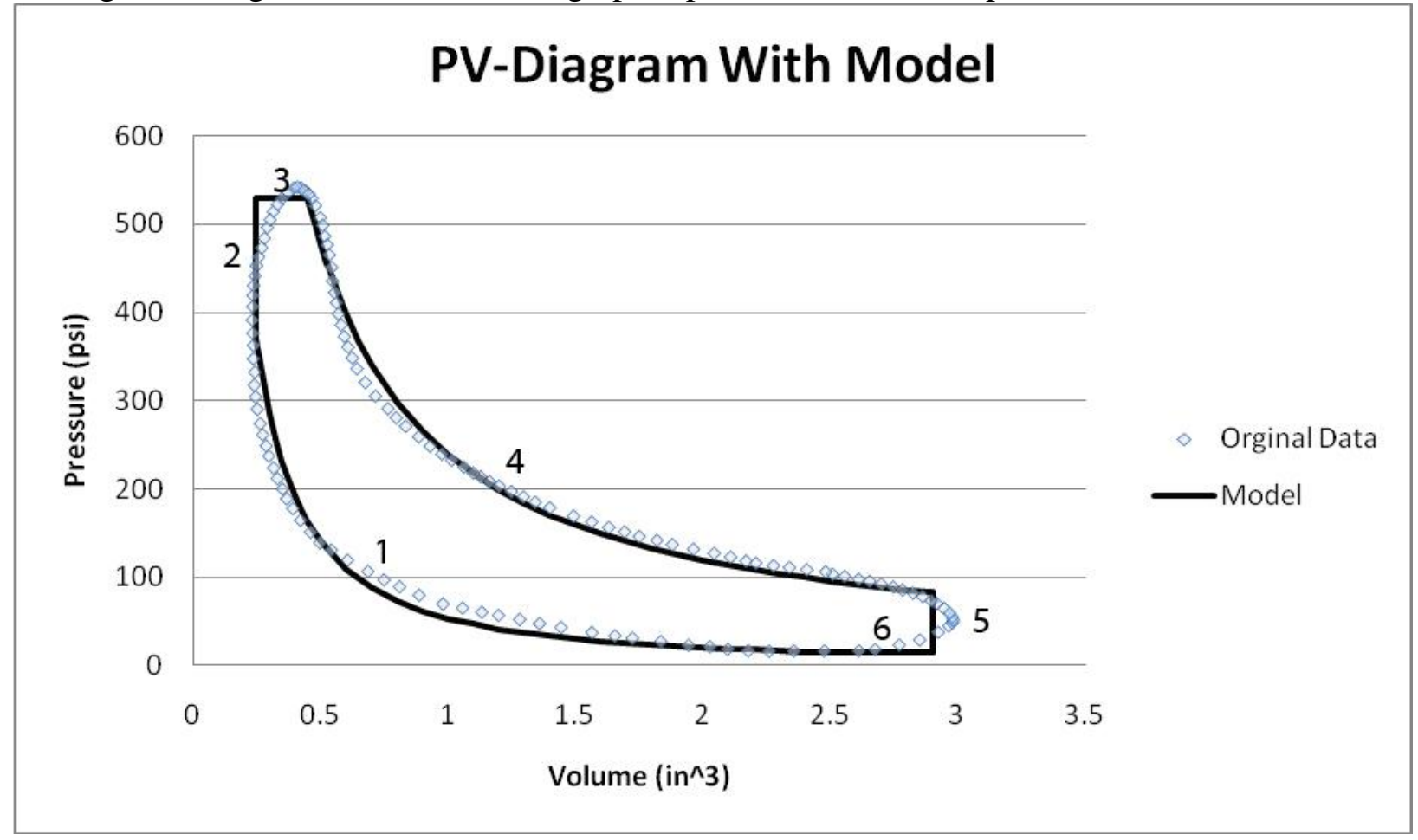


Here is a table of each process and its corresponding, calculated delta $\mathrm{U}, \mathrm{Q}$, and $\mathrm{W}$ values:

\begin{tabular}{|l|l|l|l|}
\hline Process & Delta U & Q (ft-lbf) & W (ft-lbf) \\
\hline 1 & 11.59701009 & 0 & -11.59701009 \\
\hline 2 & 8.311930119 & 8.311930119 & 0 \\
\hline 3 & 22.04018446 & 30.87018446 & 8.83 \\
\hline 4 & 0 & 37.0286 & 37.0286 \\
\hline 5 & -40.72651821 & -40.72651821 & 0 \\
\hline 6 & -1.222606459 & -1.712606459 & -.49 \\
\hline
\end{tabular}

For the full cycle, the delta U, Q, W, and efficiency calculations are:

Delta U: Sum of all Delta U for each process: $2.0792 \times 10^{\wedge}-10$ (should be zero)

Q (ft-lbf): Sum of all Q's for each process: 33.77

W (ft-lbf): Sum of all W's for each process: 33.77

Efficiency $(\eta):\left(\mathrm{W}_{\text {cycle }}\right) /\left(\mathrm{Q}_{\text {in }}\right)=44.3 \%$

Based on our analysis there are two main options for increasing the efficiency, and therefore the performance, of the engine. In the most general sense, there are two ways to increase preformance, which is to either increase the amount of work produced by the cycle or decrease amount of heat to be put into the system. One specific method for increasing preformance would be to change process 1 to an isothermal process instead of an adiabatic. Doing this would decrease the area under the process, meaning there would be less negative work the cycle must preform, and therfore increasing net work and preformance. Alternately, by raising the temperature of the isothermal process the same conclusion will be reached with a larger area within the cycle cooresponding the work being produced.

The majority of the calculations were performed using Microsoft Excel, and all of the data and final results are in the same Excel file. If requested, this file can be sent to supplement this memo.

Sincerely,

(Names Omitted)

ME 302-01 


\section{Reflections on your Supermileage Engine Performance Analysis}

\section{ME 302 Thermodynamics (with Andrew Kean)}

\section{Name: (omitted)}

(Please answer the following questions directly in this document and email it back to me at akean@calpoly.edu as soon as possible (no later than Friday). Throughout this reflection exercise, please underline your selections from the lists provided)

Engineers play an important role in the globalized and as Thomas Friedman put it, an increasingly "flat" world. As future engineering professionals you will make decisions and designs that impact the lives of many people. A lot of your coursework and employment will be based in teams and require you to learn new concepts on your own. Reflection can be a part of your learning process, and this self evaluation will help you understand what you gained from this exercise.

More about "reflection" From Hatton and Smith:

Historically Dewey (1933) is acknowledged as a key originator in the twentieth century of the concept of reflection. He considered it to be a special form of problem solving, thinking to resolve an issue which involved active chaining, and a careful ordering of ideas linking each with its predecessors. Within the process, consideration is to be given to any form of knowledge or belief involved and the grounds for its support*. His basic ideas indicate that reflection may be seen as an active and deliberative cognitive process, involving sequences of interconnected ideas which take account of underlying beliefs and knowledge. Reflective thinking generally addresses practical problems, allowing for doubt and perplexity before possible solutions are reached.

* Adler, 1991; Cutler, Cook \& Young, 1989; Calderhead, 1989; Gilson, 1989; Farrah, 1988

\section{Process Focused Questions}

1. Problem solving is a major part of engineering and designing solutions. Problem solving is thinking about and finding answers for a relatively clearly-defined situation for which there are one or more reasonable answers. We are interested in how your team solved this exercise. Please look at the graphs on the next page to help you answer the following question. Points A$\mathrm{H}$ represent moments in time over the last week.

2. Select one of the four graphs from below that most closely matches the path that your team took while working on this assignment. Please select a lettered point on the graph of two critical points in your team's problem solving process that stands out. A critical point is a major change in thinking or an "aha" moment. Please describe the strategy your team used the start of the assignment and then how it changed at each of the two points.

Graph Number (select one): I, II, III or IV

Critical point 1 (select letter): A, $\underline{B}, \mathrm{C}, \mathrm{D}, \mathrm{E}, \mathrm{F}, \mathrm{G}$, or $\mathrm{H} \quad$ Strategy Change: went from 6 to 4 processes
Critical point 2 (select letter):
$A, B, C, D, \underline{E}, F, G$, or $H$
Strategy Change: calculating works 
I.

Progress Over Time

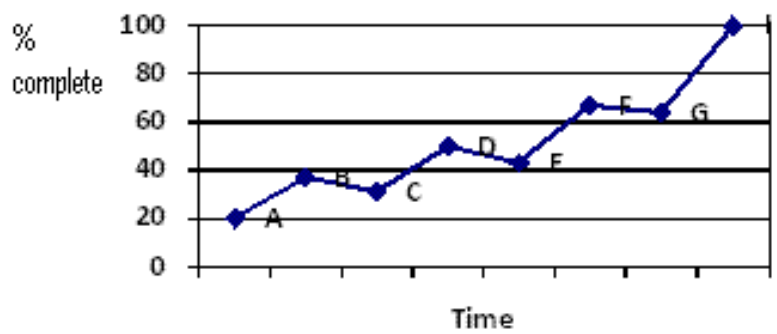

II.

Progress Over Time

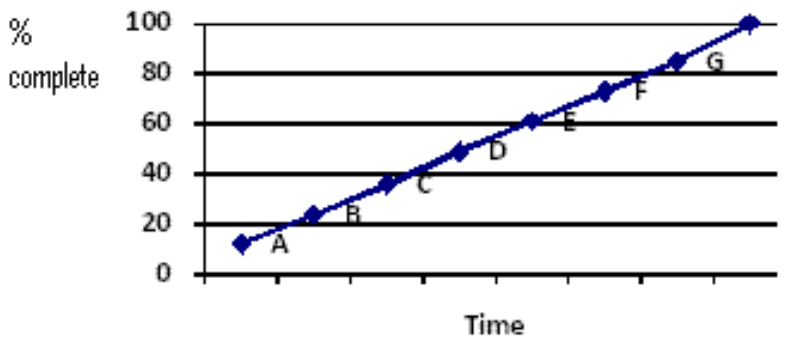

III.

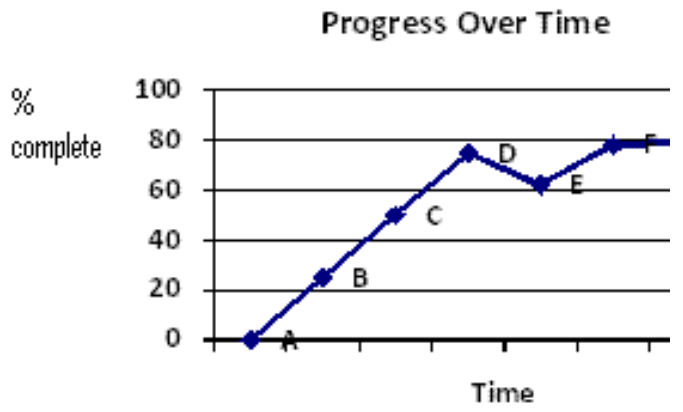

IV.

Progress Over Time

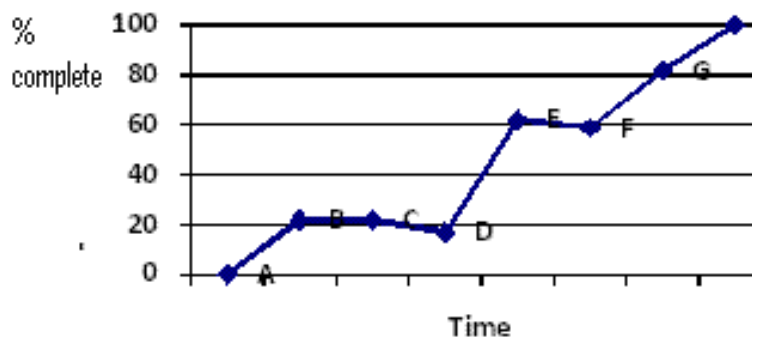

3. In engineering problem solving you make assumptions to arrive at a solution. Assumptions are what information and/or constraints that you considered in forming your answer. Please describe the key assumptions that your team used in solving the exercise. Why did you make each assumption?

- The assumptions we made were that the initial conditions of the cylinder were at sea level and room temperature, there's no friction inside the cylinder, and the fluid is just air. We made these assumptions so we know $T_{1}$ and we don't need to account for friction, plus if it's just air then we can use ideal gas.

4. While working on this group project, what did you personally contribute to the problem solving process? Please explain.

- I contributed ideas in class and on our first meeting. I missed the second meeting because I went back home for $4^{\text {th }}$ of July, then on our third meeting I helped working on the memo.

5. Did your group have difficulty agreeing on a final solution? Yes № Maybe How did your group make the decision on what was the final answer?

- $\quad$ By using the equations based on the processes. 
6. Did you have a method or suggestion that did not end up in the final solution?

Yes No Maybe

Please explain.

- The final solution is pretty much what we came up with.

7. I was satisfied with my group's final solution (select one).

- Strongly disagree

- Somewhat disagree

- Neutral

- Somewhat agree

- Strongly agree

Please explain.

- We treated some processes as isobaric and isochoric but that is not $100 \%$ correct, although it's very close.

\section{Problem Solving Focused Questions}

8. Thompson has outlined some commonly used stages of engineering problem solving that can be categorized as:

a. Problem Identification; i.e., identify and state the problem

b. Model/Solution Formulation; i.e., formulating the problem and abstraction, problem solving approaches, variables, assumptions, constraints and criteria. Modeling the problem: translation

c. Collecting Information and Analyzing Data; i.e., collect information, data and resources. Analyzing and/or solving

d. Evaluating and Revising the Solution; i.e., interpreting results, evaluating potential solutions and selects solution. Reflecting and revising; using feedback and improving

e. Documentation; i.e., writing and reporting

Thinking back to the two critical points that you identified earlier in question 2, please also identify the stage of the project, your level of involvement (none, low, medium, high) and approximate time in minutes when it occurred. 


\section{Critical Point 1:}

Stage (select one):

- Problem Identification

- Model/solution formulation

- Collecting information and/or analyzing data

- Evaluating and revising the solution

- Documentation

Level of Involvement (select one):

- None

- Low

- $\quad$ Medium

- High

Time of Critical Point:

- Critical Point 1 at $\_$days (or minutes if on Day 1 )

\section{Critical Point 2:}

Stage (select one):

- Problem Identification

- Model/solution formulation

- Collecting information and/or analyzing data

- Evaluating and revising the solution

- Documentation

Level of Involvement (select one):

- None

- Low

- Medium

- High 
Time of Critical Point (in days):

- Critical Point 2 at $\underline{2-3}$ days (or minutes if on Day 1 )

\section{Concepts Learned Questions}

10. Below are some of the engineering concepts that might have been included in the exercise. Which ones do you now understand better as a result of this exercise? What prompted or helped you gain the concepts better? How did you notice this change?

Processes, cycles, first law of thermodynamics as applied to a process, first law of thermodynamics as applied to a cycle, modeling processes with the polytropic relationship, thermal efficiency, ideal gases, evaluating internal energy for an ideal gas,

others (fill in blank).

- Processes, thermal efficiency, ideal gases, and evaluating internal energy. Since I needed to know these in order to solve the problem it kind of forced me to do more research outside of class like read more from books, internets, etc. (which is a good thing).

11. Were there any other concepts or skills beyond those mentioned in the previous question that you discovered or now understand better? What prompted or helped you gain these skills or concepts better? How did you notice this change?

professional writing, using software (such as excel), apply engineering concepts, analyze data, interpret data, working with realistic constraints, teamwork, solve engineering problems, professional responsibility, ethical responsibility, communication skills, engineering in a global context, engineering in a societal context, engineering in an environmental context, engineering in an economic context, recognition of life long learning, other (fill in blank)

- Professional writing: I took Eng 149 a while ago so my memo writing skill was a little rusty. This assignment helped me polish my writing skill.

12. Engineers must face conflicting interests and "gray areas" in decision making. Did you notice any ethical issues ("moral issues and decisions confronting individuals and organizations involved in engineering", Martin and Schinzinger) that should be considered as part of the solution? Yes № Please explain.

- There're really no ethical issues in this assignment. 
13. According to Bodner, Gardner and Briggs, a broad definition of the term "model" refers to a simplified or idealized description or conception of a particular system, situation, or process, often in mathematical terms, that is put forward as a basis for theoretical or empirical understanding, or for calculations, predictions, etc.; a conceptual or mental representation of something; and the term "modeling" refers to devise a model or simplified description of a phenomenon or system.

Harrison and Treagust define modeling as the essence of thinking and working scientifically.

Taking this into consideration, what other applications do you think your solution could be applied to? Or what other areas could you apply the skills and concepts you learned in this exercise?

- Maybe in Fluid Mechanics? and some BMED courses that I'm about to take in the upcoming year.

14. I enjoyed this problem solving experience (select one).

Strongly disagree $\quad$ Disagree Neutral $\quad$ Agree $\quad$ Strongly agree

15. Did you feel that the piston-cylinder classroom demonstration showing how $p-V$ data are obtained improved your understanding of the central concepts (select one)?

Strongly disagree $\quad$ Disagree Neutral $\quad$ Agree $\quad \underline{\text { Strongly agree }}$

16. Would you get more out of this MEA if you were required to obtain your own $p-V$ data, rather than have it provided to you (select one)?

$\begin{array}{llll}\text { Strongly disagree } \quad \text { Disagree } & \text { Neutral } & \text { Agree } & \text { Strongly agree }\end{array}$

17. How generalizable (i.e.applicable to similar problems) do you think your solution was (select one)?

Not applicable to any other problem

Generalizable to only similar other problems

Neither generalizable, nor not generalizable

Generalizable to similar and non similar problems

18. In what other ways could we improve this MEA the next time we assign it?

- Nothing really, I think it was quite good. The directions were clear and we knew what to do from the start.

Thanks for your time in helping improve this activity. 
APPENDIX D: Industrial Process MEA Supplemental Material 


\section{MEMORANDUM}

TO: Jennifer Conover, Industrial Process Designs. Inc.

CC: $\quad$ Andrew Kean, California Polytechnic State University

FROM: Thermodynamics Analysis Team

DATE: $\quad 05 / 31 / 2010$

RE: $\quad$ Industrial Process Waste Heat Utilization

As per your request, we have analyzed the three options to incorporate a steam power plant within your Industrial facility to make it more environmentally friendly.

Let's explain our calculation approach by first relating the new temperature difference in the river (denoting $\Delta T_{r}{ }^{\prime}$ below) to quantities can easily be found in a typical T-s diagram.

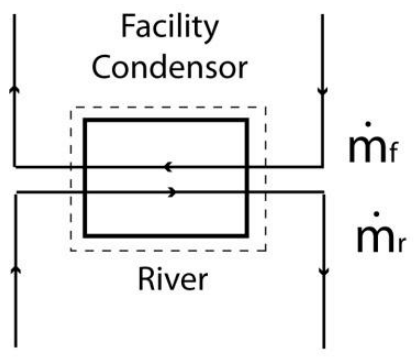

CV 1

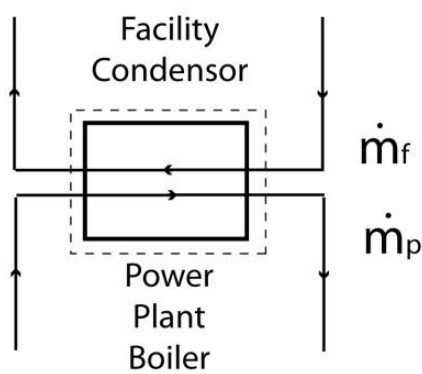

CV 2

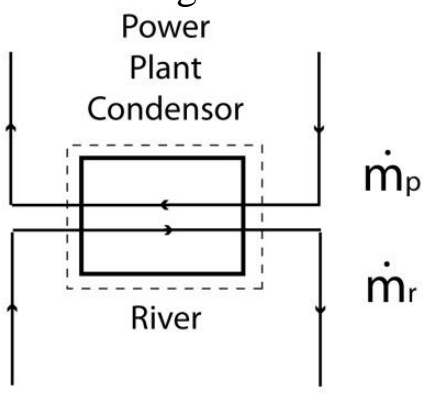

CV 3

Figure 1. Control Volumes for Energy Conservation Calculations.

We start by fixing properties of the four different states and processes in the power plant. Then we apply the First Law of Thermodynamics for the control volumes in Figure 1.

$$
\left.\begin{array}{rl}
\text { CV1: } \quad \dot{m}_{f} \Delta h_{f}+\dot{m}_{r} \Delta h_{r}=0 \Leftrightarrow \dot{m}_{r}=-\frac{\Delta h_{f}}{\Delta h_{r}} \dot{m}_{f} \\
\text { CV2: } \quad \dot{m}_{p} \Delta h_{f 1}+\dot{m}_{f} \Delta h_{f}=0 \Leftrightarrow \dot{m}_{p}=-\frac{\Delta h_{f}}{\Delta h_{f 1}} \dot{m}_{f} \\
\text { CV } 3: \quad \dot{m}_{p} \Delta h_{f 2}+\dot{m}_{r} \Delta h_{r}{ }^{\prime}=0 \Leftrightarrow \Delta h_{r}{ }^{\prime}=-\frac{\dot{m}_{p}}{\dot{m}_{r}} \Delta h_{f 2}
\end{array}\right\} \Delta h_{r}{ }^{\prime}=-\frac{\Delta h_{f 2}}{\Delta h_{f 1}} \Delta h_{r}
$$

For the river, which is a compressed liquid (water) with constant specific heat, we have

$$
\Delta T_{r}{ }^{\prime}=\frac{\Delta h_{r}{ }^{\prime}}{c}=-\frac{1}{c}\left(\frac{\Delta h_{f 2}}{\Delta h_{f 1}}\right) \Delta h_{r}
$$

For the calculations of work of the turbine, we apply Energy Conservation in CV2 shown in Figure 2, and the efficiency follows.

$$
\begin{gathered}
\dot{W}_{T}=-\dot{m} \Delta h_{12} \\
\eta=1-\frac{Q_{\text {out }}}{Q_{\text {in }}}
\end{gathered}
$$

The properties of each state and process, work, efficiency, and $\Delta T_{r}{ }^{\prime}$ are tabulated in the model attached.

For $\Delta T_{r}^{\prime}$, the ratio $\left(-\frac{\Delta h_{f 2}}{\Delta h_{f 1}}\right)$ determines how small $\Delta T_{r}{ }^{\prime}$ could be.

Since every process is reversible, area under the T-s diagram (Figure 3 ) represents heat transfer; combine with the First Law applied to the control volumes $1 \& 3$ shown in Figure 2, we have

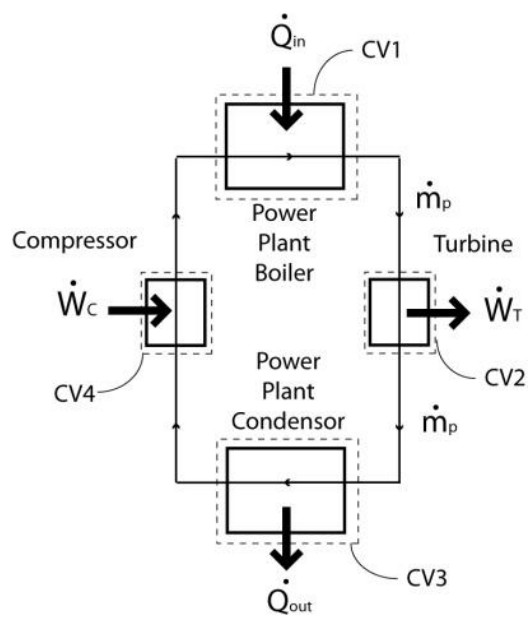

Figure 2. CV's for Power Plants. 


$$
-\frac{\Delta h_{f 2}}{\Delta h_{f 1}}=-\frac{\frac{\dot{Q_{\text {out }}}}{\dot{m}}}{\frac{\dot{Q_{\text {ln }}}}{\dot{m}}}=\frac{\left|Q_{\text {out }}\right|}{\left|Q_{\text {in }}\right|}=\frac{\text { Area }_{\text {under } 32}}{\text { Area }}
$$

Thus, the area ratio under the T-s diagram is a direct reflection of how far we can go. In order to minimize $\Delta T_{r}{ }^{\prime}$, we need to maximize $\left|Q_{\text {in }}\right|$ and minimize $\left|Q_{\text {out }}\right|$.
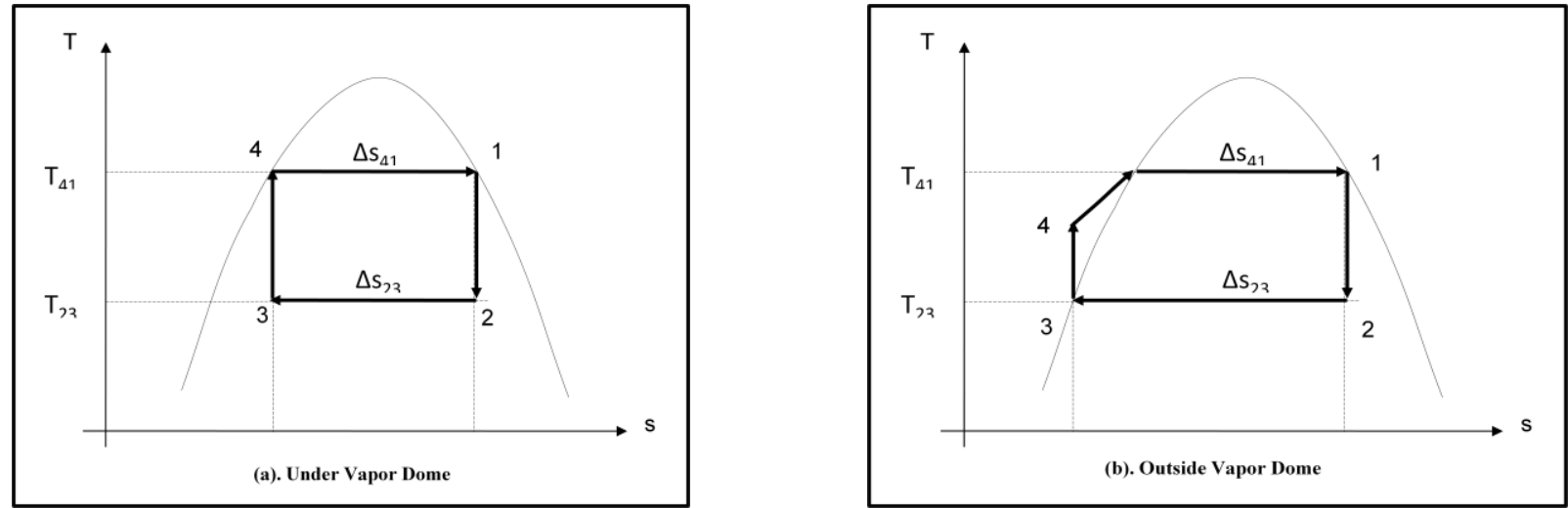

Figure 3. T-s Diagrams for the Two Configurations Analyzed.

Under the vapor dome, since $\Delta s_{41}=\Delta s_{23}$, from Figure 3(a), it follows that

$$
\frac{\text { Area }_{\text {under } 32}}{\text { Area }_{\text {under } 41}}=\frac{T_{23}}{T_{41}} \quad \text { (under vapor dome) }
$$

By inspection, we can see that the area ratio is higher outside the vapor dome. Thus, if the target $\Delta T_{r}{ }^{\prime}$ cannot be achieved under the vapor dome, it could definitely not be achieved outside the vapor dome. The calculation in the model proves this point.

In the model attached, we reserve a tab for each of the three options. Under the limitation of ambient pressure, $T_{23}$ is a constant, and we have $\Delta T_{r}^{\prime} \propto \frac{T_{23}}{T_{41}}=\frac{T_{23}}{T_{23}+\Delta T}$, which shows a greater $\Delta T$ between the boiler and condenser in the power plant can lower $\Delta T_{r}{ }^{\prime}$ in the river. For option 1 and 2 , we tried the limiting condition with the greatest $\Delta T$ under the vapor dome. Unfortunately, it failed to achieve the goal. Thus, both option 1 and option 2 are not possible. The tabulated trials in these two options prove this point. Without the ambient pressure limitation, however, we are able to make $\Delta T_{r}{ }^{\prime}$ barely less than $5^{\circ} \mathrm{F}$ in option 3 . It is important to note that it was analyzed as an idealized cycle (reversible). Due to the irreversibilities in the real world, the thermal efficiency $\eta$ is lowered in reality. From $\eta=1-\frac{Q_{\text {out }}}{Q_{\text {in }}}$, we conclude that $\Delta T_{r}^{\prime} \propto \frac{Q_{\text {out }}}{Q_{\text {in }}}$ could be larger than desired. Thus, option 3 might also not be possible in the real world. To lower $\Delta T_{r}{ }^{\prime}$, we suggest a greater temperature difference inside the power plant and a reduction in factors of irreversibilities.

The model attached is designed so that you can fill every properties needed by following the instructions in the red cells. The biggest advantage is its self-explanatory feature. We can easily adjust specific values for the power plant depending upon the limitations in each option. An obvious weakness is that one needs to look up appropriate thermodynamic tables to get appropriate properties. Since these tables are not programmed into our spreadsheet, this requires the user to constantly refer to tables to complete the analysis. Hope the model helps.

Sincerely, 
Mini Reflection Exercise

1) Below are some of the engineering concepts that might have been included in the exercise. Which ones do you now understand better as a result of this exercise? (Circle all that apply)
a) Power cycle thermal efficiency
b) Heat exchanger modeling
c) Specific heats
d) Entropy
e) Carnot cycle
f) Entropy generation
g) First law of thermodynamics
h) Closed systems
i) Open systems
j) Second law of thermodynamics
k) Mass balances
1) Condensers and boilers
m) Steam power plants
n) Thermodynamic property evaluation
o) Modeling processes and devices
p) Kelvin-Planck statement of the second law (i.e, You need two thermal reservoirs to produce work with a cycle)
Other (fill in the blank)

2) I was satisfied with my group's final solution. (Circle your answer and explain)

Strongly disagree - Somewhat disagree - Neutral - Somewhat agree - Strongly agree Please explain.

3) I enjoyed this problem solving experience. (Circle your answer and explain)

Strongly disagree - Somewhat disagree - Neutral - Somewhat agree - Strongly agree Please explain.

4) My time was well spent during this problem solving exercise. (Circle your answer and explain) Strongly disagree - Somewhat disagree - Neutral - Somewhat agree - Strongly agree Please explain. 